\title{
Spinning Reserves from Controllable Packaged Through the Wall Air Conditioner (PTAC) Units
}

November 2002

\author{
Prepared by \\ B. J. Kirby, M. R. Ally \\ Oak Ridge National Laboratory
}




\title{
DOCUMENT AVAILABILITY
}

Reports produced after January 1, 1996, are generally available free via the U.S. Department of Energy (DOE) Information Bridge:

Web site: http://www.osti.gov/bridge

Reports produced before January 1, 1996, may be purchased by members of the public from the following source:

National Technical Information Service

5285 Port Royal Road

Springfield, VA 22161

Telephone: 703-605-6000 (1-800-553-6847)

TDD: 703-487-4639

Fax: 703-605-6900

E-mail: info@ntis.fedworld.gov

Web site: http://www.ntis.gov/support/ordernowabout.htm

Reports are available to DOE employees, DOE contractors, Energy Technology Data Exchange (ETDE) representatives, and International Nuclear Information System (INIS) representatives from the following source:

Office of Scientific and Technical Information

P.O. Box 62

Oak Ridge, TN 37831

Telephone: 865-576-8401

Fax: 865-576-5728

E-mail: reports@adonis.osti.gov

Web site: http://www.osti.gov/contact.html

\begin{abstract}
This report was prepared as an account of work sponsored by an agency of the United States Government. Neither the United States government nor any agency thereof, nor any of their employees, makes any warranty, express or implied, or assumes any legal liability or responsibility for the accuracy, completeness, or usefulness of any information, apparatus, product, or process disclosed, or represents that its use would not infringe privately owned rights. Reference herein to any specific commercial product, process, or service by trade name, trademark, manufacturer, or otherwise, does not necessarily constitute or imply its endorsement, recommendation, or favoring by the United States Government or any agency thereof. The views and opinions of authors expressed herein do not necessarily state or reflect those of the United States Government or any agency thereof.
\end{abstract}


ORNL/TM-2002/286

\title{
Consortium for Electric Reliability Technology Solutions
}

\section{Spinning Reserves from Controllable Packaged Through the Wall Air Conditioner (PTAC) Units}

\author{
Brendan Kirby \\ Moonis Ally \\ Oak Ridge National Laboratory
}

November 2002

The work described in this report was coordinated by the Consortium for Electric Reliability Technology Solutions on behalf of the California Energy Commission, the Assistant Secretary for Energy Efficiency and Renewable Energy, Office of Power Technologies, Transmission Reliability Program of the U. S. Department of Energy under Contract No. DE-AC03-76SF00098.

\section{A Phase I Report}

Prepared for the

Consortium for Electric Reliability Technology Solutions (CERTS) Program,

U.S. Department of Energy

Prepared by

Oak Ridge National Laboratory

Oak Ridge, Tennessee 37831-6070

Managed by

UT-BATTELLE, LLC

for the

U. S. Department of Energy

under contract DE-AC05-00OR22725 



\section{Table of Contents}

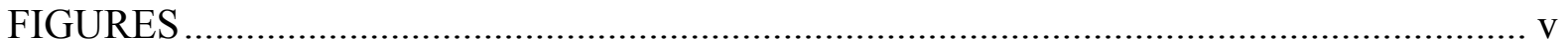

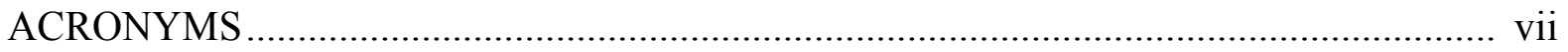

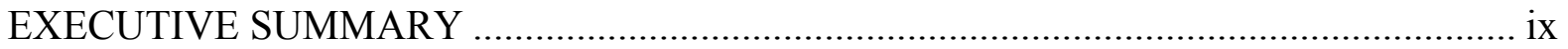

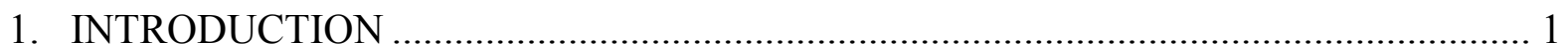

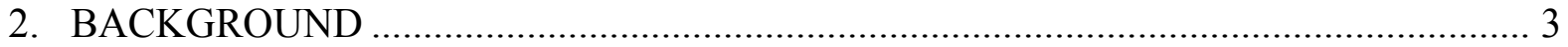

2.1. SPINNING RESERVE REQUIREMENTS ........................................................ 3

2.2. LOAD PROVISION OF SPINNING RESERVES ............................................. 4

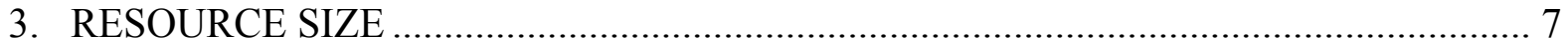

3.1. COMMERCIAL COOLING DEMAND IN THE U.S........................................... 7

3.2. RESIDENTIAL COOLING DEMAND IN THE U.S.......................................... 8

3.3. FIELD EVALUATION OF PTAC SUPERVISORY CONTROLLERS ................... 8

3.3.1. Data Collection and Data Reduction.............................................................. 10

3.3.2. Hourly and Seasonal PTAC Availability.................................................. 11

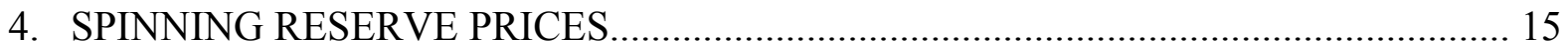

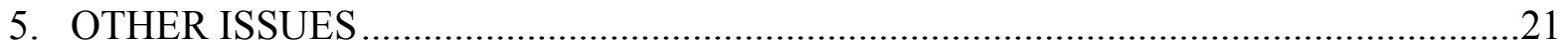

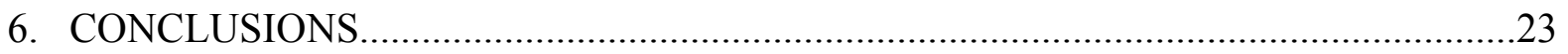

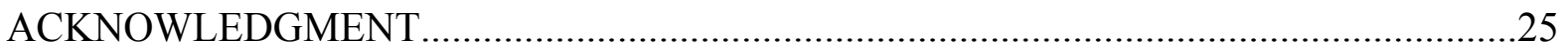

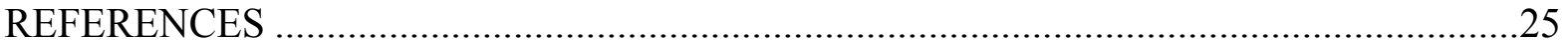

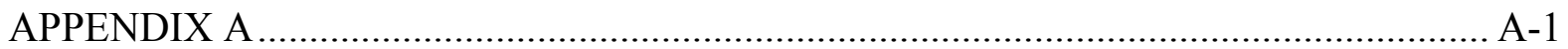

A.1. Split of Residential Energy End-Use Demand in the U.S............................... A-3

A.2. Total Number of Households, Floorspace and Household Size .......................... A-3

A.3. Share of Households by Housing Type and by Type of Ownership..................... A-4

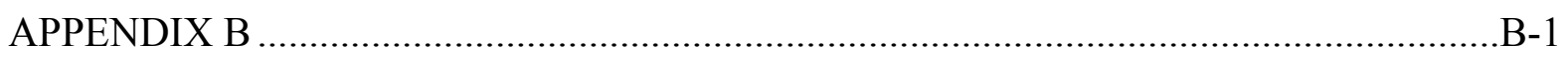

B.1. Summer Data: Controlled Rooms - July .............................................................

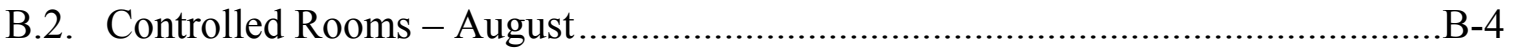

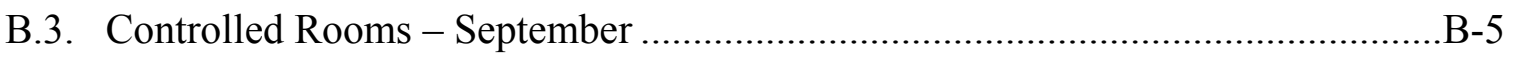

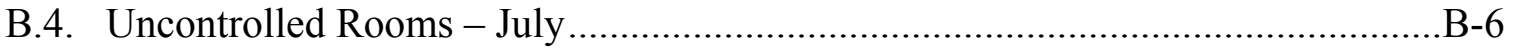

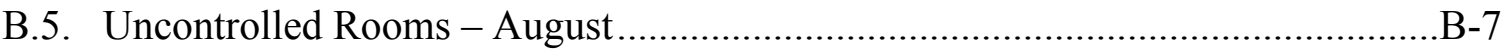


B.6. Uncontrolled Rooms - September ..............................................................

B.7. Composite Summer Data on Controlled Rooms ..................................................

B.8. Composite Summer Data for Uncontrolled Rooms ..........................................

B.9. Occupancy Rate During Summer for Controlled and Uncontrolled Rooms........B-11

B.10. Winter Data: Controlled Rooms - January ..................................................

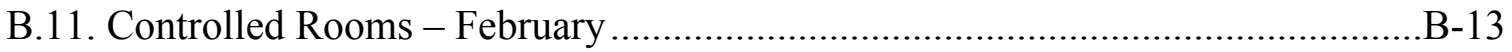

B.12. Controlled Rooms - March ...............................................................................

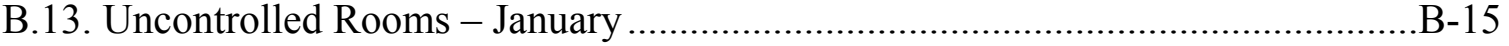

B.14. Uncontrolled Rooms - February …......................................................

B.15. Uncontrolled Rooms - March ......................................................................... 


\section{Figures}

1. Spinning reserve stands ready to immediately respond when contingencies occur ......... 3

2. Spinning reserve is relieved by supplemental reserves and backup supply fairly quickly 4

3. Segmented commercial cooling demand in the U.S. ............................................... 7

4. Test site (Pigeon Forge, Tennessee ...................................................................... 9

5. Clockwise from left: front desk controller at motel, installed Digi-Log unit and control board, ORNL data processing and data transfer module .......................................... 9

6. Schematic of the signal initiation, reception, and data collection..................................10

7. Graph of electric demand for cooling versus time of day for July, August and September

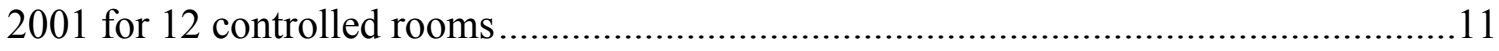

8. Graph of electric demand for cooling versus time of day for July, August and September 2001 for 12 uncontrolled rooms ............................................................................. 12

9. Graph of electric demand for heating versus time of day for January, February and

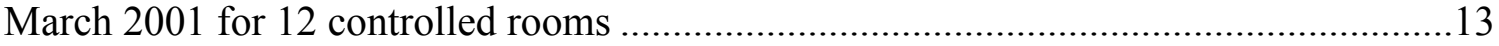

10. Graph of electric demand for heating versus time of day for January, February and March 2001 for 12 uncontrolled rooms ...................................................................13

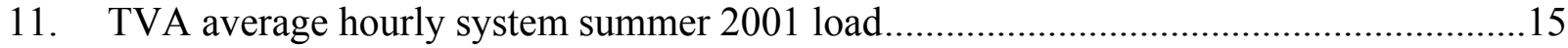

12. TVA average hourly system summer 2001 marginal energy cost .............................16

13. TVA average hourly system winter $2001 \mathrm{load}$.....................................................16

14. TVA average hourly system winter 2001 marginal energy cost...............................17

15. Average hourly CAISO spinning reserve prices for July and February 2002 ................18

16. NYISO spinning reserve prices for July 2001 do not reflect all of the compensation a

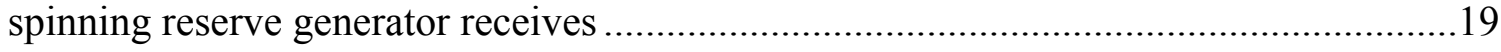





\section{Acronyms}

ACE area control error

CA ISO California Independent System Operator

CEC California Energy Commission

CERTS Consortium for Electric Reliability Technology Solutions

CDWR California Department of Water Resources

DCS Disturbance Control Standard

DOE U.S. Department of Energy

ERCOT Electric Reliability Council of Texas

HVAC heating, ventilation and air conditioning

$\mathrm{Hz} \quad$ hertz

ISO independent system operator

ISO-NE New England independent system operator

$\mathrm{kW}-\mathrm{h} \quad$ kilowatts of spinning reserve available for use in one hour period

kWh kilowatt-hour

LIPA Long Island Power Authority

MW megawatt

MWh megawatt-hour

NERC North American Electric Reliability Council

NYISO New York Independent System Operator

NYSERDA New York Energy Research and Development Authority

ORNL Oak Ridge National Laboratory

PTAC controlled packaged through the wall air conditioner

SCE Southern California Edison

WECC Western Electricity Coordinating Council 



\section{Executive Summary}

This report summarizes the feasibility of providing spinning reserves from packaged through the wall air conditioning (PTAC) units. Spinning reserves, together with non-spinning reserves, compose the contingency reserves; the essential resources that the power system operator uses to restore the generation and load balance and maintain bulk power system reliability in the event of a major generation or transmission outage. Spinning reserves are the fastest responding and most expensive reserves. Many responsive load technologies could (and we hope will) be used to provide spinning reserve. It is also easier for many loads (including air conditioning loads) to provide the relatively shorter and less frequent interruptions required to respond to contingencies than it is for them to reduce consumption for an entire peak period. Oak Ridge National Laboratory (ORNL) is conducting research on obtaining spinning reserve from large pumping loads and from residential and small commercial thermostat controlled heating, ventilation and air conditioning (HVAC) units. The technology selected for this project, Digi-Log's retrofit PTAC controller, offers significant advantages.

To evaluate the availability of spinning reserve capacity from responsive heating and air conditioning loads, ORNL obtained data from a number of units operating over a year at a motel in the TVA service territory. A total of 24 PTAC units in as many rooms were fitted with DigiLog's supervisory control unit that could be controlled from the motel front desk. Twelve of the rooms formed the group in which the controller was controlled from the hotel front desk only. The remaining twelve rooms were controlled by the occupant and formed the uncontrolled group. This enables us to evaluate the spinning reserve capacity from PTACS that were operating normally and from those under active energy management.

A second generation of the Digi-Log controller that will respond quickly enough to provide spinning reserve has been designed but not yet manufactured. Manufacture of these units is pending arrival of funds from NYSERDA. The new Digi-Log equipment will utilize satellite signals from Skytel to activate the controller from a remote site by the ISO and to respond to curtailment events.

PTACs account for approximately $3 \%$ of the total commercial cooling load in the US, equivalent to an average energy consumption rate of 3,000 MW with peak consumption being significantly higher. Hence PTACs alone represent a sizable opportunity for providing spinning reserves from load. The residential buildings sector cooling and heating load averages about 33,000 MW, more than 10 times the commercial PTAC load. The buildings sector represents an even greater opportunity than the PTAC commercial sector for providing spinning reserves from load. Technology to implement load curtailment and monitor its effect already exists and can readily be further customized to meet ISO and utility needs.

Further research is needed to prove the technical feasibility of PTAC units and other small loads providing spinning reserves. Aggregation, communication, control, and monitoring issues remain to be addressed. If the technical issues can be resolved however, it is likely that system operators, loads, and regulators will have significant incentives to resolve these other resources since spinning reserve from load has the potential to provide large benefits to each community. 



\section{INTRODUCTION}

This report summarizes the feasibility of providing spinning reserves from packaged through the wall air conditioning (PTAC) units. Spinning reserves, together with non-spinning reserves, compose the contingency reserves; the essential resources that the power system operator uses to restore the generation and load balance and maintain bulk power system reliability in the event of a major generation or transmission outage. Spinning reserves are the fastest responding and most expensive reserves. While North American Electric Reliability Council (NERC) rules do not currently allow loads to provide spinning reserve there is increasing recognition that these rules should be changed. This project examines how much spinning reserve a specific type of load (PTAC units) could provide and how that reserve capacity varies with time of day, month, and power system needs.

Providing spinning reserves from load has several advantages for both the power system and the responding load. It is likely to be more reliable and faster than reserve supplied from generation. Some loads are inherently better suited to provide spinning reserves as opposed to providing demand relief, though provision of both is also possible. Also, when loads provide spinning reserves it frees existing generating capacity to serve load. The net result is to increase the capacity and reliability of the power system without increasing the number of operating power plants. This is especially important in capacity-constrained regions of the country.

Many responsive load technologies could (and we hope will) be used to provide spinning reserve. Oak Ridge National Laboratory (ORNL) is conducting research on obtaining spinning reserve from large pumping loads and from residential and small commercial thermostat controlled heating, ventilation and air conditioning (HVAC) units. The technology selected for this project, Digi-Log's retrofit PTAC controller, offers significant advantages. The loads they control represent a large resource that is highly correlated with power system load and power system stress. The technology is already developed for reducing energy consumption and peak shaving. ORNL has compatible monitoring equipment to record test facility performance. Extending the capabilities of the existing technology to provide spinning reserve appears to be feasible. Rapid full deployment is possible if the demonstration project proves the viability of loads providing spinning reserve. The cost of full implementation should also be low. Adding spinning reserve capability will provide a significant additional incentive for utilities and independent system operators (ISOs) to adopt the technology in their regions.

The Department of Energy (DOE) is interested in collaborating with utilities, ISOs, equipment manufacturers, and loads to examine the technical potential for responsive loads to supply spinning reserves to the power system. We recognize that current NERC rules do not allow loads to supply spinning reserves. However, preliminary discussions with NERC as well as the ongoing work of the NERC Policy 10 and Policy 1 committees as well as work by WECC show that the utility industry is starting to recognize that responsive load can provide spinning reserve. The critical technical requirement for spinning reserve is to rapidly restore the generation/load balance after a serious contingency (the loss of a major generator or transmission link). Fundamentally, this restoration can be addressed from either the generation or load side. The time is right to initiate testing of responsive load providing spinning reserve. 
ORNL is working with Long Island Power Authority (LIPA), the New York State Energy Research and Development Authority (NYSERDA) and the New York ISO on a project to demonstrate the use of controllable PTAC units to obtain spinning reserve from hotel/motel rooms. All three organizations are familiar with and interested in the concept of load providing spinning reserve and are interested in testing supplying spinning reserves from PTAC units. ORNL also has spinning reserve and ancillary service projects involving responsive load with the California Independent System Operator (CA ISO), California Energy Commission (CEC), and the California Department of Water Resources (CDWR) and is discussing projects with the New England Independent System Operator (NEISO).

This report summarizes the feasibility of providing spinning reserves from an experiment conducted with the controller in 24 rooms in a motel in Pigeon Forge, Tennessee. The cost of data collection was leveraged from DOE's Emerging Technology Program which is studying the energy savings benefits of the same technology. 


\section{BACKGROUND}

\subsection{SPINNING RESERVE REQUIREMENTS}

The power system has essentially no energy storage capability. It must hold sufficient fast responding resources in reserve ready to respond in case a generator or transmission line suddenly trips off line. NERC's Disturbance Control Standard (DCS) requires control areas to restore their area control error (ACE) within fifteen minutes of a significant contingency. To be prepared to accomplish this, NERC and regional reliability council rules require each control area to have sufficient contingency reserves available to compensate for the largest credible contingency. This is often the loss of the largest generator in the region. NERC rules also currently require the spinning reserves to be generation that is on line, unloaded, responsive to system frequency deviations, under automatic control, able to begin responding immediately, and fully responsive within ten minutes. Non-spinning reserves also have to be fully responsive in ten minutes but they do not have to begin responding immediately or be responsive to system frequency.

Though spinning reserves are required to be continuously available they are deployed relatively infrequently, typically a few times per month. Figure 1 shows the required rapid power system response when a contingency occurs. In this case the Texas ERCOT system lost $2600 \mathrm{MW}$ of generation but successfully recovered within ten minutes.

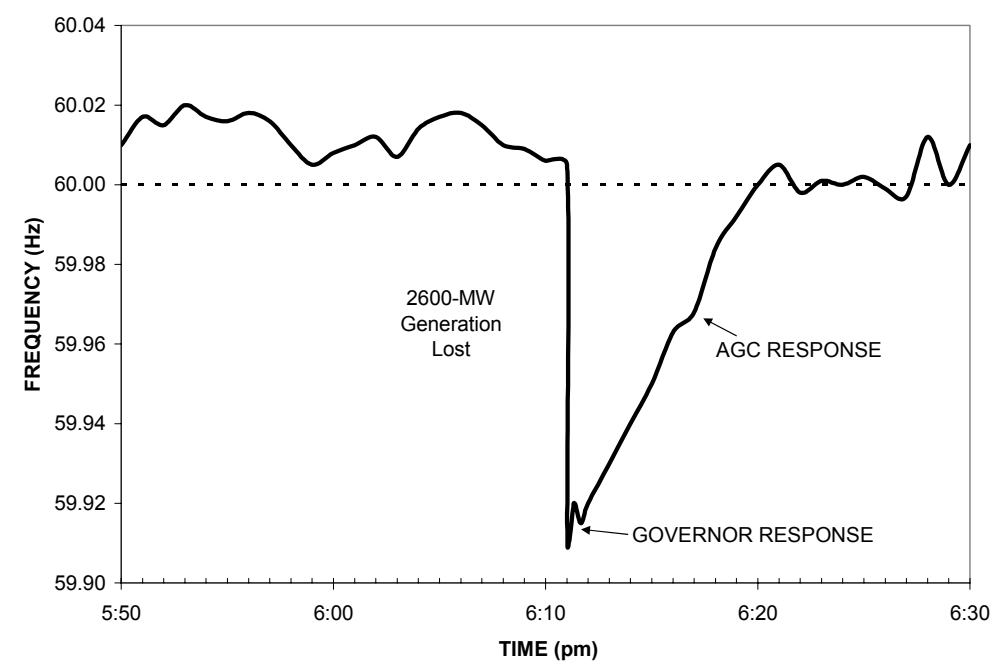

Fig. 1. Spinning reserve stands ready to immediately respond when contingencies occur. 
In the restructured environment ISOs typically procure spinning reserves through markets; hourly competitive auctions. Prices for spinning reserves can be quite high and are usually set by the lost opportunity cost for the generator supplying the reserves. That is, the largest cost is the lost profit the generator could have made if it had been selling energy rather than sitting idle ready to respond if a contingency occurred.

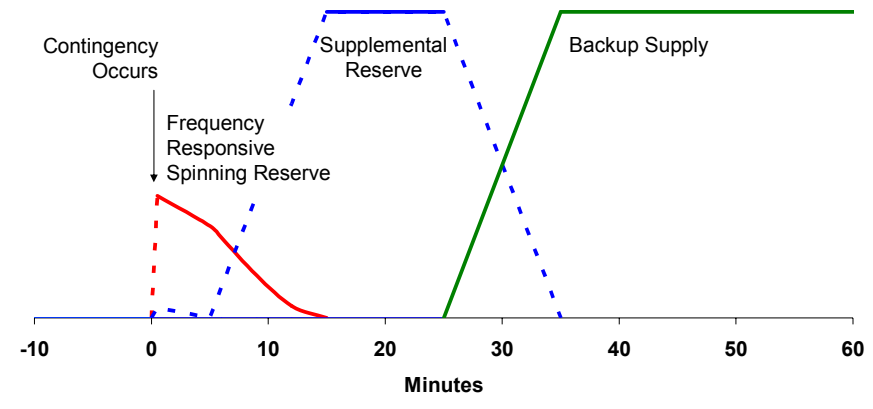

Fig. 2. Spinning reserve is relieved by supplemental reserves and backup supply fairly quickly.

Spinning reserves are relieved as quickly as possible by supplemental reserves. Supplemental reserves can be off-line generation that is able to start quickly or load that can be reduced quickly. Supplemental reserve typically commands a somewhat lower price than spinning reserve. Supplemental reserves are themselves relieved by backup supplies which return the power system to commercial market operation. The exact duration for each of these reserves varies from system to system but the system is typically restored to full commercial operation within two hours. Figure 2 shows the coordinated timing of reliability reserve services.

\subsection{LOAD PROVISION OF SPINNING RESERVES}

Spinning reserves typically command the highest price when the system load is highest. System load is highest when customer air conditioners are also running the most, on the hottest days. It is also easier for air conditioning loads to provide the relatively shorter and less frequent interruptions required to respond to contingencies than it is for them to reduce consumption for an entire peak period due to the limited thermal storage available from the typical hotel/motel room. Finally, both the load and the system want the air conditioners to return to service as quickly as possible (understanding the need to stagger their return to service). The load wants to return to service to re-cool the room. The power system wants the loads returned to service and be re-armed so that the fast spinning reserve response capability is available in case of a subsequent contingency. Unlike generators, responsive loads do not have a minimum run time that the system operator must accommodate. 
Fortunately too, providing spinning reserves complements the load's energy management function. Thermal storage is limited. Air conditioners cannot be cycled off for more than a fraction of an hour under normal conditions. Obtaining an overall demand reduction of $1 \mathrm{MW}$, for example, might require sequentially cycling $3 \mathrm{MW}$ of air conditioners. When providing spinning reserve, however, all of the air conditioners would be cycled off simultaneously providing the full $3 \mathrm{MW}$ of spinning reserve instead of $1 \mathrm{MW}$ of energy reduction. Further, while providing $1 \mathrm{MW}$ of energy consumption reduction the remaining $2 \mathrm{MW}$ is still available as spinning reserve. And the cost to implement the spinning reserve function is only the incremental cost for additional monitoring and communications. 


\section{RESOURCE SIZE}

Contingency reserves only have value to the bulk power system if they are sufficiently large to make a significant contribution. While most individual loads are not large enough to have such an impact, aggregations of loads are. The scope of the Phase I work is to establish the feasibility of generating spinning reserves from load and to estimate the magnitude of spinning reserves that may be available at various times of the day when load is in demand. The project involved working with private companies, corporations, utilities and the ISOs to the extent that such voluntary cooperation was mutually beneficial and possible. Data gathering and analysis would be in support of preparing a NERC waiver if the utilities and ISOs perceived that the data from this DOE Consortium for Electric Reliability Technology Solutions (CERTS) program was sufficiently compelling.

\subsection{COMMERCIAL COOLING DEMAND IN THE U.S.}

The commercial cooling demand in the U.S is $1.4 \operatorname{Quad}^{1}\left(1.4 \times 10^{15} \mathrm{Btu}\right.$ or $\left.4.1 \times 10^{11} \mathrm{kWh}\right)$ and is segmented as shown in figure 3 .

Of the 1.4 Quads, PTACs provide $3 \%$ or $4.2 \times 10^{13} \mathrm{Btu}\left(1.23 \times 10^{10} \mathrm{kWh}\right)$. Based on 8760 hours in a year and essentially half the year when cooling is needed, $1.23 \times 10^{10} \mathrm{kWh}$ of energy is

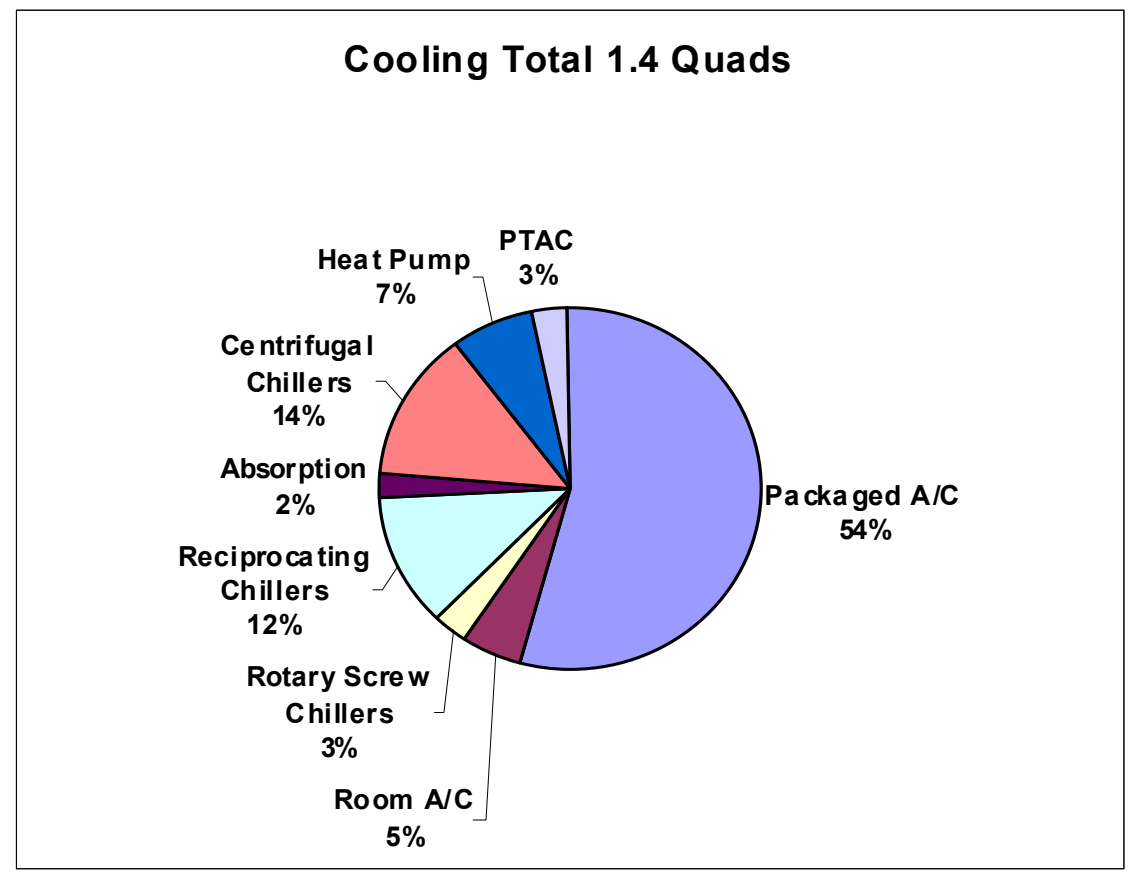

Fig. 3. Segmented commercial cooling demand in the U.S.

\footnotetext{
${ }^{1}$ Source: Energy Consumption Characteristics of Commercial Building HVAC Systems Volume I: Chillers, Refrigerant Compressors, and Heating systems. Final Report prepared by A. D. Little, Inc. for U.S. Department of Energy Office of Building Technology, April 2001.
} 
equivalent to an energy consumption rate of 3,000 MW, much more during peak usage periods. Hence PTACs represent a sizable market in terms of megawatts, albeit only $3 \%$ of commercial cooling load in the U.S. This number jumps to an average of $14,000 \mathrm{MW}$ (much greater on peak) if small, thermostat controlled heating and AC units are included.

\subsection{RESIDENTIAL COOLING DEMAND IN THE U.S.}

Tables for the residential load for cooling and heating, average household size, and type of ownership are given in Appendix A. In year 2000, there were 105.4 million households with an average population of 2.6 persons/household. Electric cooling and heating load from 105.4 million households can provide 37,000 MW towards spinning reserve

Each household has thermostatic control and hence the residential market is an excellent sector for providing spinning reserves from load. The technology to access spinning reserves is already present and has been deployed by utility companies. We are working with the commercial vendors, utilities and ISOs to further develop this capability.

Inclusion of residential units would increase the potential averaged resource size to over 40,000 MW based on 8760 hours in a year for cooling and heating (excluding resistance heating). Clearly, the resource pool is extremely large even if no other load types are considered.

\subsection{FIELD EVALUATION OF PTAC SUPERVISORY CONTROLLERS}

To evaluate the availability of spinning reserve capacity from responsive heating and air conditioning loads, ORNL obtained data from a number of units operating over a year at a motel in the TVA service territory. This facility was already participating in an evaluation of the energy savings benefits of the Digi-Log technology. A total of 24 PTAC units in as many rooms were fitted with Digi-Log's supervisory control unit that could be controlled from the motel front desk. Twelve of the rooms formed the group in which the controller was controlled from the hotel front desk only. The remaining twelve rooms were controlled by the occupant and formed the uncontrolled group. The occupancy rate, defined as the number of days in a month the rooms were occupied, was maintained as equal as possible. This enables us to evaluate the spinning reserve capacity from PTACS that were operating normally and from those under active energy management.

Photographs of the site where data was collected and installation of the controllers under the PTACs are shown in Figure 4. 


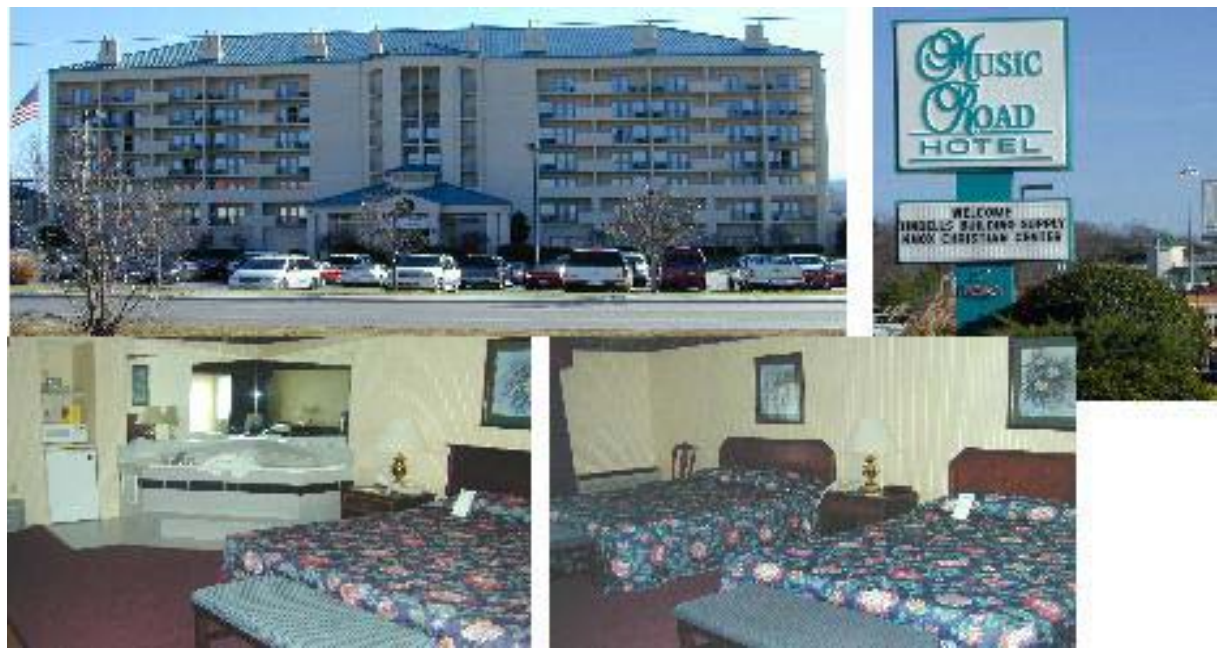

Fig. 4. Test site (Pigeon Forge, Tennessee)

Data downloads from the 24 ORNL monitored-rooms were conducted automatically nightly, using an on-board, dial-out modem inside the monitoring device.

The Power Controller Unit was developed by Digi-Log Technologies Inc. as a tool for reducing energy consumption and protecting the HVAC units in low and high voltage situations, therefore lowering operating costs in the lodging industry. The primary functions of the Power Control Unit are to: monitor the power supply of the HVAC unit (protect it from high or low voltages), respond to room temperature extremes and/or an alarming smoke detector (by generating a phone call followed by an alarm code, also lowering motel insurance costs), and enable remote programming and control of various dial up commands and functions. A communication link via telephone (computer modem or touch-tone phone keypad) is established between each Power Controller Unit and the front desk, using the room phone line and a phone line splitter. When a PC is used, Digi-Log Technologies Inc. software and Host Interface Unit are required. The equipment is shown in Figure 5.
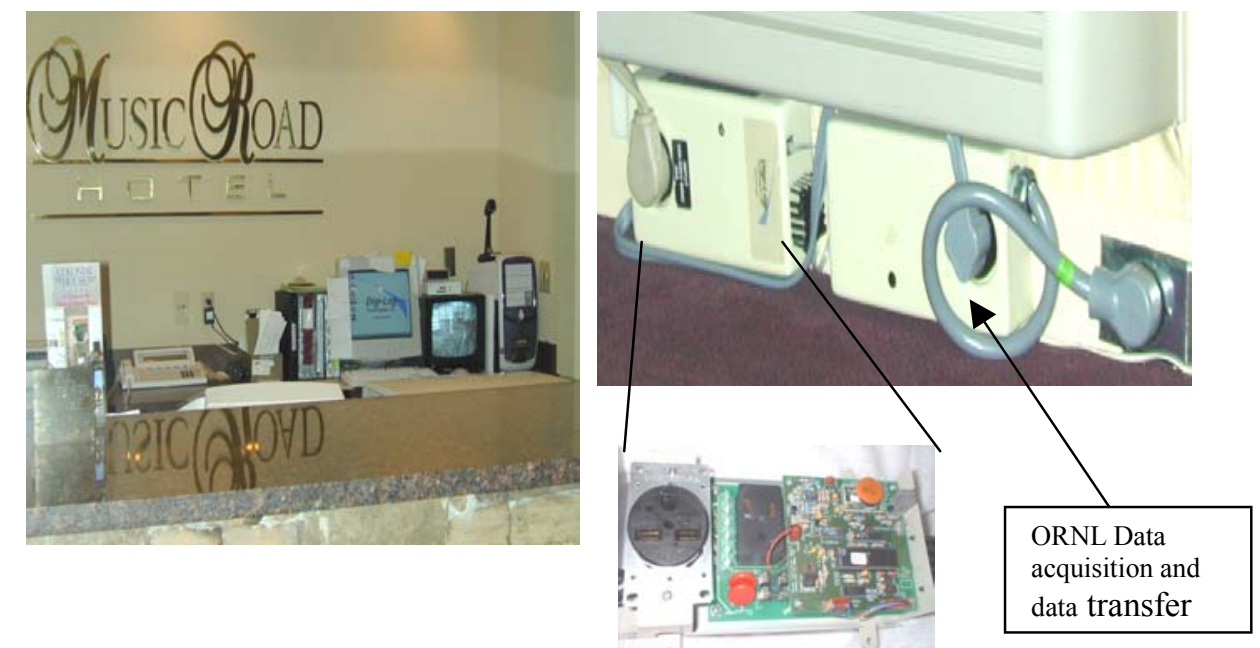

Fig. 5. Clockwise from left: front desk controller at motel, installed Digi-Log unit and control board, ORNL data processing and data transfer module. 
A second generation of the Digi-Log controller that will respond quickly enough to provide spinning reserve has been designed but not yet manufactured. Manufacture of these units is pending arrival of funds from NYSERDA, expected in November 2002. The new Digi-Log equipment will utilize satellite signals from Skytel to activate the controller from a remote site by the ISO as shown in Figure 6, and to respond to curtailment events. Performance monitoring will still be through the phone system.

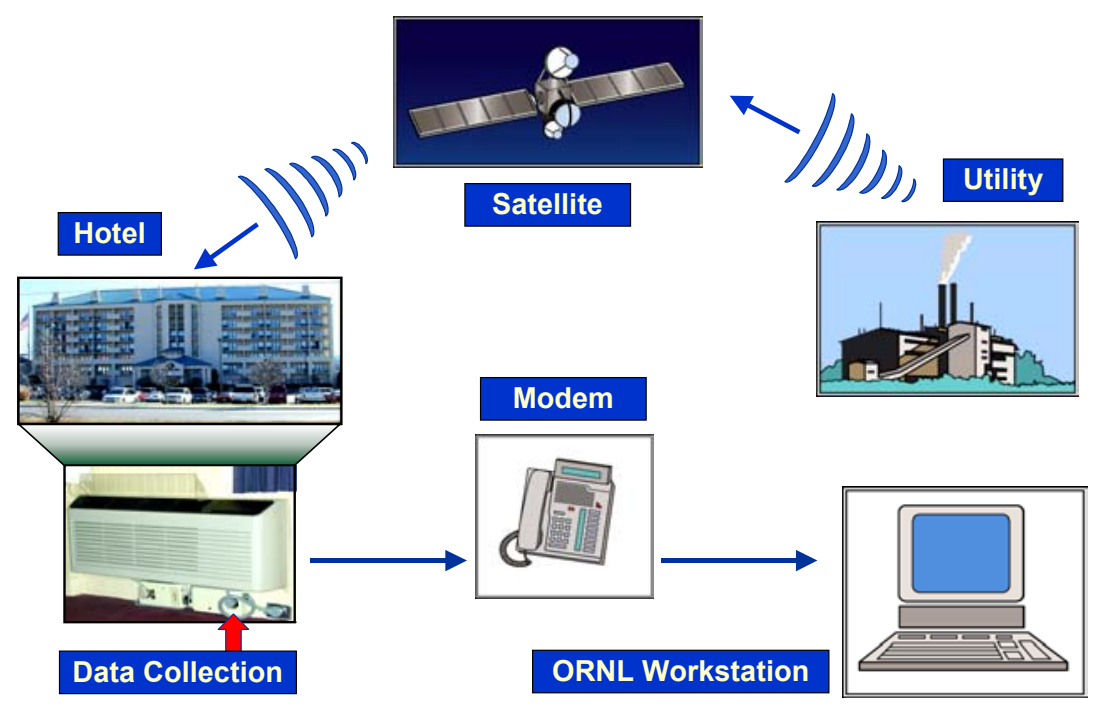

Fig. 6. Schematic of the signal initiation, reception, and data collection

\subsubsection{Data Collection and Data Reduction}

Data was collected at one minute intervals, stored and subsequently downloaded automatically at predetermined times via a modem connection. Data consisted of a time stamp, current, voltage, humidity and room temperature. For analyses, data were averaged over a one-hour period. The energy consumption was calculated assuming a conservative (understating energy consumption) power factor of 0.8. The averaged values for each one-hour interval were summed for each of the 12 rooms in the controlled and uncontrolled sets. For example, power $(\mathrm{kW})$ demand from 8:00 a.m. to 9:00 a.m. (one-hour) consists of the sum of the averaged demand for each of the 12 rooms in the particular control set. In this manner the profile of $\mathrm{kW}$ versus time of day in hourly intervals could be constructed to ascertain the load that may be available as spinning reserve. The room temperature profiles and the electric demand give a consistent picture of how the PTAC is being used during heavy load demand in the peak summer months of July, August and September. The data in this report covers the peak summer months and the peak winter months of January, February and March.

Detailed data for the summer (July, August, September) and winter (January, February, March) are given in Appendix B. 


\subsubsection{Hourly and Seasonal PTAC Availability}

This Phase I study on 24 motel rooms clearly presents a compelling case for load to contribute towards spinning reserve. For example, consider the cooling load during summer shown below in Figures 7 and 8, in which load is plotted versus time of day. As expected, the cooling load rises between 11:00 am and 5:00 pm when solar insulation is higher than early morning or later in the afternoon. Also, the cooling demand is greatest in July than it is in August or September because occupancy rates are highest in July than in the following two months for this motel. This trend is observed for both sets of control (Figure 7) and uncontrolled rooms (Figure 8) in the Phase I study.

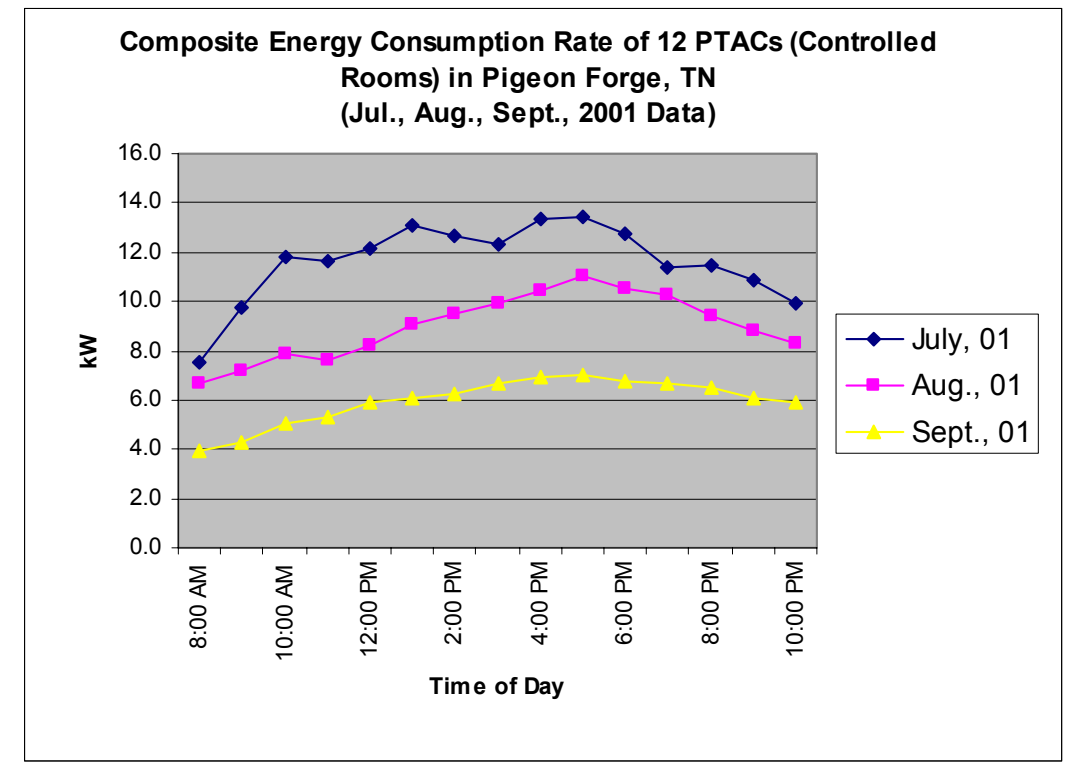

Fig. 7. Graph of electric demand for cooling versus time of day for July, August and September 2001 for 12 controlled rooms.

It is worthwhile to note that the energy consumption rates for the uncontrolled rooms (Figure 8) are higher than those for the controlled rooms in which the front desk had the override option. The tables in Appendix B for the total kWhs in July for the uncontrolled and controlled rooms are 182.9 and 174.0, respectively. This indicates that spinning reserves are significant for uncontrolled as well as controlled rooms and that these reserves are available over and above energy management activities, as in the case of the controlled rooms. Note that during maximum load demand times $(2: 30 \mathrm{pm}-5: 00 \mathrm{pm})$, approximately $1.1 \mathrm{~kW}$ of spinning reserves is available per PTAC for uncontrolled and controlled sets of rooms. 


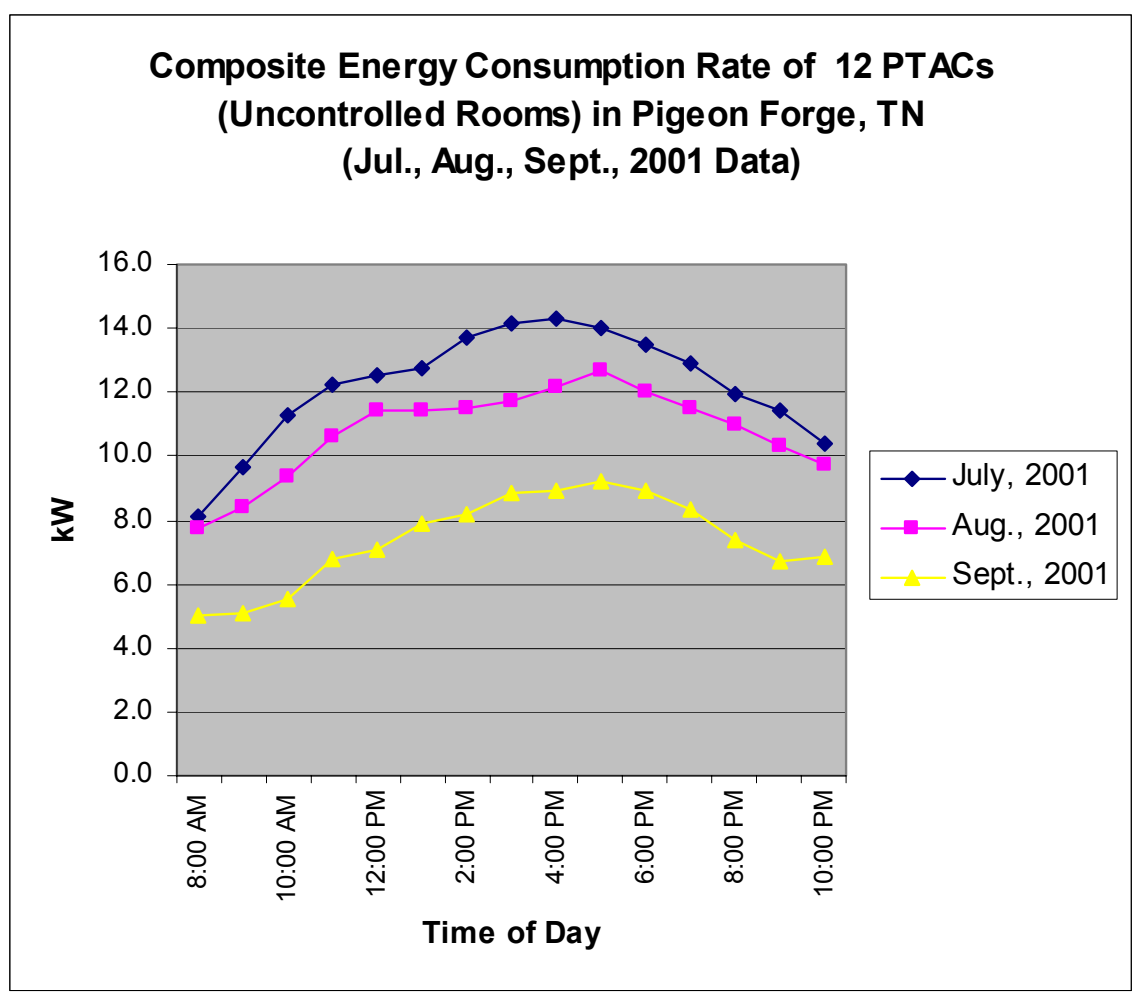

Fig. 8. Graph of electric demand for cooling versus time of day for July, August and September 2001 for 12 uncontrolled rooms.

The amount of energy savings in the control and uncontrolled sets of rooms depends upon the room occupancy rate, which were kept similar for a valid comparison of the energy consumption rates. During occupancy, supervisory control saved an average of 31\% of total room HVAC energy consumption. During vacancy, supervisory control saved $43 \%$ of total energy consumption. This translates into about $2,190 \mathrm{kWh}$ per room per year. At electricity cost of $\$ 0.08 / \mathrm{kWh}$, the savings are approximately $\$ 175$ per room per year. Digi-Log, Inc. custom made 24 PTAC controller units at a cost of $\$ 399$ each. At this price, the payback is 2.28 years. Mass production of the controller units would dramatically reduce unit costs, making the payback more attractive.

The winter data represents the heating load. All of the PTACs used electric resistance elements for heating. Winter occupancy for this motel is low compared to the summer months. Still, the heating load is significant. Figures 9 and 10 present the composite winter heating loads for the uncontrolled and controlled rooms.

During January, February and March, the potential for spinning reserves are shown in Figures 9 and 10 for the controlled and uncontrolled rooms, respectively. Note the heavy heating load in January depicted by the concave downward trend of the curve and the "inverted" (concave upward) heating curves for both February and March. The averaged January temperatures for the 12 rooms (controlled and uncontrolled) are quite high $(74.6 \mathrm{~F}$ and $73.6 \mathrm{~F}$, respectively) compared to the averaged temperatures in February of $70.2 \mathrm{~F}$ (controlled) and $69.2 \mathrm{~F}$ (uncontrolled). Similarly for March, the average temperatures were $69.9 \mathrm{~F}$ (controlled) and 68.5 F (uncontrolled). That might explain why the heating energy is higher in January versus the 
following two winter months of February and March. Also, as the day progresses, the sun's energy warms the ambient and that along with seasonal milder temperatures headed into Spring further explains the concave upward trend in the energy consumption rates in February and March in contrast to the concave downward trend in January. These trends seem to be corroborated by the load curves from the utilities discussed in following pages.

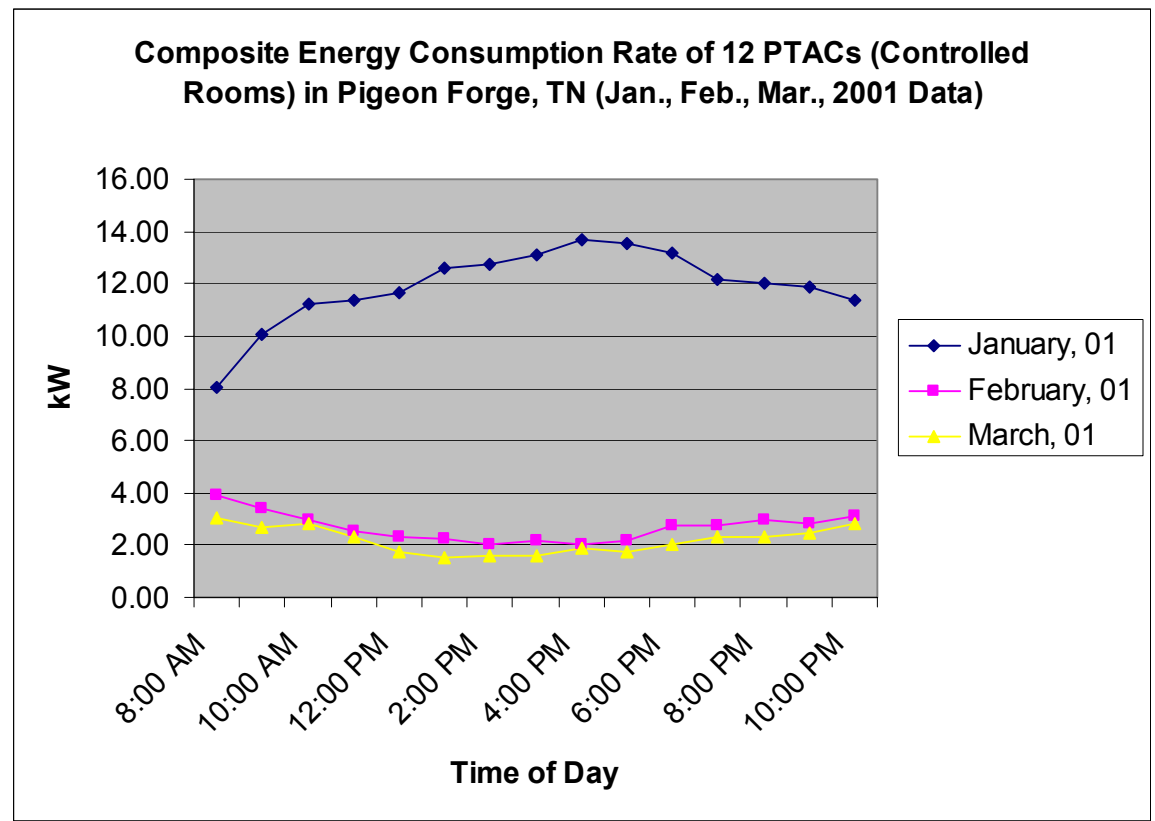

Fig. 9. Graph of electric demand for heating versus time of day for January, February and March 2001 for 12 controlled rooms.

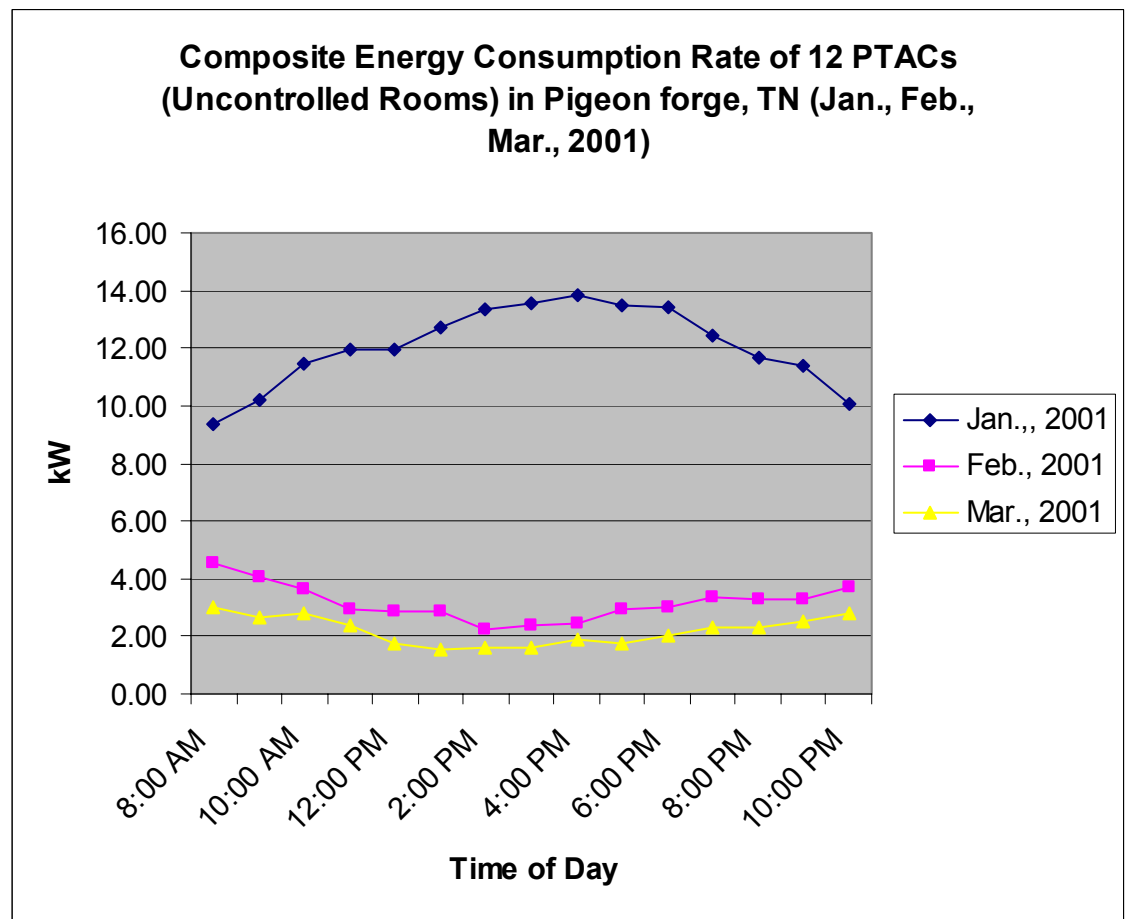

Fig. 10. Graph of electric demand for heating versus time of day for January, February and March 2001 for 12 uncontrolled rooms. 



\section{SPINNING RESERVE PRICES}

Under restructuring, spinning reserves are generally obtained through hourly markets. It is useful to examine spinning reserve market prices for two reasons. First, they provide an indication of the financial viability of loads providing spinning reserves. Second, they provide an indication of when the system values spinning reserves. While the system's need for spinning reserves is relatively constant the supply from generators is not. There are times when excess generation is on line but unloaded. This often occurs at night when units that can not be shut down are operated at reduced load awaiting the following day's peak when they will be needed. These unloaded generators can supply spinning reserves very cheaply during these hours. There is no need for loads to respond. At other times, however, there is great value in having loads respond. Hourly spinning reserve prices indicate that value.

TVA - The test motel is located in Pigeon Forge Tennessee which is in the TVA service territory. Unfortunately TVA does not yet operate an hourly spinning reserve market, so spinning reserve prices could not be matched to the hourly PTAC availability data. Average hourly system load is presented in Figures 11 and 12; average hourly system marginal energy cost is presented in Figures 13 and 14. These provide a rough proxy for determining when spinning reserve would have a high value.

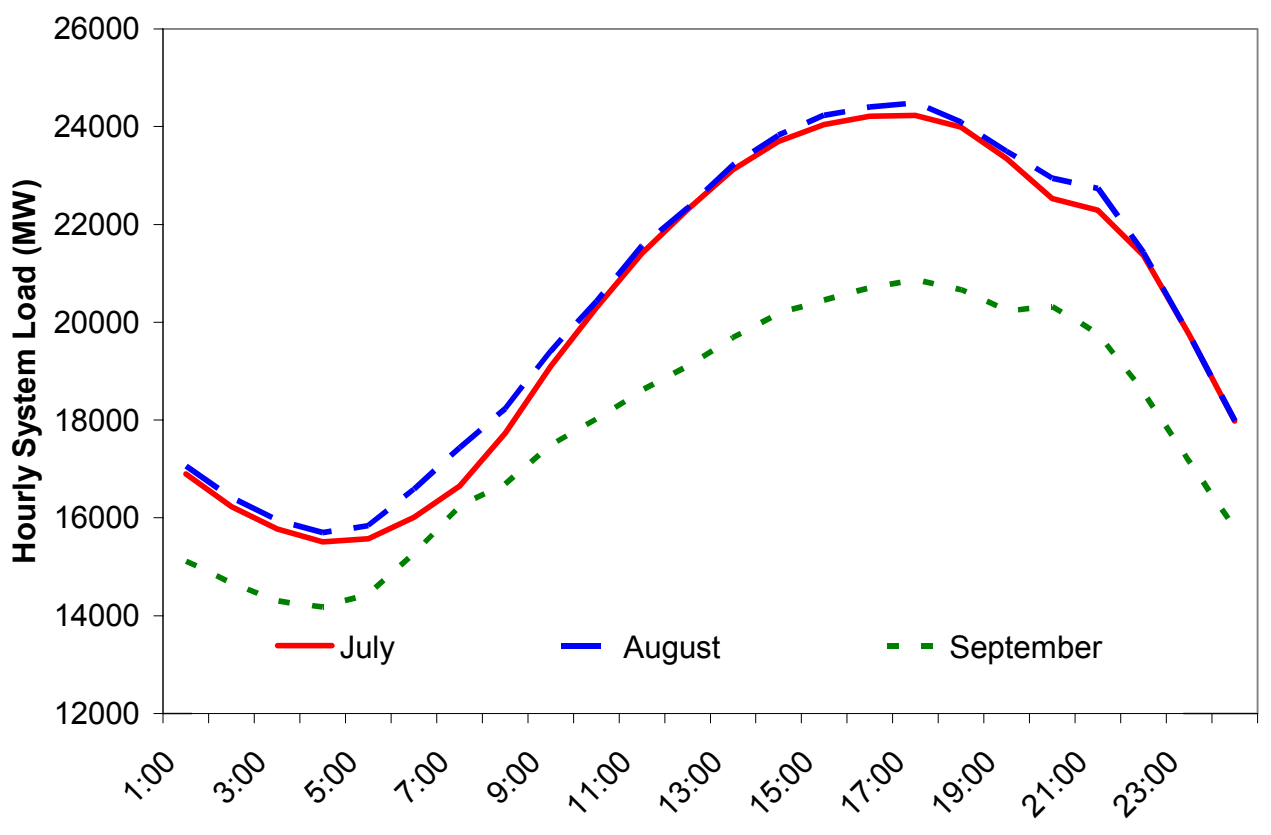

Fig. 11. TVA average hourly system summer 2001 load. 


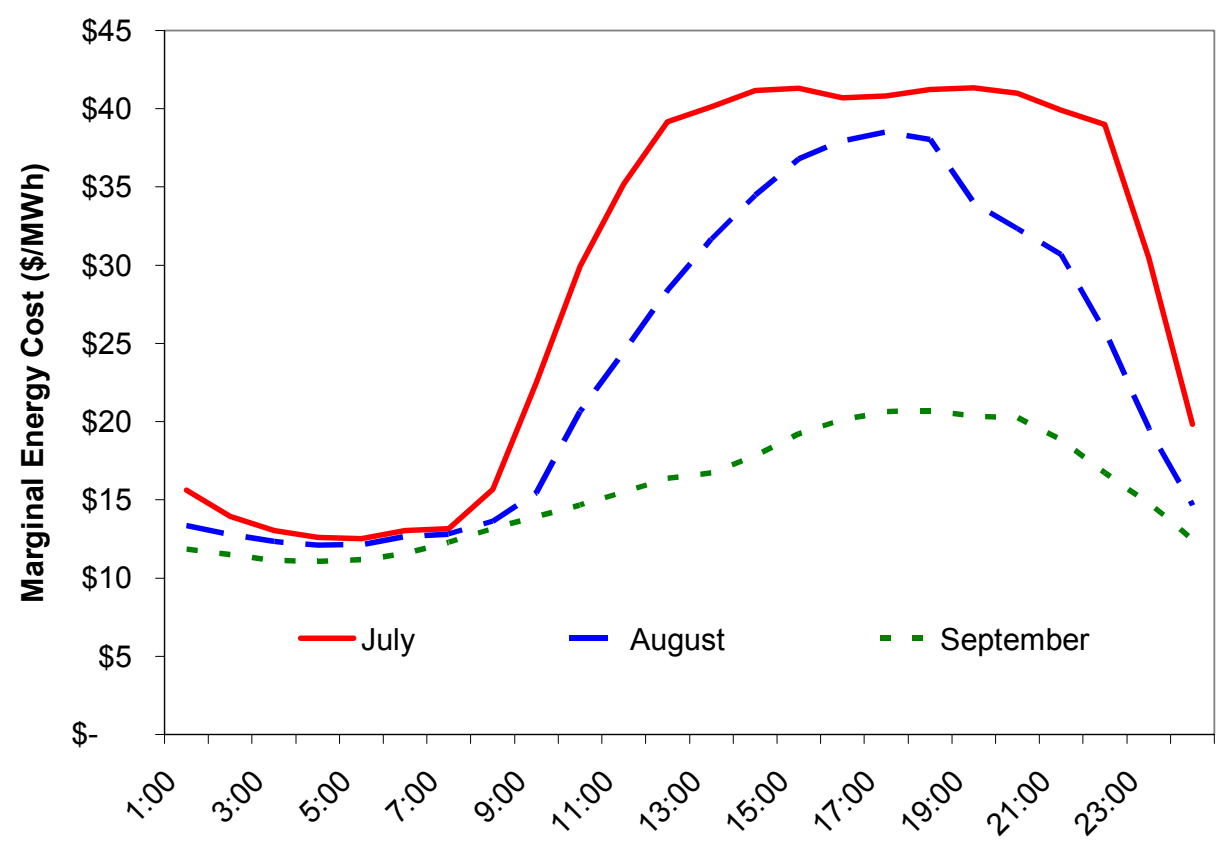

Fig. 12. TVA average hourly system summer 2001 marginal energy cost.

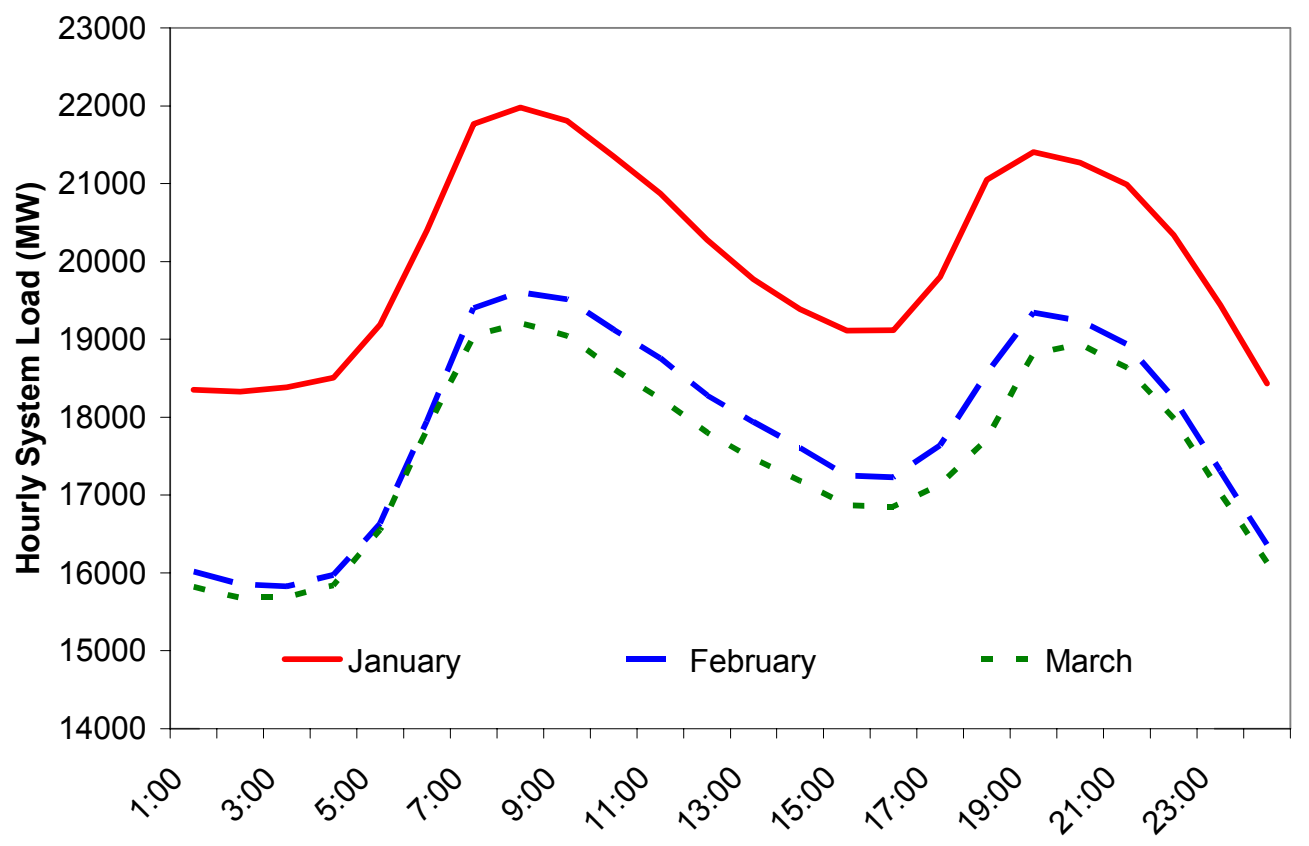

Fig. 13. TVA average hourly system winter 2001 load. 


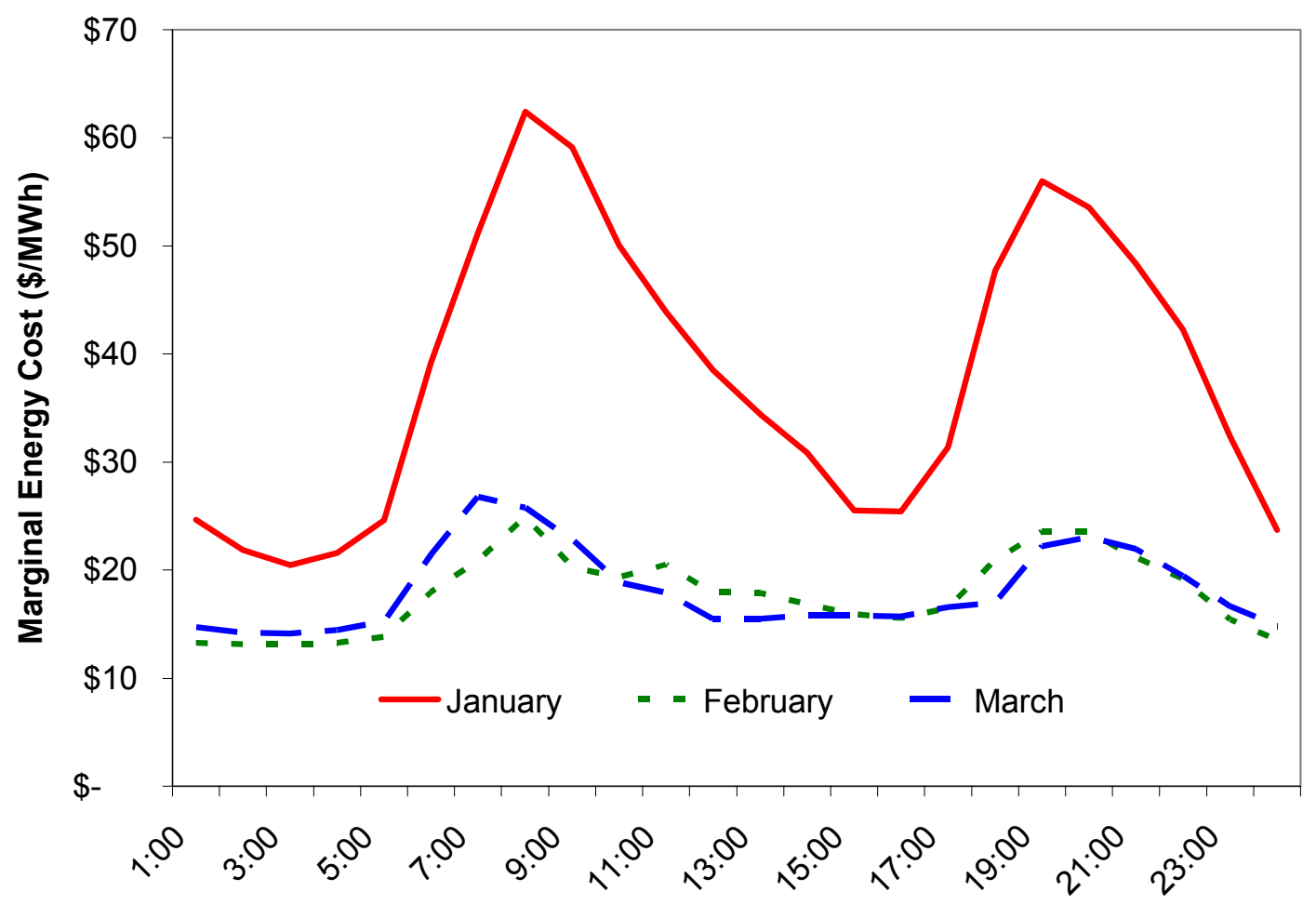

Fig. 14. TVA average hourly system winter 2001 marginal energy cost.

Comparing Figures 7 and 11 it can be seen that the PTAC unit's hourly energy requirements and spinning reserve availability are consistent with the overall TVA system load requirements. As expected, system marginal energy costs (Figure 12) also track system load. Spinning reserve costs are likely to show a similar pattern but probably with increased volatility.

Comparing winter conditions shown in Figures 8 and 13 confirms that for both the motel and the overall system February and March were milder than January. One observable winter difference is that the system as a whole shows the typical winter double hump with load dropping in the middle of the day while the PTAC units do not reflect this pattern.

Supervisory thermostat control is economically attractive to utilities and end-users. Conservatively, gas turbine generation cost is about $\$ 500 / \mathrm{kW}$. The cost of a pager to provide thermostatic supervisory control is approximately $\$ 50$ and each PTAC can contribute up to 1.1 $\mathrm{kW}$ towards spinning reserves or essentially, $\$ 46 / \mathrm{kW}$. The cost of each $\mathrm{kW}$ from spinning reserves therefore, is approximately one-tenth the cost of producing it using gas turbines. It behooves us to consider generating spinning reserves from responsive loads versus new generation. On a yearly basis, a typical PTAC in the Southeastern United States consumes 3363 $\mathrm{kWh}$ for cooling (7 months) and $3636 \mathrm{kWh}$ for heating (5 months). In field tests, supervisory controllers can save at least $28 \%$ of energy which amounts to $\$ 113$ per year, based on $\$ 0.059$ per $\mathrm{kWh}$. Mass produced supervisory controllers are projected to cost $\$ 30$ each, enabling a payback of approximately 4 months. Spinning reserves from the utility's standpoint as well as from the end-user's standpoint is economically viable. 
California - The CA ISO does run an hourly market for spinning reserve (and the other ancillary services). Figure 15 presents average hourly prices from February and July 2002 (the California markets were not well behaved in 2001). As can be seen, ancillary service prices are quite volatile and vary throughout the day. Not surprisingly, spinning reserve prices are highest when air-conditioning demand is highest. Fortunately this is when air-conditioning can supply the most spinning reserve. Also not surprisingly, prices in February are well below prices in July in California.

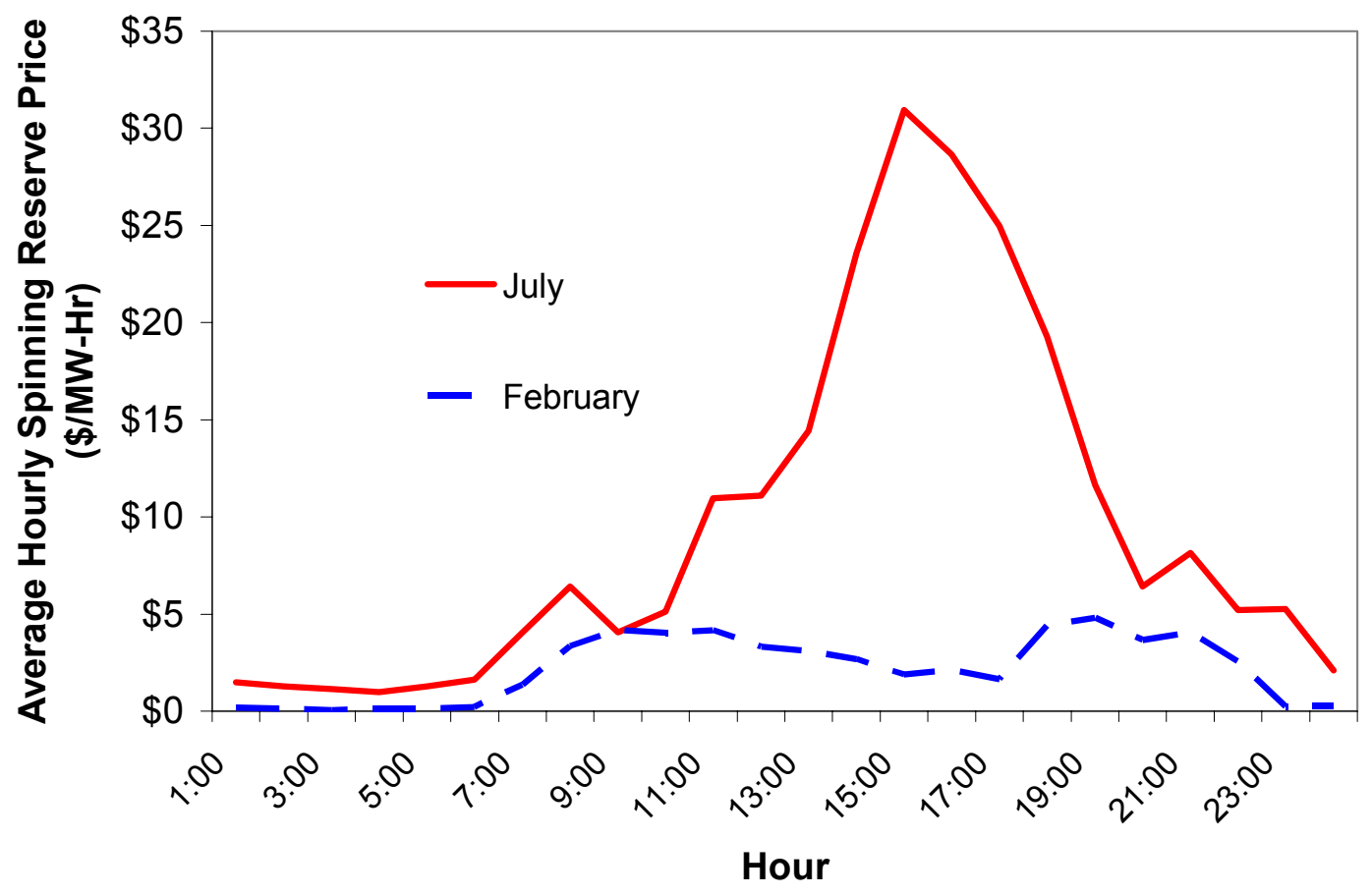

Fig. 15. Average hourly CAISO spinning reserve prices for July and February 2002.

New York - The current spinning reserve market in New York does not capture the full costs of supplying spinning reserve from generation. As shown in Figure 16, average market prices for spinning reserve were low in 2001 due to the market structure and bidding requirements for energy and the ancillary services. In addition to the hourly spinning reserve market prices generators supplying spinning reserves are compensated for their lost opportunity cost - the profits the generators lost because they could not sell into the energy market while they were providing spinning reserves. Generators supplying spinning reserves also typically receive installed capacity payments. New York recognizes these shortcomings in their ancillary service markets and is working to correct them. Still, the pattern does reflect higher value in the afternoon and evening than overnight, matching the PTAC capabilities. 


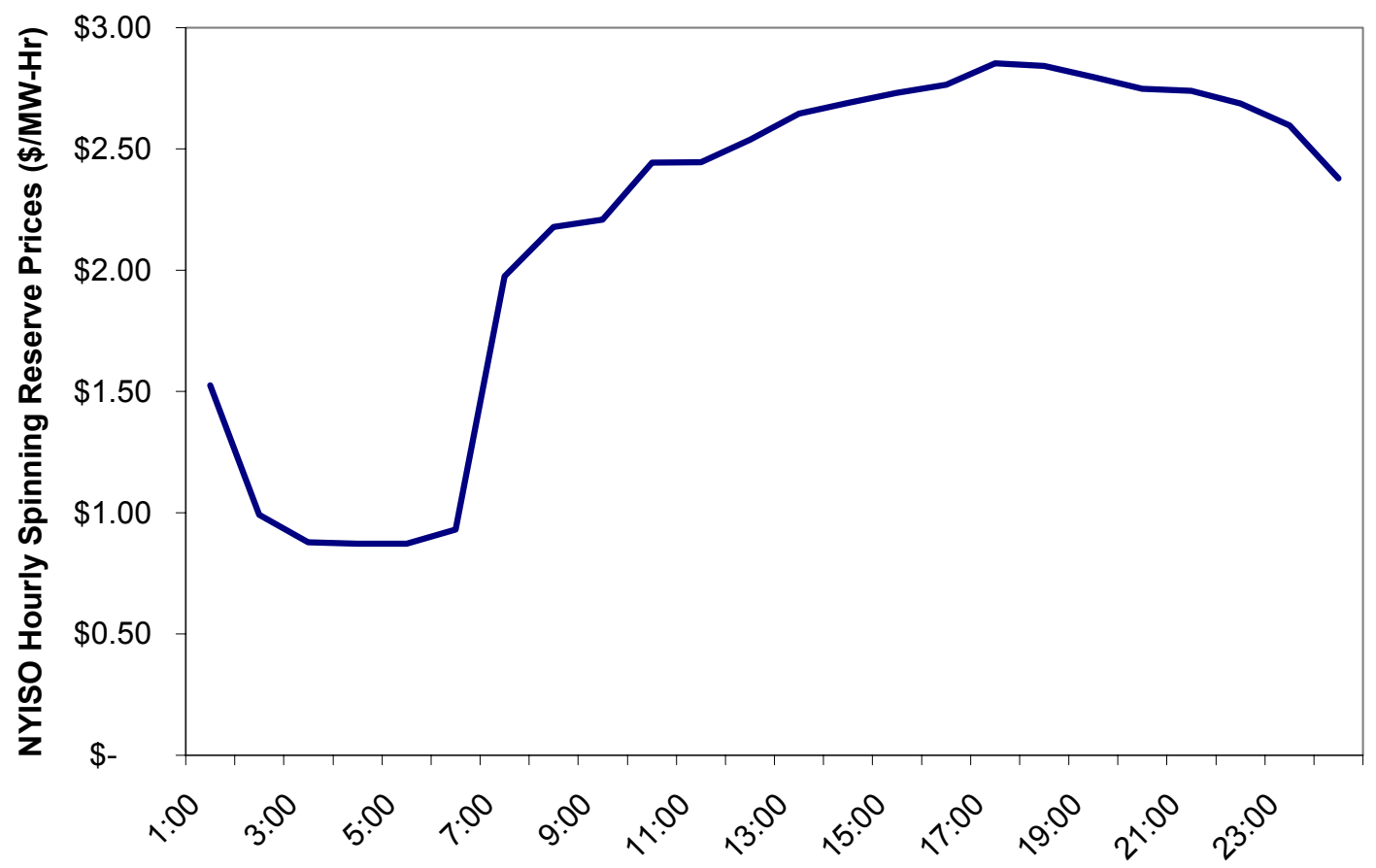

Fig. 16. NYISO spinning reserve prices for July 2001 do not reflect all of the compensation a spinning reserve generator receives.

Generation Cost - Another way to take a preliminary look at the financial viability is to compare the cost of obtaining spinning reserve from a conventional resource such as a generator. There the primary cost is the capital cost of having a generator available but not selling into the energy market. A simple comparison of capital costs ( $\$ / \mathrm{kW}$ capacity) indicates that the incremental cost of adding a spinning reserve response capability to a responsive load energy management system is much lower than the cost of generation capacity $(\sim 500-\$ 1000 / \mathrm{kW})$. 



\section{OTHER ISSUES}

This project was not designed to address every concern associated with providing spinning reserve from responsive load. Its scope is limited to addressing the size of the resource and its coincidence with power system needs. We recognize that there are additional concerns. We feel that there are good reasons to believe that these other issues can be satisfactorily addressed if the concept proves out technically. Further, we believe that there will be strong incentives to address these other issues once the technical questions are addressed because this concept (spinning reserve from responsive loads) provides benefits to power system operators, supplying loads, generators (freeing them to sell energy rather than constraining them to supply spinning reserves), to all other loads (by increasing power system reliability, decreasing reliability costs, and increasing the available energy supply), and to the transmission system owners (by increasing the transmission system's effective capacity). We provide a brief discussion of some of these additional issues to demonstrate that they are recognized and that further research will address them.

Real-Time Response Monitoring - Spinning reserve is such a critical reliability service, the resources supplying the service (generators) are individually so large (typically hundreds of MW), and the service has to be supplied so fast that the system operator monitors the response of each resource in real-time. Signals are sent from each generator to the system operator's central control facility every two to eight seconds. Under normal conditions (before a contingency event occurs) the system operator uses this monitoring to provide assurance that the reserves are available. When a contingency event occurs, the system operator uses this monitoring to provide assurance that each spinning reserve supplier is indeed responding. The system operator can rapidly take corrective action if one of the generators is not responding as expected.

Real-time monitoring of responsive load could also be provided when loads supply spinning reserve. But there are good reasons to think that this may not be required due to differences in the inherent nature of loads versus generators. First, loads are turning off when they supply spinning reserve while generators are increasing output. As a general rule turning off a load is more reliable than ramping up a generator: fewer things have to go right for the process to be successful. Second, individual loads are typically much smaller than individual generators. If a single $1 \mathrm{~kW}$ load fails to respond, for example, there is much less impact on the power system than if a single generator that is supplying $100 \mathrm{MW}$ of spinning reserve fails to respond. Third, individual loads are distributed throughout the power system so problems on the transmission system are less likely to significantly impact the availability of a large amount of spinning reserve. It is critical to assure that the reserves do respond, without monitoring or verification there is no incentive for the supplier to continue to supply, but that monitoring may not need to be telemetered to the system operator from each load in real time. After-the-fact monitoring or periodic verification may be adequate if it captures the required fast-response. The reason this issue is of interest is because real-time telemetry can be a significant cost.

Frequency Response - Spinning reserve resources must be automatically and autonomously responsive to system frequency. If system frequency drops sufficiently, spinning reserve resources should try to restore the generation/load balance without waiting for instructions from 
the system operator. For loads supplying spinning reserve this response is similar to under frequency load shedding except that the response occurs much closer to the $60 \mathrm{~Hz}$ operating frequency, within the generator governor response band (starting at about $+/-0.035 \mathrm{~Hz}$ ). Technically, automatic frequency response is not difficult to implement. The response of individual units could be staggered in frequency such that the aggregated load response duplicates the $5 \%$ droop characteristic of a typical generator. 


\subsection{CONCLUSIONS}

This Phase I study on 24 motel rooms clearly presents a compelling case for load to contribute towards spinning reserve. Examination of hourly load patterns for both controlled and uncontrolled PTAC units shows that they are consistent with overall system loading and spinning reserve prices in the summer. The cooling load rises between 11:00am and 5:00pm when solar insolation is higher than early morning or later in the evening. The same physical forces are driving the overall system load and the PTAC load.

In the commercial sector PTACs account for approximately $3 \%\left(1.23 \times 10^{10} \mathrm{~kW}-\mathrm{h}\right)$ of the total cooling load ( $\left.4.2 \times 10^{11} \mathrm{~kW}-\mathrm{h}\right)$. Based on 8760 hours in a year and half a year of cooling season, the $1.23 \times 10^{10} \mathrm{~kW}$-h of energy is equivalent to an average energy consumption rate of 3,000 MW with peak consumption being significantly higher. Hence PTACs alone represent a sizable opportunity for providing spinning reserves from load. Each PTAC can contribute approximately $1.1 \mathrm{~kW}$ towards spinning reserves in the summer time.

The residential buildings sector comprises of 105.4 million units whose cooling and heating loads for the year is equivalent to a yearly average of $32,792 \mathrm{MW}$, more than 10 times the commercial PTAC load. The buildings sector represents an even greater opportunity than the PTAC commercial sector for providing spinning reserves from load.

Technology to implement load curtailment and monitoring its effect on conditioned space from a physically remote site already exists and can readily be further customized or tailored for the ISO and utilities.

Our discussion with the utility companies, LIPA, Southern California Edison (SCE), Commonwealth Edison and with manufacturers of controllable thermostats indicate a strong interest determining the technical viability of obtaining spinning reserves from responsive loads.

Benefits to the ISO and to the public are that complete feeders need not be targeted during curtailment, but only those loads that do not have a high priority, for example air-conditioning can be remotely turned off for short periods of time (10 - 15 minutes) until generation that is not on-line and is not fully loaded can be brought on to the grid and/or more traditional (and slower) interruptible load can respond.

Controllable PTAC units give the ISO added leverage to be ready for the next curtailment event, should one occur within a short time span.

Further research is needed to prove the technical feasibility of PTAC units and other small loads providing spinning reserves. Aggregation, communication, control, and monitoring issues remain to be addressed. If the technical issues can be resolved, however, it is likely that system operators, loads, and regulators will have significant incentives to resolve these other issues since spinning reserve from load has the potential to provide large benefits to each community. 



\section{ACKNOWLEDGMENT}

The authors would like to acknowledge the support provided by the DOE EERE Emerging Technology Program management (James R. Brodrick and Rick Orrison) to evaluate the energy savings of the distributed controllers. The authors also wish to thank Evelyn Baskin, Building Equipment Group, for providing energy savings data and to Susan Johnsen for formatting and preparing this report.

\section{REFERENCES}

1. Energy Consumption Characteristics of Commercial Building HVAC Systems Volume I: Chillers, Refrigerant Compressors, and Heating systems. Final Report prepared by A. D. Little, Inc. for U.S. Department of Energy Office of Building Technology, April 2001.

2. 2000 BTS Core Databook, U.S. DOE Office of Building Technology, State and Community Programs, August 7, 2000. 

APPENDIX A 



\section{A.1 Split of Residential Energy End-Use Demand in the U.S (Ref. 2).}

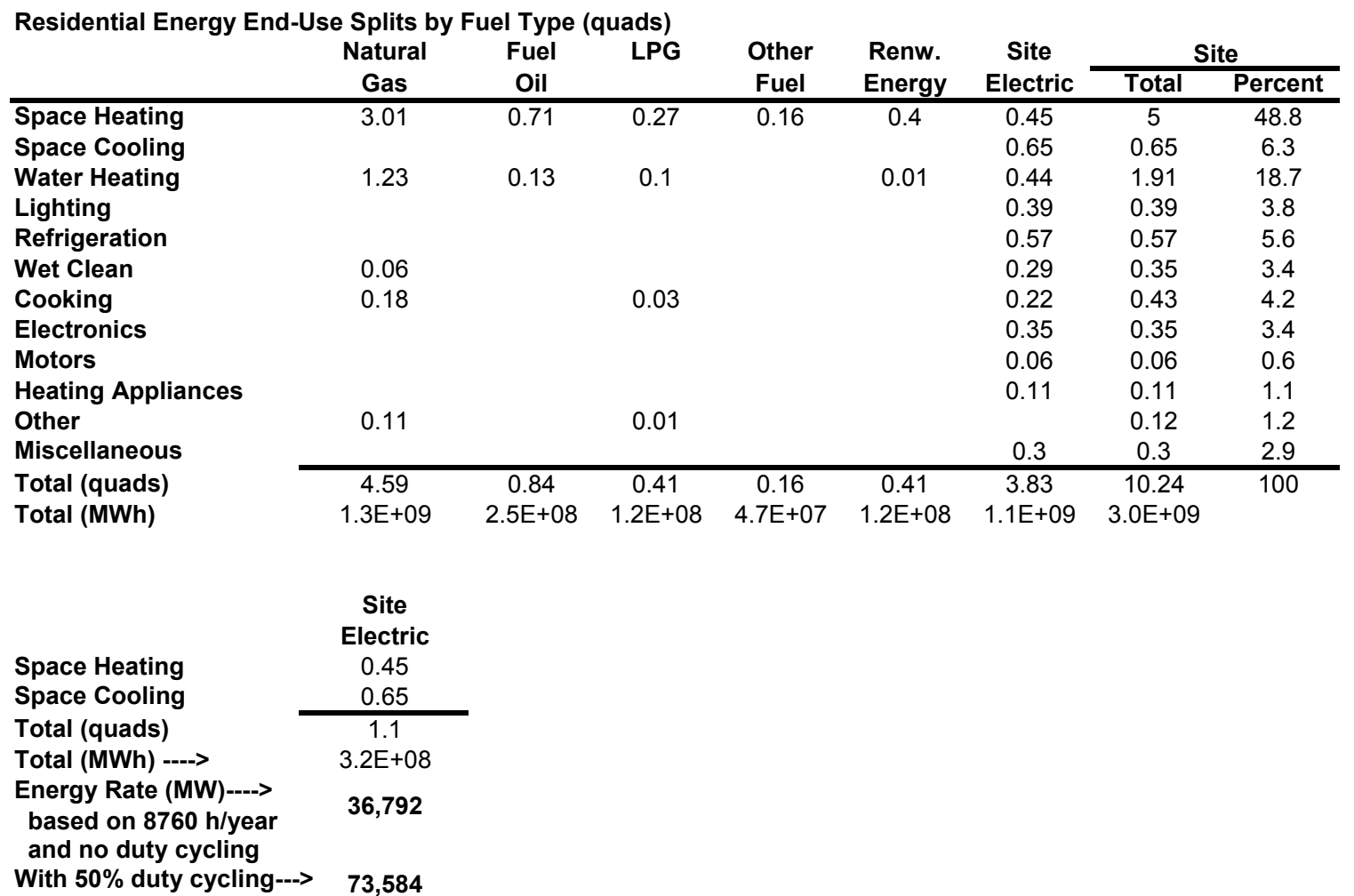

\section{A.2 Total Number of Households, Floorspace and Household Size}

\begin{tabular}{|l|c|c|c|c|c|c|}
\hline \multicolumn{7}{|c|}{ Total Number of Households and Buildings, and Housesize by by Year } \\
\hline Year & $\begin{array}{c}\text { Households } \\
\text { (millions) }\end{array}$ & $\begin{array}{c}\text { Percent Post- } \\
\mathbf{1 9 9 0} \text { Households }\end{array}$ & $\begin{array}{c}\text { Buildings } \\
\text { (millions) }\end{array}$ & $\begin{array}{c}\text { Floorspace } \\
\text { (billion sf) }\end{array}$ & $\begin{array}{c}\text { U.S. Population } \\
\text { (millions) }\end{array}$ & $\begin{array}{c}\text { Average } \\
\text { Household Size }\end{array}$ \\
\hline 1980 & 79.6 & N/A & 65.5 & 142.5 & 228 & 2.9 \\
\hline 1990 & 94.2 & N/A & 74.2 & 169.2 & 250 & 2.7 \\
\hline 1998 & 102.8 & $14 \%$ & 82.6 & 168.8 & 271 & 2.6 \\
\hline $\mathbf{2 0 0 0}$ & $\mathbf{1 0 5 . 4}$ & $\mathbf{1 8 \%}$ & N/A & N/A & $\mathbf{2 7 5}$ & $\mathbf{2 . 6}$ \\
\hline 2010 & 117.1 & $32 \%$ & N/A & N/A & 298 & 2.5 \\
\hline 2020 & 127.5 & $44 \%$ & N/A & N/A & 323 & 2.5 \\
\hline
\end{tabular}




\section{A.3 Share of Households by Housing Type, and by Type of Ownership}

\section{Share of Households, by Housing Type, and by Type of Ownership}

\begin{tabular}{|c|c|c|c|}
\hline Housing Type & Owned (\%) & Rented (\%) & Total (\%) \\
\hline Single-Family: & $\mathbf{6 0 . 3}$ & 12.4 & 72.7 \\
\hline - Detached & 54.8 & 8 & 62.8 \\
\hline - Attached & 5.4 & 4.4 & 9.8 \\
\hline Multi-Family: & $\mathbf{2 . 1}$ & 19 & 21.1 \\
\hline - 2 to 4 units & 0.9 & 4.6 & 5.5 \\
\hline - 5 or more units & 1.2 & 14.4 & 15.6 \\
\hline Mobile Homes & $\mathbf{5 . 2}$ & 1.1 & 6.3 \\
\hline TOTAL & $\mathbf{6 7 . 6}$ & $\mathbf{3 2 . 5}$ & $\mathbf{1 0 0}$ \\
\hline & & & \\
\hline
\end{tabular}




\section{APPENDIX B}





\section{B.1 Summer Data: Controlled Rooms - July}

\begin{tabular}{|c|c|c|c|c|c|c|c|c|c|c|c|c|c|}
\hline \multicolumn{3}{|c|}{ CONTROLLED ROOMS (July, 2001) } & & & & & & & & & & & \\
\hline & Room 501 & Room 508 & Room 509 & Room 513 & Room 516 & Room 519 & Room 520 & Room 523 & R00m 524 & Room 528 & Room 727 & & Adj. For 12 Rooms \\
\hline Time & $\mathrm{kW}$ & $\mathrm{kW}$ & $\mathrm{kW}$ & $\mathrm{kW}$ & $\mathrm{kW}$ & $\mathrm{kW}$ & $\mathrm{kW}$ & $\mathrm{kW}$ & $\mathrm{kW}$ & $\mathrm{kW}$ & $\mathrm{kW}$ & Sum kW & Sum kW \\
\hline 8:00 AM & 0.7 & 0.605 & 0.609 & 0.411 & 0.695 & 0.603 & 0.775 & 0.345 & 0.629 & 0.488 & 1.029 & 6.889 & 7.515 \\
\hline 9:00 AM & 0.755 & 0.658 & 0.654 & 0.405 & 0.738 & 0.985 & 0.748 & 0.994 & 0.87 & 0.772 & 1.386 & 8.965 & 9.780 \\
\hline $10: 00 \mathrm{AM}$ & 0.762 & 1.027 & 0.797 & 0.734 & 0.701 & 1.162 & 0.885 & 1.562 & 1.28 & 0.758 & 1.161 & 10.829 & 11.813 \\
\hline $11: 00 \mathrm{AM}$ & 0.921 & 0.88 & 0.629 & 0.847 & 0.702 & 1.045 & 0.755 & 1.607 & 1.305 & 0.792 & 1.159 & 10.642 & 11.609 \\
\hline 12:00 PM & 1.121 & 0.806 & 0.596 & 1.109 & 0.573 & 1.294 & 0.768 & 1.394 & 1.164 & 0.853 & 1.456 & 11.134 & 12.146 \\
\hline 1:00 PM & 1.142 & 0.852 & 0.637 & 0.884 & 0.639 & 1.363 & 0.946 & 2.01 & 1.192 & 0.87 & 1.449 & 11.984 & 13.073 \\
\hline $2: 00 \mathrm{PM}$ & 1.402 & 0.813 & 0.658 & 0.965 & 0.707 & 1.243 & 0.839 & 1.517 & 1.13 & 0.838 & 1.463 & 11.575 & 12.627 \\
\hline $3: 00$ PM & 1.275 & 0.846 & 0.894 & 1.052 & 0.623 & 1.164 & 0.873 & 0.867 & 1.119 & 1.117 & 1.427 & 11.257 & 12.280 \\
\hline 4:00 PM & 1.391 & 0.967 & 0.693 & 0.982 & 0.839 & 1.09 & 1.024 & 1.171 & 1.308 & 1.128 & 1.611 & 12.204 & 13.313 \\
\hline 5:00 PM & 1.129 & 1.131 & 0.669 & 1.037 & 0.623 & 1.061 & 1.261 & 1.421 & 1.257 & 0.965 & 1.745 & 12.299 & 13.417 \\
\hline 6:00 PM & 1.198 & 0.7 & 0.731 & 0.981 & 0.591 & 1.059 & 1.355 & 1.301 & 1.091 & 0.997 & 1.711 & 11.715 & 12.780 \\
\hline $7: 00$ PM & 1.071 & 0.696 & 0.707 & 0.933 & 0.593 & 0.918 & 1.206 & 1.011 & 1.042 & 0.963 & 1.318 & 10.458 & 11.409 \\
\hline 8:00 PM & 0.974 & 0.867 & 0.63 & 0.872 & 0.547 & 1.058 & 1.121 & 1.157 & 0.981 & 0.943 & 1.358 & 10.508 & 11.463 \\
\hline 9:00 PM & 1.086 & 0.77 & 0.691 & 0.761 & 0.565 & 1.159 & 0.993 & 0.824 & 0.937 & 0.872 & 1.27 & 9.928 & 10.831 \\
\hline 10:00 PM & 0.694 & 0.723 & 0.458 & 0.593 & 0.784 & 0.914 & 1.206 & 0.483 & 0.943 & 0.813 & 1.51 & 9.121 & 9.950 \\
\hline & 15.621 & 12.341 & 10.053 & 12.566 & 9.92 & 16.118 & 14.755 & 17.664 & 16.248 & 13.169 & 21.053 & & 174.009 \\
\hline & & & & & & & & & & & & & \\
\hline & Temp. & Temp. & Temp. & Temp. & Temp. & Temp. & Temp. & Temp. & Temp. & Temp. & Temp. & Avg. temp. & \\
\hline Time & $\mathrm{F}$ & $\mathrm{F}$ & $\mathrm{F}$ & $\mathrm{F}$ & $\mathrm{F}$ & $\mathrm{F}$ & $\mathrm{F}$ & $\mathrm{F}$ & $\mathrm{F}$ & $\mathrm{F}$ & $\mathrm{F}$ & $\mathrm{F}$ & \\
\hline $8: 00 \mathrm{AM}$ & 69.7 & 74.9 & 74.4 & 77.7 & 70.8 & 75.6 & 74.7 & 76.3 & 76 & 76.1 & 71.6 & 74.3 & \\
\hline 9:00 AM & 71 & 75.1 & 74.8 & 77.6 & 70.3 & 75.1 & 74.8 & 75.2 & 76.4 & 75.9 & 71.7 & 74.4 & \\
\hline $10: 00 \mathrm{AM}$ & 71.8 & 74.2 & 74.5 & 76.5 & 70.3 & 74.6 & 74.5 & 74.8 & 74.8 & 76.1 & 73.2 & 74.1 & \\
\hline $11: 00 \mathrm{AM}$ & 72.9 & 73.9 & 74.3 & 75.3 & 70.8 & 74.6 & 74.5 & 73.9 & 74.7 & 76 & 75.6 & 74.2 & \\
\hline 12:00 PM & 72.4 & 74.1 & 74.6 & 74.1 & 70.7 & 74.4 & 74.5 & 72.1 & 74.5 & 76.1 & 75.5 & 73.9 & \\
\hline 1:00 PM & 71.7 & 74.2 & 74.7 & 73.7 & 70.1 & 74.4 & 73.9 & 69.8 & 74.4 & 76.2 & 75.3 & 73.5 & \\
\hline 2:00 PM & 71.6 & 74.2 & 74.9 & 73.2 & 70 & 74.4 & 74 & 73.4 & 74.3 & 76.5 & 75.4 & 73.8 & \\
\hline $3: 00$ PM & 72.2 & 74.3 & 74.6 & 72.7 & 70.7 & 74.8 & 75 & 74 & 74.4 & 76 & 75.7 & 74.0 & \\
\hline 4:00 PM & 72.1 & 74.1 & 74.3 & 73.4 & 70.6 & 75.1 & 74.7 & 73.6 & 74.3 & 75.6 & 75.9 & 74.0 & \\
\hline 5:00 PM & 72.5 & 73.7 & 75 & 73.8 & 71.8 & 76.1 & 74.1 & 74.6 & 74.3 & 75.7 & 76.4 & 74.4 & \\
\hline $6: 00 \mathrm{PM}$ & 72 & 74.2 & 75.2 & 73.8 & 72.3 & 76.3 & 73.6 & 74.8 & 74.8 & 76.1 & 77.1 & 74.6 & \\
\hline $7: 00 \mathrm{PM}$ & 72 & 75.1 & 75 & 73.7 & 72.4 & 76 & 73.6 & 74 & 75 & 76 & 77.5 & 74.6 & \\
\hline 8:00 PM & 72.8 & 74.8 & 74.7 & 74.2 & 72.5 & 75.6 & 73.9 & 74.4 & 75.4 & 76 & 77.8 & 74.7 & \\
\hline 9:00 PM & 73.4 & 74.7 & 74.6 & 75.4 & 72.6 & 75.3 & 74.5 & 74.7 & 75.2 & 75.7 & 77.5 & 74.9 & \\
\hline 10:00 PM & 75.7 & 75.1 & 74.2 & 76.6 & 72.3 & 75.3 & 73.9 & 76.3 & 75.1 & 75.7 & 77.1 & 75.2 & \\
\hline & & & & & & & & & & & & 74.3 & \\
\hline & & & & & & & & & & & & & \\
\hline
\end{tabular}

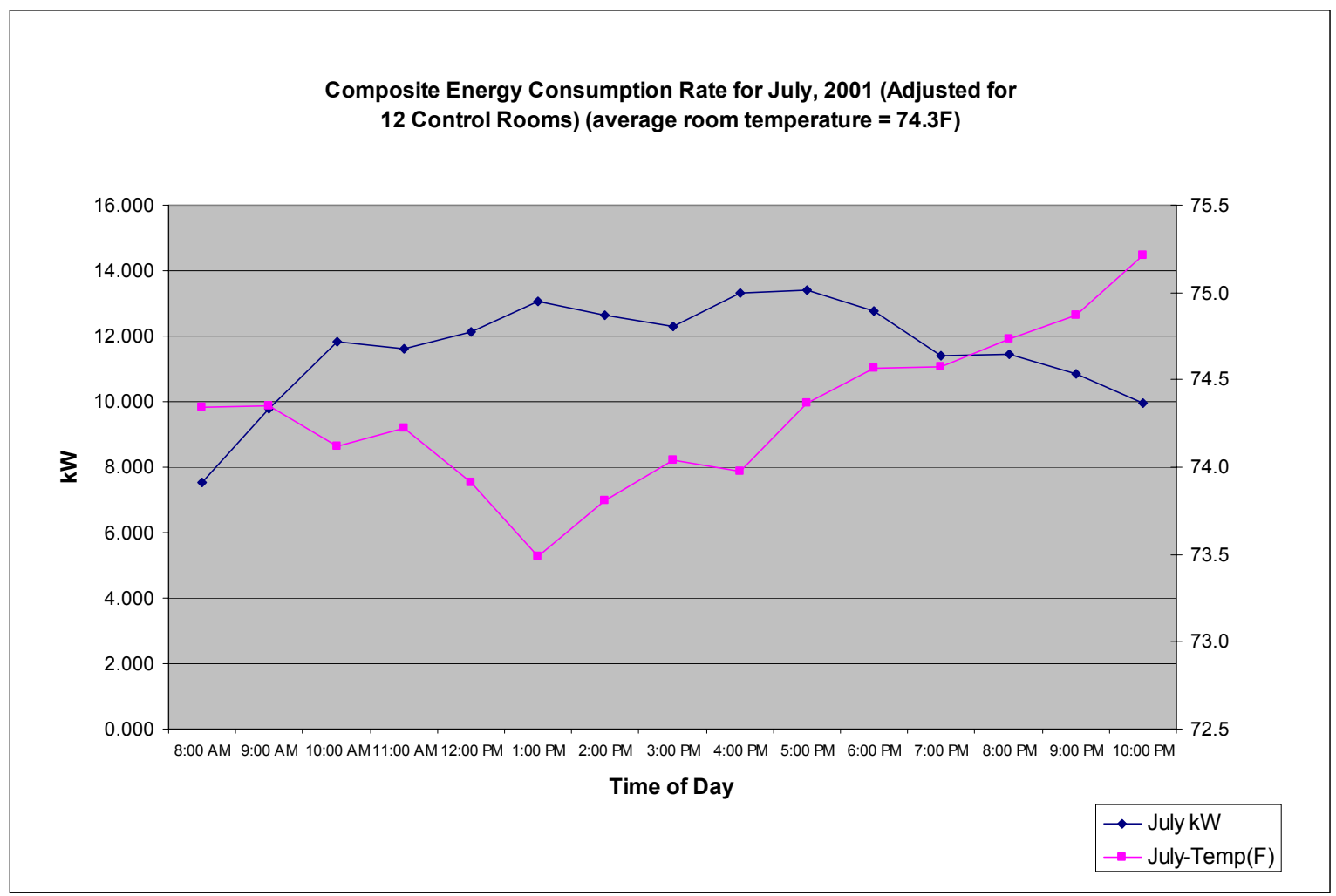

B-3 


\section{B.2 Controlled Rooms - August}

\begin{tabular}{|c|c|c|c|c|c|c|c|c|c|c|c|c|c|c|}
\hline \multicolumn{15}{|c|}{ CONTROLLED ROOMS } \\
\hline & Room 501 & Room 502 & Room 508 & Room 509 & Room 513 & Room 516 & Room 519 & Room 520 & Room 523 & Room 524 & Room 528 & $\begin{array}{l}\text { Room } 727 \\
\end{array}$ & & \\
\hline Time & $\mathrm{kW}$ & $\mathrm{kW}$ & $\mathrm{kW}$ & $\mathrm{kW}$ & $\mathrm{kW}$ & $\mathrm{kW}$ & $\mathrm{kW}$ & $\mathrm{kW}$ & $\mathrm{kW}$ & $\mathrm{kW}$ & $\mathrm{kW}$ & $\mathrm{kW}$ & Time & Sum kW \\
\hline 8:00 AM & 0.367 & 0.381 & 0.559 & 0.431 & 0.59 & 1.207 & 0.228 & 0.725 & 0.419 & 0.413 & 0.721 & 0.604 & 8:00 AM & 6.645 \\
\hline 9:00 AM & 0.406 & 0.438 & 0.589 & 0.327 & 0.739 & 0.863 & 0.245 & 1.115 & 0.533 & 0.494 & 0.709 & 0.737 & 9:00 AM & 7.195 \\
\hline 10:00 AM & 0.44 & 0.423 & 0.627 & 0.452 & 0.916 & 0.878 & 0.435 & 1.193 & 0.527 & 0.566 & 0.741 & 0.677 & 10:00 AM & 7.875 \\
\hline 11:00 AM & 0.434 & 0.381 & 0.629 & 0.586 & 0.89 & 1.005 & 0.366 & 0.855 & 0.485 & 0.643 & 0.705 & 0.654 & $11: 00 \mathrm{AM}$ & 7.633 \\
\hline 12:00 PM & 0.524 & 0.348 & 0.677 & 0.365 & 0.885 & 0.852 & 0.513 & 1.071 & 0.727 & 0.806 & 0.725 & 0.742 & 12:00 PM & 8.235 \\
\hline 1:00 PM & 0.529 & 0.351 & 0.686 & 0.691 & 0.988 & 0.892 & 0.709 & 1.157 & 0.751 & 0.836 & 0.744 & 0.709 & 1:00 PM & 9.043 \\
\hline 2:00 PM & 0.673 & 0.403 & 0.712 & 0.731 & 1.062 & 0.896 & 0.581 & 1.418 & 0.697 & 0.748 & 0.797 & 0.77 & 2:00 PM & 9.488 \\
\hline 3:00 PM & 0.474 & 0.44 & 0.689 & 0.846 & 1.11 & 0.957 & $\begin{array}{l}0.7 \\
\end{array}$ & 1.453 & 0.706 & 0.689 & 0.967 & 0.855 & 3:00 PM & 9.886 \\
\hline 4:00 PM & 0.562 & 0.554 & 0.807 & 0.72 & 1.125 & 0.966 & 0.762 & 1.195 & 1.228 & 0.721 & 0.999 & 0.821 & 4:00 PM & 10.46 \\
\hline 5:00 PM & 0.454 & 0.691 & 0.834 & 0.866 & 1.125 & 0.915 & 0.677 & 1.137 & 1.411 & 0.869 & 0.942 & 1.08 & 5:00 PM & 11.001 \\
\hline 6:00 PM & 0.549 & 0.675 & 0.749 & 0.978 & 1.027 & 0.614 & 0.631 & 1.095 & 1.262 & 0.853 & 0.962 & 1.154 & 6:00 PM & 10.549 \\
\hline 7:00 PM & 0.541 & 0.679 & 0.828 & 1.08 & 1.057 & 0.629 & 0.593 & 0.935 & 1.128 & 0.902 & 0.833 & 1.02 & $7: 00$ PM & 10.225 \\
\hline 8:00 PM & 0.477 & 0.482 & 0.82 & 1.015 & 0.928 & 0.58 & 0.572 & 1.155 & 0.98 & 0.711 & 0.713 & 0.987 & 8:00 PM & 9.42 \\
\hline 9:00 PM & 0.448 & 0.394 & 0.734 & 0.797 & 0.875 & 0.635 & 0.47 & 1.035 & 1.016 & 0.675 & 0.749 & 0.974 & 9:00 PM & 8.802 \\
\hline \multirow[t]{21}{*}{ 10:00 PM } & 0.473 & 0.433 & 0.682 & 0.62 & 0.761 & 0.897 & 0.334 & 1.147 & 0.764 & 0.611 & 0.886 & 0.706 & $10: 00 \mathrm{PM}$ & 8.314 \\
\hline & 7.351 & 7.073 & 10.622 & 10.505 & 14.078 & 12.786 & 7.816 & 16.686 & 12.634 & 10.537 & 12.193 & 12.49 & & 134.771 \\
\hline & & & & & & & & & & & & & & \\
\hline & Temp. & Temp. & Temp. & Temp. & Temp. & Temp. & Temp. & Temp. & Temp. & Temp. & Temp. & Temp. & Avg. Temp. & \\
\hline & $\mathrm{F}$ & $\mathrm{F}$ & $\mathrm{F}$ & $\mathrm{F}$ & $\mathrm{F}$ & $\mathrm{F}$ & $\mathrm{F}$ & $\mathrm{F}$ & $\mathrm{F}$ & $\mathrm{F}$ & $\mathrm{F}$ & $\mathrm{F}$ & $\mathrm{F}$ & \\
\hline & 73.3 & 72.5 & 74.7 & 74.2 & 72.8 & 75.8 & 79 & 75.4 & 75.6 & 76.1 & 74.6 & 68.9 & 74.4 & \\
\hline & 74.6 & 71.9 & 75 & 74.6 & 73.6 & 76.2 & 78.6 & 74.2 & 75.6 & 76.7 & 75.1 & 70 & 74.7 & \\
\hline & 76 & 71.5 & 74.7 & 75.1 & 73.7 & 77.7 & 78.9 & 73.4 & 75.8 & 76.7 & 75.5 & 71.8 & 75.1 & \\
\hline & 77 & 71.6 & 74.7 & 74.9 & 73 & 78 & 78.4 & 74.6 & 76 & 76.4 & 75.6 & 72.8 & 75.3 & \\
\hline & 76.6 & 71.8 & 74.7 & 75.5 & 72.8 & 78.1 & 78.9 & 74.5 & 76.2 & 75.7 & 75.7 & 72.9 & 75.3 & \\
\hline & 77.6 & 72.3 & 74.7 & 75.6 & 73.2 & 78.1 & 79 & 74.1 & 76.4 & 75.1 & 75.9 & 73.3 & 75.4 & \\
\hline & 77 & 72.5 & 74.7 & 74.4 & 74 & 78.1 & 79.6 & 73.6 & 76.5 & 75.2 & 75.9 & 73.8 & 75.4 & \\
\hline & 78.2 & 72.6 & 74.8 & 73.1 & 74.3 & 78 & 78.4 & 73 & 77 & 75.6 & 75.7 & 74.7 & 75.5 & \\
\hline & 77.5 & 72.3 & 74.9 & 74 & 74 & 78.4 & 78.4 & 73.4 & 76.2 & 75.4 & 75.4 & 74.7 & 75.4 & \\
\hline & 78.8 & 71.2 & 74.7 & 73.7 & 74 & 78.5 & 78.4 & 74 & 74.8 & 75.5 & 75.6 & 74.7 & 75.3 & \\
\hline & 77.9 & 71.1 & 75.1 & 73.1 & 74 & 78.6 & 78.5 & 74.4 & 74.7 & 75.8 & 75.7 & 73.8 & 75.2 & \\
\hline & 78.3 & 71 & 74.7 & 72.2 & 73.9 & 78.5 & 78.5 & 75.3 & 75.1 & 75.7 & 75.8 & 73.3 & 75.2 & \\
\hline & 79.3 & 71.6 & 74.8 & 71.5 & 73.8 & 78.4 & 78.8 & 75.2 & 75.3 & 76.1 & 75.9 & 73.1 & 75.3 & \\
\hline & 79 & 72 & 74.6 & 71.6 & 74 & 78.2 & 79.2 & 74.7 & 75.6 & 76.2 & 76 & 73.5 & 75.4 & \\
\hline & 77.3 & 72.1 & 74.5 & 72.7 & 73.6 & 78.1 & 79.2 & 74.5 & 75.9 & 76.2 & 75.3 & 73.2 & 75.2 & \\
\hline & & & & & & & & & & & & & 75.2 & \\
\hline & & & & & & & & & & & & & & \\
\hline
\end{tabular}

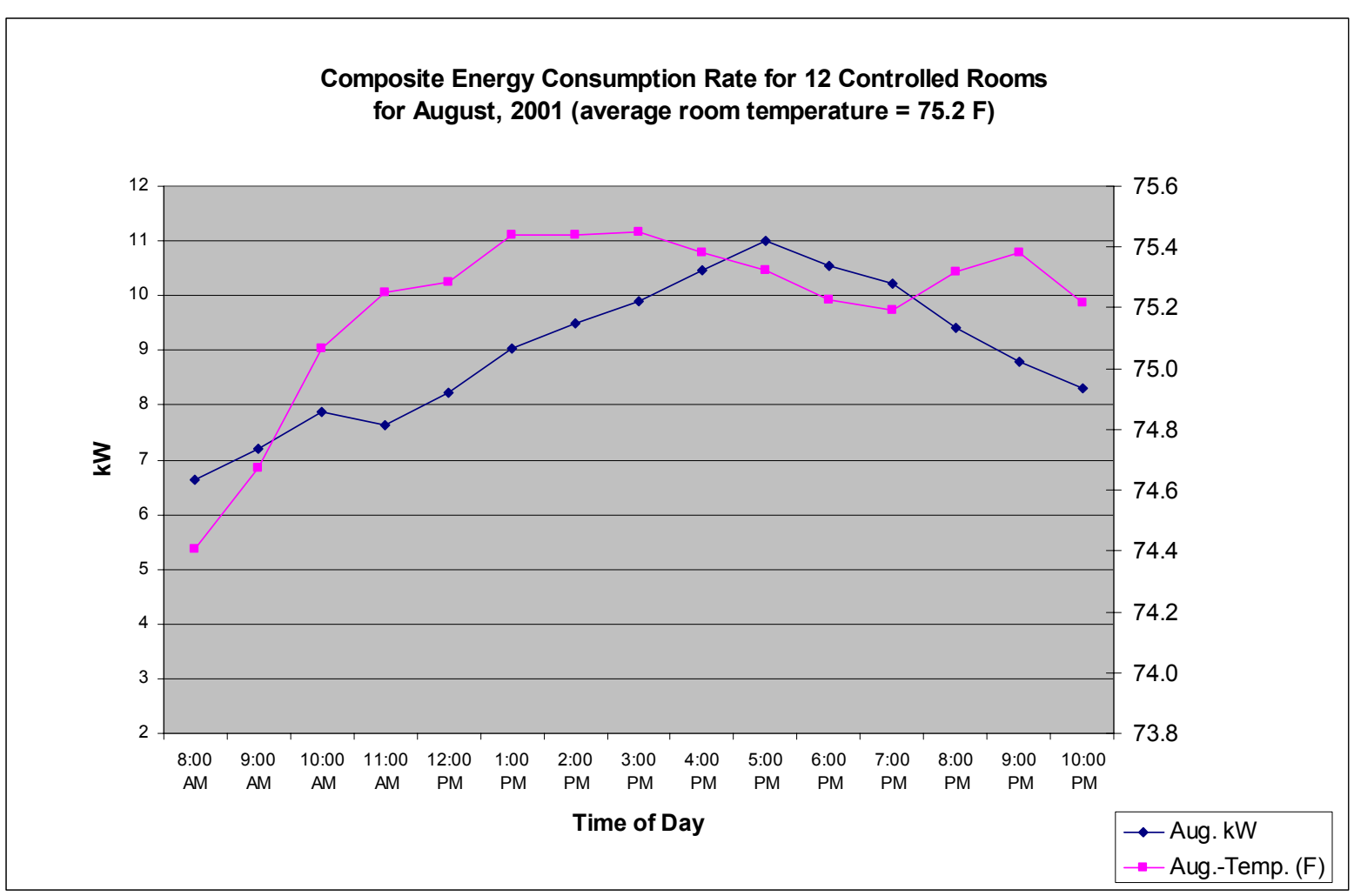




\section{B.3 Controlled Rooms - September}

\begin{tabular}{|c|c|c|c|c|c|c|c|c|c|c|c|}
\hline \multicolumn{12}{|c|}{\begin{tabular}{|l|l|l|l|} 
CONTROLLED ROOMS(Sept, 2001) & & & \\
\end{tabular}} \\
\hline & Room 501 & Room 502 & Room 508 & Room 509 & Room 513 & Room 516 & Room 520 & Room 523 & Room 528 & & Adj. For 12 Rooms \\
\hline Time & $\mathrm{kW}$ & $\mathrm{kW}$ & $\mathrm{kW}$ & kW & $\mathrm{kW}$ & kW & $\mathrm{kW}$ & $\mathrm{kW}$ & kW & Sum kW & Sum kW*12/9 \\
\hline 8:00 AM & 0.299 & 0.123 & 0.309 & 0.352 & 0.423 & 0.395 & 0.549 & 0.263 & 0.257 & 2.97 & 3.960 \\
\hline 9:00 AM & 0.392 & 0.132 & 0.393 & 0.349 & 0.45 & 0.413 & 0.593 & 0.216 & 0.294 & 3.232 & 4.309 \\
\hline 10:00 AM & 0.388 & 0.102 & 0.521 & 0.357 & 0.53 & 0.583 & 0.624 & 0.289 & 0.398 & 3.792 & 5.056 \\
\hline 11:00 AM & 0.337 & 0.226 & 0.509 & 0.426 & 0.538 & 0.572 & 0.686 & 0.294 & 0.419 & 4.007 & 5.343 \\
\hline 12:00 PM & 0.415 & 0.214 & 0.49 & 0.424 & 0.506 & 0.577 & 0.663 & 0.565 & 0.542 & 4.396 & 5.861 \\
\hline 1:00 PM & 0.416 & 0.241 & 0.479 & 0.392 & 0.66 & 0.546 & 0.666 & 0.644 & 0.519 & 4.563 & 6.084 \\
\hline 2:00 PM & 0.53 & 0.248 & 0.511 & 0.403 & 0.541 & 0.58 & 0.765 & 0.555 & 0.532 & 4.665 & 6.220 \\
\hline 3:00 PM & 0.542 & 0.265 & 0.55 & 0.474 & 0.526 & 0.615 & 0.787 & 0.761 & 0.517 & 5.037 & 6.716 \\
\hline 4:00 PM & 0.506 & 0.262 & 0.545 & 0.642 & 0.567 & 0.658 & 0.787 & 0.678 & 0.578 & 5.223 & 6.964 \\
\hline 5:00 PM & 0.59 & 0.287 & 0.423 & 0.61 & 0.685 & 0.72 & 0.771 & 0.562 & 0.618 & 5.266 & 7.021 \\
\hline 6:00 PM & 0.585 & 0.225 & 0.523 & 0.535 & 0.649 & 0.707 & 0.795 & 0.501 & 0.564 & 5.084 & 6.779 \\
\hline 7:00 PM & 0.531 & 0.194 & 0.569 & 0.551 & 0.605 & 0.668 & 0.831 & 0.472 & 0.611 & 5.032 & 6.709 \\
\hline 8:00 PM & 0.579 & 0.217 & 0.547 & 0.464 & 0.595 & 0.657 & 0.821 & 0.358 & 0.626 & 4.864 & 6.485 \\
\hline 9:00 PM & 0.429 & 0.198 & 0.521 & 0.389 & 0.611 & 0.577 & 0.784 & 0.441 & 0.608 & 4.558 & 6.077 \\
\hline \multirow[t]{3}{*}{ 10:00 PM } & 0.402 & 0.161 & 0.448 & 0.404 & 0.636 & 0.615 & 0.758 & 0.472 & 0.536 & 4.432 & 5.909 \\
\hline & & & & & & & & & & & \\
\hline & Temp. & Temp. & Temp. & Temp. & Temp. & Temp. & Temp. & Temp. & Temp. & & Avg. Temp \\
\hline Time & $\mathrm{F}$ & $\mathrm{F}$ & $\mathrm{F}$ & $\mathrm{F}$ & $\mathrm{F}$ & $\mathrm{F}$ & $\mathrm{F}$ & $\mathrm{F}$ & $\mathrm{F}$ & & $\mathrm{F}$ \\
\hline $8: 00$ AM & 73.6 & 72.9 & 72.8 & 72.2 & 73.7 & 74.6 & 75 & 74.2 & 73 & & 73.6 \\
\hline 9:00 AM & 73.6 & 72.8 & 73.1 & 72.3 & 73.5 & 74.6 & 74.7 & 74.5 & 73.5 & & 73.6 \\
\hline 10:00 AM & 74 & 72.9 & 73.4 & 73 & 73.7 & 74.5 & 74.5 & 74.8 & 73.4 & & 73.8 \\
\hline 11:00 AM & 74.6 & 72.8 & 73.8 & 73.7 & 74.3 & 74.9 & 74.5 & 75.8 & 73.5 & & 74.2 \\
\hline 12:00 PM & 75.2 & 72.6 & 74.3 & 74.6 & 74.6 & 75.3 & 74.6 & 76.3 & 73.3 & & 74.5 \\
\hline 1:00 PM & 75.7 & 72.9 & 74.2 & 75.2 & 74.3 & 75.5 & 75 & 76.3 & 73.2 & & 74.7 \\
\hline 2:00 PM & 76 & 73.2 & 74.5 & 75.6 & 74.4 & 75.7 & 75.1 & 76.7 & 73.4 & & 75.0 \\
\hline 3:00 PM & 76.3 & 73.3 & 74.8 & 75.8 & 75.1 & 75.6 & 75.2 & 77.1 & 73.8 & & 75.2 \\
\hline 4:00 PM & 76.7 & 73.6 & 75.1 & 75.2 & 75.5 & 75.7 & 75.3 & 77.1 & 73.5 & & 75.3 \\
\hline 5:00 PM & 77.1 & 73.6 & 75.6 & 74.8 & 75.8 & 75.8 & 75.5 & 77.1 & 73.7 & & 75.4 \\
\hline 6:00 PM & 77.5 & 74.2 & 76 & 75 & 76 & 75.8 & 75.7 & 77.3 & 73.7 & & 75.7 \\
\hline 7:00 PM & 77.6 & 74.8 & 76 & 74.7 & 76.2 & 76.2 & 75.6 & 77.4 & 73.5 & & 75.8 \\
\hline 8:00 PM & 77.5 & 75.1 & 75.9 & 74.7 & 76.1 & 76 & 75.6 & 77.5 & 73.3 & & 75.7 \\
\hline 9:00 PM & 77 & 75 & 75.7 & 74.7 & 75.9 & 76 & 75.7 & 77.5 & 72.9 & & 75.6 \\
\hline 10:00 PM & 76.3 & 74.7 & 75.4 & 74.3 & 75.4 & 75.9 & 75.6 & 77 & 72.6 & & 75.2 \\
\hline & & & & & & & & & & & 74.9 \\
\hline & & & & & & & & & & & \\
\hline
\end{tabular}

\section{Composite Energy Consumption Rate for 12 Controlled Rooms in Pigeon Forge, TN, Sept., 2001 (average room temp. $=74.9 \mathrm{~F}$ )}

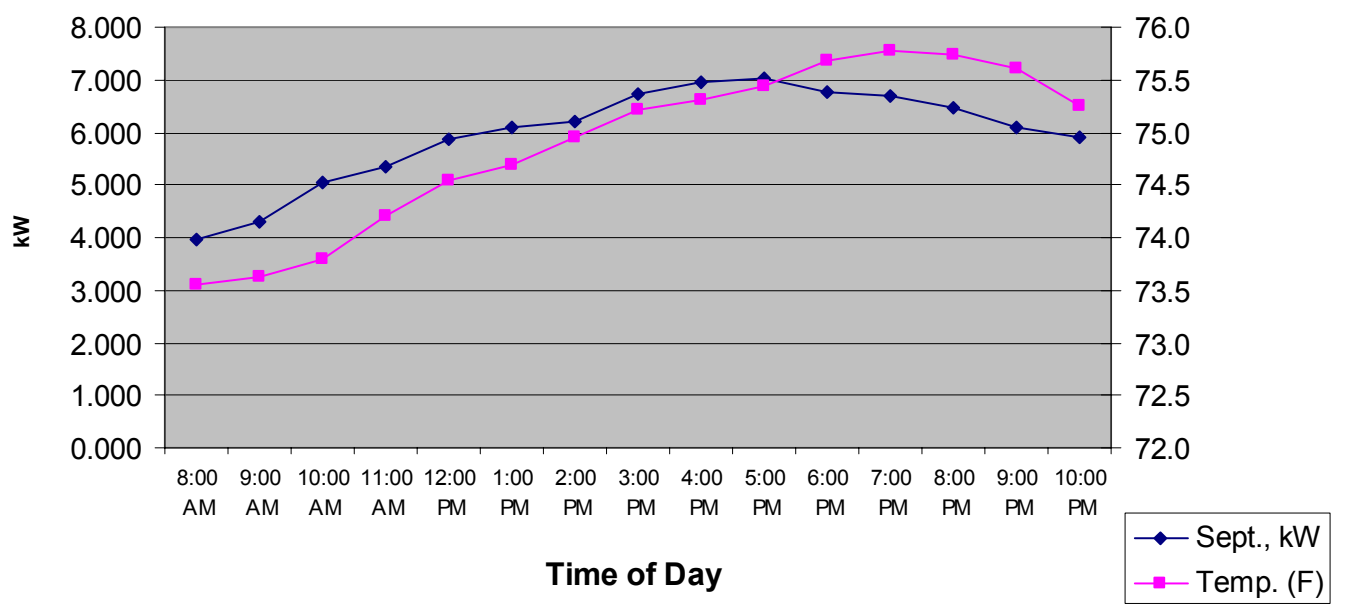




\section{B.4 Uncontrolled Rooms - July}

\begin{tabular}{|c|c|c|c|c|c|c|c|c|c|c|c|c|c|c|}
\hline \multicolumn{3}{|c|}{ Uncontrolled Rooms, July 2001.} & \multirow[b]{2}{*}{ Room 416} & \multirow{2}{*}{ Room 602} & \multirow{2}{*}{ Room 608} & \multirow{2}{*}{ Room 609} & \multirow{2}{*}{\begin{tabular}{|l|} 
Room 619 \\
\end{tabular}} & \multirow{2}{*}{ Room 620} & \multirow{2}{*}{ Room 623} & \multirow{2}{*}{ Room 624} & \multirow{2}{*}{ Room 627} & \multirow{2}{*}{ Room 628} & \multirow{2}{*}{ 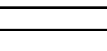 } & \multirow{2}{*}{ Sum kW } \\
\hline & Room 401 & Room 413 & & & & & & & & & & & & \\
\hline Time & $\mathrm{kW}$ & $\mathrm{kW}$ & $\mathrm{kW}$ & $\mathrm{kW}$ & $\mathrm{kW}$ & $\mathrm{kW}$ & $\mathrm{kW}$ & $\mathrm{kW}$ & $\mathrm{kW}$ & $\mathrm{kW}$ & $\mathrm{kW}$ & $\mathrm{kW}$ & Time & \\
\hline 8:00 AM & 1.068 & 0.621 & 0.902 & 0.656 & 0.576 & 0.444 & 0.504 & 0.788 & 0.499 & 0.728 & 0.611 & 0.749 & $8: 00 \mathrm{AM}$ & 8.146 \\
\hline $9: 00 \mathrm{AM}$ & 1.033 & 0.775 & 1.123 & 0.556 & 0.737 & 0.581 & 0.543 & 0.854 & 0.795 & 0.948 & 0.698 & 0.994 & $9: 00 \mathrm{AM}$ & 9.637 \\
\hline 10:00 AM & 1.04 & 0.898 & 1.278 & 0.801 & 0.884 & 0.565 & 0.726 & 1.049 & 0.887 & 1.04 & 0.992 & 1.085 & 10:00 AM & 11.245 \\
\hline 11:00 AM & 1.277 & 0.872 & 1.213 & 0.812 & 0.908 & 0.75 & 0.952 & 0.965 & 0.956 & 1.258 & 1.107 & 1.164 & 11:00 AM & 12.234 \\
\hline $12: 00 \mathrm{PM}$ & 1.488 & 0.868 & 1.234 & 0.75 & 0.767 & 0.763 & 0.974 & 1.228 & 0.971 & 1.265 & 1.089 & 1.154 & $12: 00 \mathrm{PM}$ & 12.551 \\
\hline 1:00 PM & 1.428 & 0.823 & 1.26 & 0.794 & 0.748 & 0.821 & 1.062 & 1.287 & 1.102 & 1.298 & 1.012 & 1.11 & 1:00 PM & 12.745 \\
\hline $2: 00$ PM & 1.468 & 0.955 & 1.44 & 0.982 & 0.814 & 0.951 & 1.083 & 1.335 & 1.161 & 1.232 & 1.197 & 1.133 & $2: 00$ PM & 13.751 \\
\hline 3:00 PM & 1.628 & 1.169 & 1.472 & 0.966 & 0.933 & 0.931 & 1.016 & 1.383 & 1.117 & 1.127 & 1.313 & 1.083 & 3:00 PM & 14.138 \\
\hline 4:00 PM & 1.602 & 1.418 & 1.317 & 0.912 & 1.057 & 0.851 & 1.136 & 1.485 & 1.082 & 1.035 & 1.279 & 1.139 & 4:00 PM & 14.313 \\
\hline 5:00 PM & 1.436 & 1.401 & 1.429 & 0.866 & 1.087 & 0.789 & 1.044 & 1.476 & 0.896 & 1.207 & 1.177 & 1.184 & 5:00 PM & 13.992 \\
\hline 6:00 PM & 1.125 & 1.454 & 1.434 & 0.799 & 1.101 & 0.886 & 1.008 & 1.302 & 0.96 & 1.127 & 1.165 & 1.137 & 6:00 PM & 13.498 \\
\hline 7:00 PM & 1.165 & 1.115 & 1.474 & 0.793 & 1.087 & 0.773 & 0.973 & 1.279 & 0.905 & 1.063 & 1.138 & 1.147 & 7:00 PM & 12.912 \\
\hline 8:00 PM & 1.095 & 0.869 & 1.17 & 0.678 & 1.172 & 0.694 & 0.935 & 1.358 & 0.817 & 1.12 & 1.076 & 0.939 & 8:00 PM & 11.923 \\
\hline 9:00 PM & 0.935 & 0.964 & 1.051 & 0.605 & 1.119 & 0.597 & 0.87 & 1.236 & 0.814 & 1.214 & 1.054 & 0.951 & 9:00 PM & 11.410 \\
\hline \multirow[t]{5}{*}{ 10:00 PM } & 0.943 & 1.101 & 0.977 & 0.562 & 0.926 & 0.54 & 0.783 & 1.232 & 0.492 & 1.116 & 0.922 & 0.787 & 10:00 PM & 10.381 \\
\hline & 18.731 & 15.303 & 18.774 & 11.532 & 13.916 & 10.936 & 13.609 & 18.257 & 13.454 & 16.778 & 15.830 & 15.756 & & 182.876 \\
\hline & & & & & & & & & & & & & & \\
\hline & & & & & & & & & & & & & & \\
\hline & Temp & Temp. & Temp. & Temp & Temp. & Temp. & Temp. & Temp. & Temp. & Temp. & Temp. & Temp. & Avg. Temp. & \\
\hline Time & $\mathrm{F}$ & $\mathrm{F}$ & $F$ & $\mathrm{~F}$ & $\mathrm{~F}$ & $\mathrm{~F}$ & $\mathrm{~F}$ & $F$ & $\mathrm{~F}$ & $\mathrm{~F}$ & $\mathrm{~F}$ & $\mathrm{~F}$ & $\mathrm{~F}$ & \\
\hline 8:00 AM & 71.8 & 74.8 & 74.3 & 74.3 & 72.2 & 75.9 & 75.6 & 73.8 & 74.7 & 74.7 & 75 & 73.4 & 74.2 & \\
\hline 9:00 AM & 72 & 75.3 & 74.1 & 74.5 & 71.8 & 76.1 & 75.7 & 73 & 74.6 & 74.5 & 74.9 & 72.4 & 74.1 & \\
\hline $10: 00 \mathrm{AM}$ & 72.7 & 75.3 & 73.5 & 72.2 & 71.6 & 76.4 & 75.8 & 72 & 73.6 & 73.8 & 75.4 & 71.9 & 73.7 & \\
\hline $11: 00 \mathrm{AM}$ & 72.3 & 74.9 & 73.4 & 73.5 & 71.6 & 76.1 & 75.3 & 71.6 & 73.4 & 73.1 & 75.4 & 71.3 & 73.5 & \\
\hline $12: 00 \mathrm{PM}$ & 70.9 & 74.3 & 73.7 & 73.1 & 72 & 76 & 75 & 71.3 & 73.3 & 72.4 & 74.8 & 71.1 & 73.2 & \\
\hline 1:00 PM & 69.9 & 74.9 & 73.5 & 73.1 & 71.8 & 75.9 & 74.6 & 70.8 & 72.7 & 71.9 & 74.9 & 71.4 & 73.0 & \\
\hline 2:00 PM & 71.3 & 75.1 & 73.7 & 72.3 & 72.2 & 75.8 & 74.6 & 70.5 & 72.5 & 71.9 & 74.6 & 71.7 & 73.0 & \\
\hline 3:00 PM & 70 & 75.2 & 73.5 & 72 & 71.9 & 75.5 & 75 & 70.5 & 72.3 & 72.4 & 74.1 & 71.9 & 72.9 & \\
\hline 4:00 PM & 70.1 & 75 & 71.9 & 72.4 & 71.4 & 75.7 & 75.1 & 69.7 & 72.3 & 73.7 & 74.1 & 72.2 & 72.8 & \\
\hline 5:00 PM & 70.3 & 74.3 & 72.4 & 73 & 71.1 & 75.9 & 75 & 69.8 & 72.3 & 73.4 & 74.5 & 72.1 & 72.8 & \\
\hline 6:00 PM & 70.9 & 74.4 & 72.3 & 74.2 & 71.2 & 76 & 75 & 70.4 & 73.2 & 73 & 74.3 & 72.1 & 73.1 & \\
\hline 7:00 PM & 71.5 & 74.1 & 72.6 & 74.7 & 71.7 & 76.3 & 75.2 & 70.6 & 73.2 & 73.8 & 74.7 & 71.9 & 73.4 & \\
\hline 8:00 PM & 71.9 & 74.5 & 73.7 & 75 & 71 & 76.5 & 75.3 & 70.9 & 73.3 & 73.5 & 75 & 72.4 & 73.6 & \\
\hline 9:00 PM & 72.2 & 74.9 & 74.4 & 75.5 & 70.6 & 76.8 & 75.2 & 70.8 & 73.5 & 73.4 & 75.3 & 72.8 & 73.8 & \\
\hline \multirow[t]{3}{*}{ 10:00 PM } & 73 & 75.1 & 74.5 & 75.6 & 70.9 & 76.9 & 75.3 & 71 & 74.3 & 73.1 & 75.2 & 73.1 & 74.0 & \\
\hline & & & & & & & & & & & & & 73.4 & \\
\hline & & & & & & & & & & & & & & \\
\hline
\end{tabular}

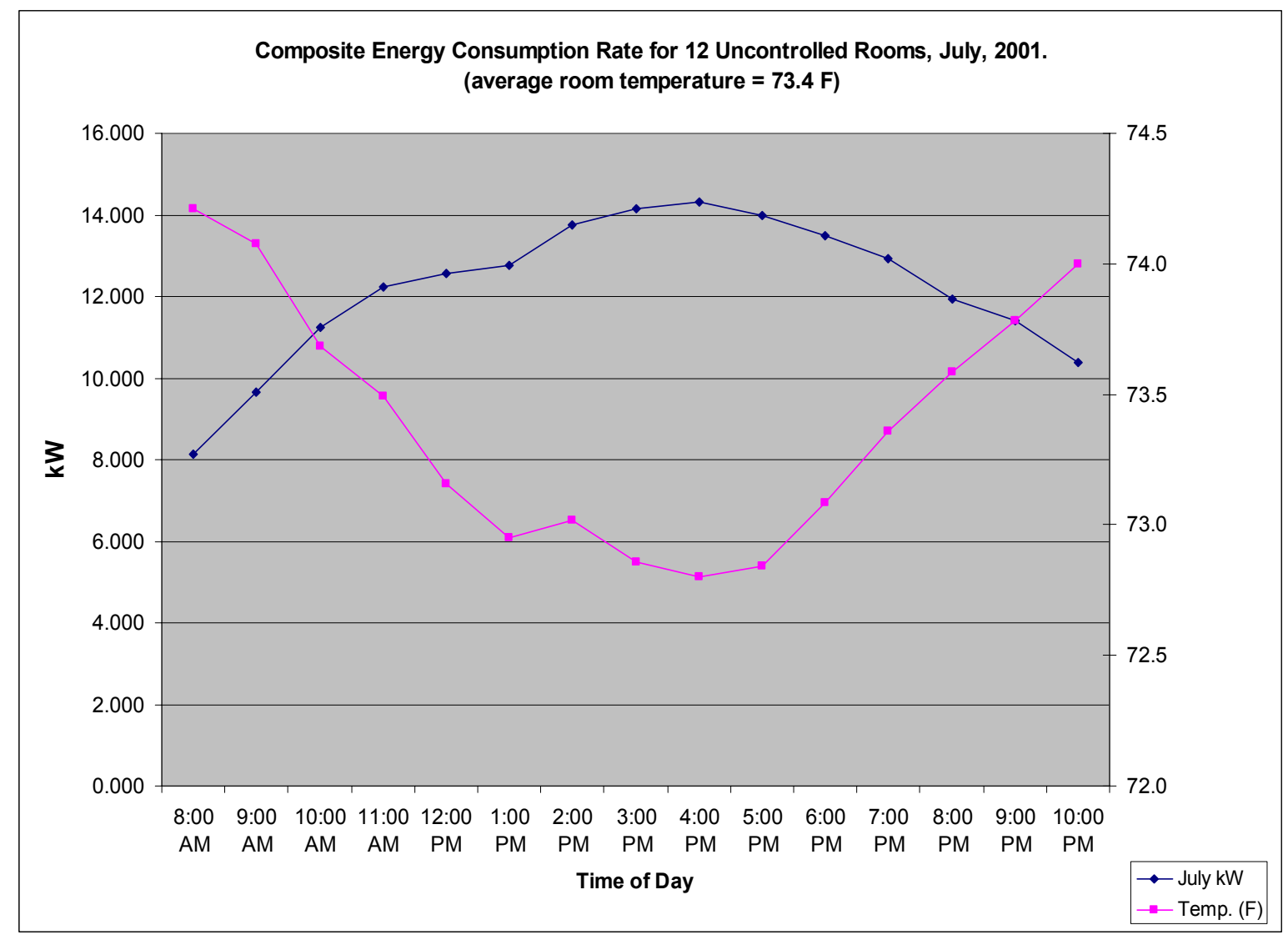

B-6 


\section{B.5 Uncontrolled Rooms - August}

\begin{tabular}{|c|c|c|c|c|c|c|c|c|c|c|c|c|c|c|}
\hline \multicolumn{3}{|c|}{ Uncontrolled Rooms-August } & \multirow[b]{2}{*}{ Room 416} & \multirow[b]{2}{*}{ Room 602} & \multirow[b]{2}{*}{ Room 608} & \multirow[b]{2}{*}{ Room 609} & \multirow[b]{2}{*}{ Room 619} & \multirow[b]{2}{*}{ Room 620} & \multirow[b]{2}{*}{ Room 623} & \multirow[b]{2}{*}{ Room 624} & \multirow[b]{2}{*}{ Room 627} & \multirow[b]{2}{*}{ Room 628} & \multirow{3}{*}{ Time } & \multirow[b]{2}{*}{ Sum } \\
\hline & Room 401 & Room 413 & & & & & & & & & & & & \\
\hline Time & \begin{tabular}{|l|}
$\mathrm{kW}$ \\
\end{tabular} & kW & $\mathrm{kW}$ & $\mathrm{kW}$ & $\mathrm{kW}$ & \begin{tabular}{|l|}
$\mathrm{kW}$ \\
\end{tabular} & $\mathrm{kW}$ & $\mathrm{kW}$ & $\mathrm{kW}$ & $\mathrm{kW}$ & \begin{tabular}{|l|}
$\mathrm{kW}$ \\
\end{tabular} & $\mathrm{kW}$ & & $\mathrm{kW}$ \\
\hline $8: 00 \mathrm{AM}$ & 0.735 & 0.46 & 0.819 & 0.518 & 0.789 & 0.666 & 0.427 & 0.877 & 0.542 & 0.783 & 0.593 & 0.56 & 8:00 AM & 7.769 \\
\hline 9:00 AM & 0.92 & 0.441 & 0.905 & 0.744 & 0.79 & 0.6 & 0.471 & 0.897 & 0.594 & 0.843 & 0.61 & 0.613 & 9:00 AM & 8.428 \\
\hline $10: 00 \mathrm{AM}$ & 1.024 & 0.596 & 1.014 & 0.764 & 0.899 & 0.626 & 0.487 & 0.953 & 0.601 & 0.87 & 0.768 & 0.756 & $10: 00 \mathrm{AM}$ & 9.358 \\
\hline 11:00 AM & 1.141 & 0.694 & 1.06 & 0.783 & 1.018 & 0.905 & 0.543 & 1.057 & 0.945 & 0.906 & 0.786 & 0.802 & 11:00 AM & 10.64 \\
\hline 12:00 PM & 1.217 & 0.82 & 1.117 & 0.878 & 1.078 & 0.848 & 0.936 & 1.108 & 0.701 & 0.923 & 0.827 & 0.943 & 12:00 PM & 11.396 \\
\hline 1:00 PM & 1.213 & 0.842 & 1.176 & 0.861 & 1.081 & 0.727 & 0.951 & 1.096 & 0.762 & 0.902 & 0.853 & 0.951 & 1:00 PM & 11.415 \\
\hline 2:00 PM & 1.265 & 0.883 & 1.213 & 0.788 & 1.054 & 0.753 & 0.93 & 1.147 & 0.832 & 0.94 & 0.853 & 0.851 & 2:00 PM & 11.509 \\
\hline $3: 00$ PM & 1.169 & 0.78 & 1.229 & 0.979 & 1.11 & 0.782 & 0.885 & 1.182 & 0.903 & 0.97 & 0.895 & 0.863 & $3: 00 \mathrm{PM}$ & 11.747 \\
\hline 4:00 PM & 1.24 & 0.719 & 1.278 & 0.986 & 1.109 & 0.844 & 0.96 & 1.211 & 0.982 & 1.023 & 0.867 & 0.928 & 4:00 PM & 12.147 \\
\hline 5:00 PM & 1.062 & 0.741 & 1.239 & 1.101 & 1.094 & 0.917 & 1.061 & 1.259 & 1.027 & 1.054 & 1.091 & 1 & 5:00 PM & 12.646 \\
\hline 6:00 PM & 1.219 & 0.729 & 1.065 & 1.087 & 0.987 & 1.055 & 0.849 & 1.182 & 0.798 & 1.033 & 1.007 & 1.032 & 6:00 PM & 12.043 \\
\hline 7:00 PM & 1.165 & 0.687 & 1.081 & 0.995 & 0.881 & 0.985 & 0.809 & 1.166 & 0.772 & 0.963 & 0.937 & 1.036 & 7:00 PM & 11.477 \\
\hline 8:00 PM & 1.032 & 0.663 & 0.973 & 0.891 & 1.052 & 0.875 & 0.682 & 1.111 & 0.742 & 0.905 & 1.039 & 0.997 & 8:00 PM & 10.962 \\
\hline 9:00 PM & 1.049 & 0.766 & 0.958 & 0.791 & 0.851 & 0.872 & 0.717 & 1.032 & 0.707 & 0.842 & 0.904 & 0.798 & 9:00 PM & 10.287 \\
\hline \multirow[t]{5}{*}{ 10:00 PM } & 0.965 & 0.656 & 0.837 & 0.714 & 0.877 & 0.751 & 0.565 & 1.026 & 0.725 & 1.029 & 0.937 & 0.665 & 10:00 PM & 9.747 \\
\hline & 16.416 & 10.477 & 15.964 & 12.88 & 14.67 & 12.206 & 11.273 & 16.304 & 11.633 & 13.986 & 12.967 & 12.795 & & 161.571 \\
\hline & & & & & & & & & & & & & & \\
\hline & & & & & & & & & & & & & & \\
\hline & Temp. & Temp. & Temp. & Temp. & Temp. & Temp. & Temp. & Temp. & Temp. & Temp. & Temp. & Temp. & Avg. Temp & \\
\hline Time & $\mathrm{F}$ & $\mathrm{F}$ & $\mathrm{F}$ & $\mathrm{F}$ & $\mathrm{F}$ & $\mathrm{F}$ & $\mathrm{F}$ & $\mathrm{F}$ & $\mathrm{F}$ & $\mathrm{F}$ & $\mathrm{F}$ & $\mathrm{F}$ & $\mathrm{F}$ & \\
\hline $8: 00 \mathrm{AM}$ & 72.9 & 76 & 73.4 & 72.4 & 70.9 & 75.3 & 77 & 71.9 & 73.7 & 73.6 & 75.3 & 74.4 & 73.9 & \\
\hline 9:00 AM & 73.1 & 76.3 & 73.6 & 71.4 & 70.4 & 75.5 & 77 & 71.8 & 73.8 & 74 & 75.4 & 74.4 & 73.9 & \\
\hline $10: 00 \mathrm{AM}$ & 72.9 & 76.6 & 74.3 & 71.1 & 70 & 75.7 & 77 & 71.2 & 74 & 73.8 & 75.8 & 74.1 & 73.9 & \\
\hline $11: 00 \mathrm{AM}$ & 73.5 & 76.5 & 74.9 & 70.9 & 69.4 & 75.3 & 77.2 & 70.8 & 74 & 73.8 & 76.4 & 73.5 & 73.9 & \\
\hline 12:00 PM & 73.1 & 76 & 74.6 & 70.1 & 68.5 & 75.1 & 76.5 & 70.4 & 74.1 & 73.9 & 76.5 & 72.8 & 73.5 & \\
\hline 1:00 PM & 72.8 & 75.8 & 74.1 & 69.9 & 68.8 & 75.6 & 76.2 & 70.3 & 74.3 & 73.9 & 76.5 & 72.3 & 73.4 & \\
\hline 2:00 PM & 72.7 & 75.6 & 73.6 & 70.6 & 69.2 & 75.8 & 76.1 & 70.4 & 74.2 & 73.9 & 76.7 & 72.8 & 73.5 & \\
\hline $3: 00$ PM & 72.8 & 75.7 & 73.4 & 70.2 & 69.3 & 75.7 & 76.3 & 70.4 & 73.8 & 74.1 & 76.7 & 73.2 & 73.5 & \\
\hline 4:00 PM & 73.5 & 76.1 & 73.3 & 69.8 & 69.1 & 75.8 & 76.4 & 70.5 & 73.8 & 74.6 & 76.9 & 72.9 & 73.6 & \\
\hline 5:00 PM & 74.2 & 76.4 & 73.1 & 69.9 & 69.2 & 75.5 & 76.2 & 70.3 & 73.4 & 74.3 & 76.3 & 72.9 & 73.5 & \\
\hline 6:00 PM & 74.2 & 76.5 & 73.6 & 69.4 & 69.3 & 75.4 & 76.4 & 70.5 & 74 & 74.1 & 76.2 & 72.5 & 73.5 & \\
\hline 7:00 PM & 74.1 & 76.5 & 74 & 69.5 & 70.1 & 75.4 & 76.8 & 70.7 & 74.6 & 74.4 & 76.3 & 72.3 & 73.7 & \\
\hline $8: 00$ PM & 74.5 & 76.6 & 74.2 & 70 & 69.5 & 75.3 & 76.9 & 70.7 & 74.6 & 74.5 & 76.3 & 72 & 73.8 & \\
\hline 9:00 PM & 74.4 & 76.4 & 73.9 & 70.2 & 69.5 & 75.3 & 76.7 & 71 & 74.7 & 74.8 & 76.2 & 72.4 & 73.8 & \\
\hline $10: 00 \mathrm{PM}$ & 73.8 & 76.8 & 74.5 & 70.5 & 70.1 & 75.6 & 76.9 & 71 & 74.2 & 74.3 & 75.9 & 73.3 & 73.9 & \\
\hline & & & & & & & & & & & & & 73.7 & \\
\hline
\end{tabular}

\section{Composite Energy Consumption Rate for 12 Uncontrolled Rooms, August, 2001 (average room temp = 73.7)}

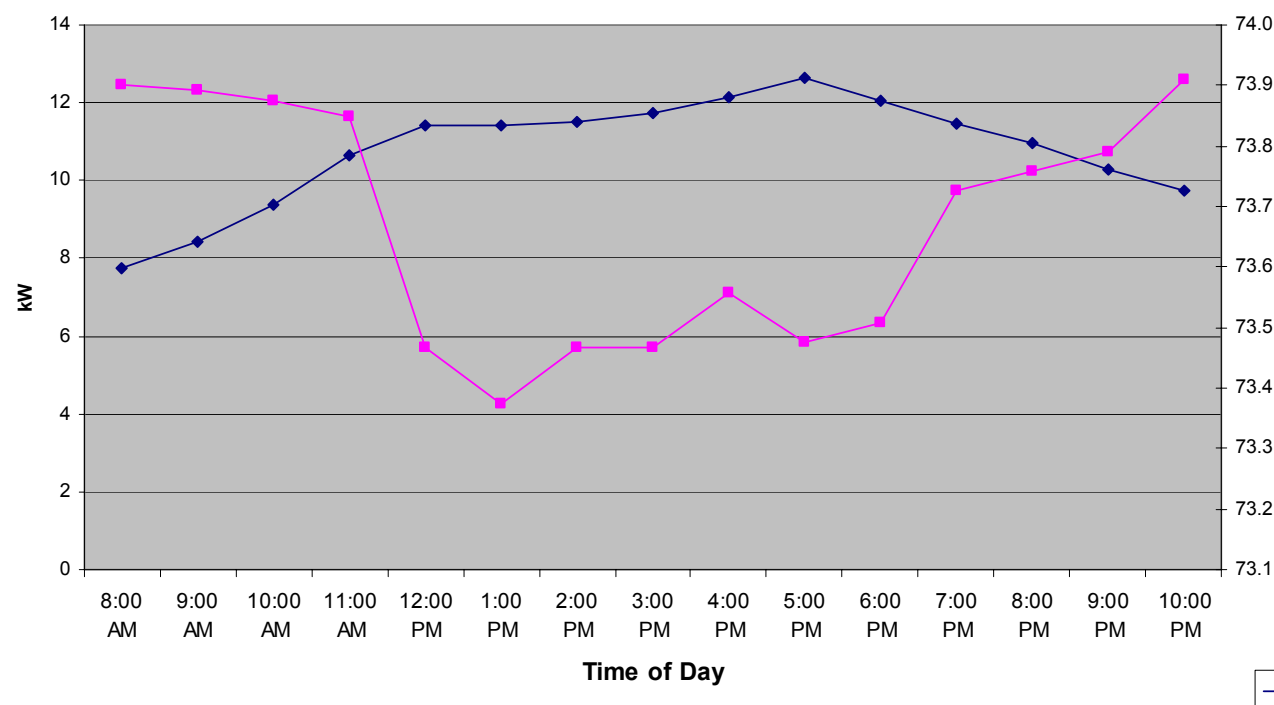




\section{B.6 Uncontrolled Rooms - September}

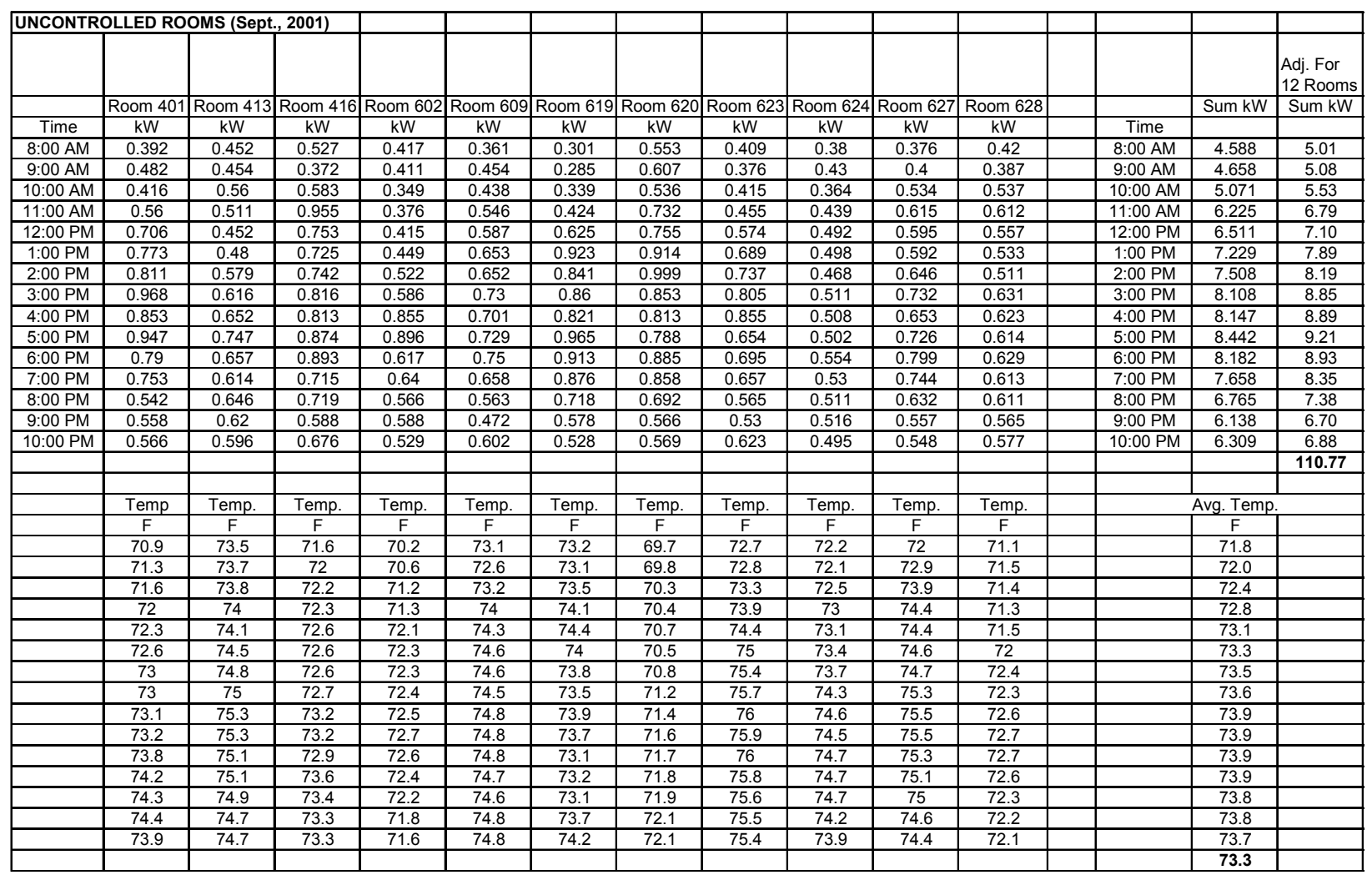

\section{Composite Energy Consumption Rate for 12 Uncontrolled Rooms for}

September, 2001 (average room temperature 73.3 F)

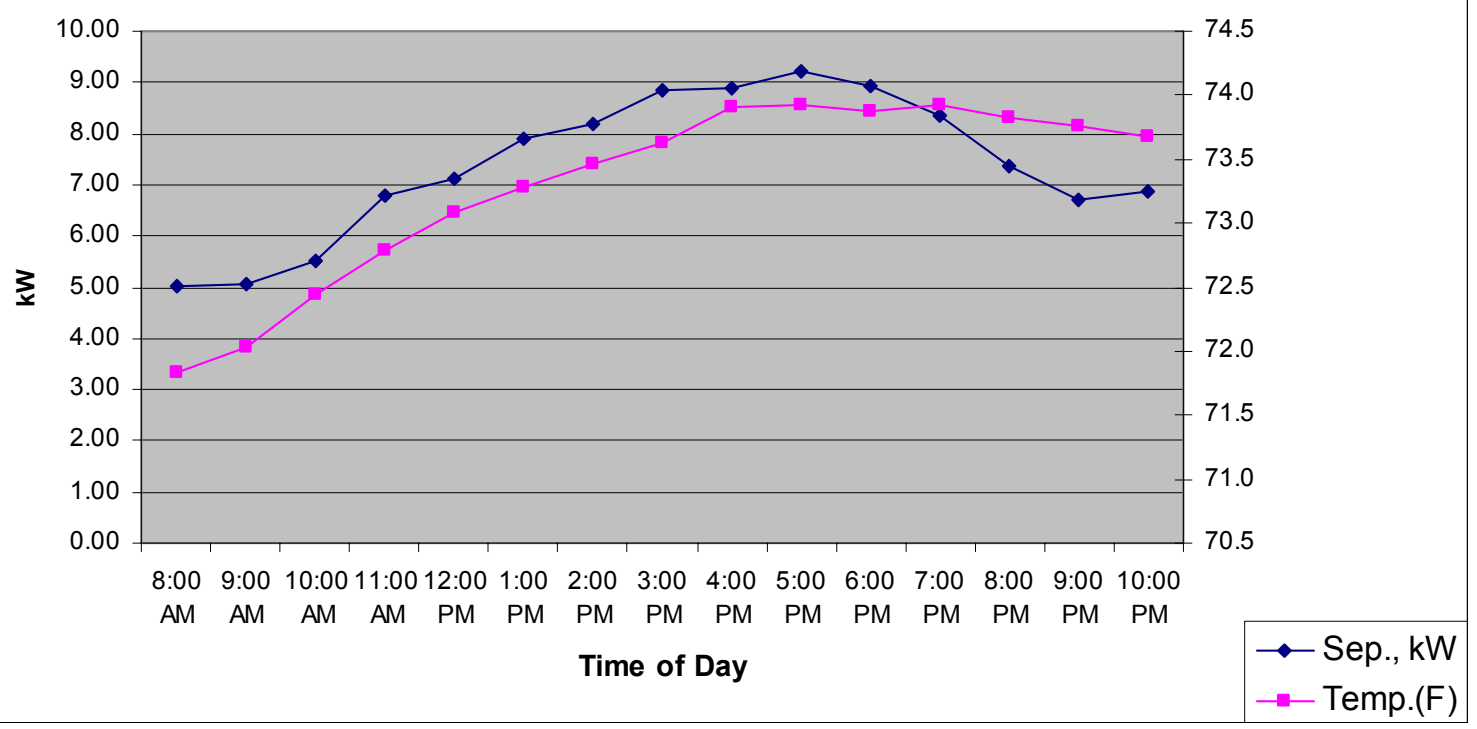




\section{B.7 Composite Summer Data on Controlled Rooms}

\begin{tabular}{|c|c|c|c|c|c|c|}
\hline \multicolumn{7}{|c|}{ CONTROLLED ROOMS } \\
\hline & July 2001 & July 2001 & AUG. 2001 & AUG. 2001 & SEPT., 2001 & SEPT., 2002 \\
\hline & Adj. For 12 Rooms & Avg. temp. & 12 Rooms & Avg. Temp. & Adj. For 12 Rooms & Avg. Temp \\
\hline Time & Sum kW & $\mathrm{F}$ & Sum kW & $\mathrm{F}$ & Sum kW & $\mathrm{F}$ \\
\hline 8:00 AM & 7.515 & 74.3 & 6.645 & 74.4 & 3.960 & 73.6 \\
\hline 9:00 AM & 9.780 & 74.4 & 7.195 & 74.7 & 4.309 & 73.6 \\
\hline $10: 00 \mathrm{AM}$ & 11.813 & 74.1 & 7.875 & 75.1 & 5.056 & 73.8 \\
\hline 11:00 AM & 11.609 & 74.2 & 7.633 & 75.3 & 5.343 & 74.2 \\
\hline 12:00 PM & 12.146 & 73.9 & 8.235 & 75.3 & 5.861 & 74.5 \\
\hline 1:00 PM & 13.073 & 73.5 & 9.043 & 75.4 & 6.084 & 74.7 \\
\hline 2:00 PM & 12.627 & 73.8 & 9.488 & 75.4 & 6.220 & 75.0 \\
\hline 3:00 PM & 12.280 & 74.0 & 9.886 & 75.5 & 6.716 & 75.2 \\
\hline 4:00 PM & 13.313 & 74.0 & 10.460 & 75.4 & 6.964 & 75.3 \\
\hline 5:00 PM & 13.417 & 74.4 & 11.001 & 75.3 & 7.021 & 75.4 \\
\hline 6:00 PM & 12.780 & 74.6 & 10.549 & 75.2 & 6.779 & 75.7 \\
\hline 7:00 PM & 11.409 & 74.6 & 10.225 & 75.2 & 6.709 & 75.8 \\
\hline 8:00 PM & 11.463 & 74.7 & 9.420 & 75.3 & 6.485 & 75.7 \\
\hline 9:00 PM & 10.831 & 74.9 & 8.802 & 75.4 & 6.077 & 75.6 \\
\hline 10:00 PM & 9.950 & 75.2 & 8.314 & 75.2 & 5.909 & 75.2 \\
\hline & 174.0 & & 134.8 & & 89.5 & \\
\hline
\end{tabular}

\section{Composite Energy Consumption Rate of 12 PTACs (Controlled \\ Rooms) in Pigeon Forge, TN (Jul., Aug., Sept., 2001 Data)}

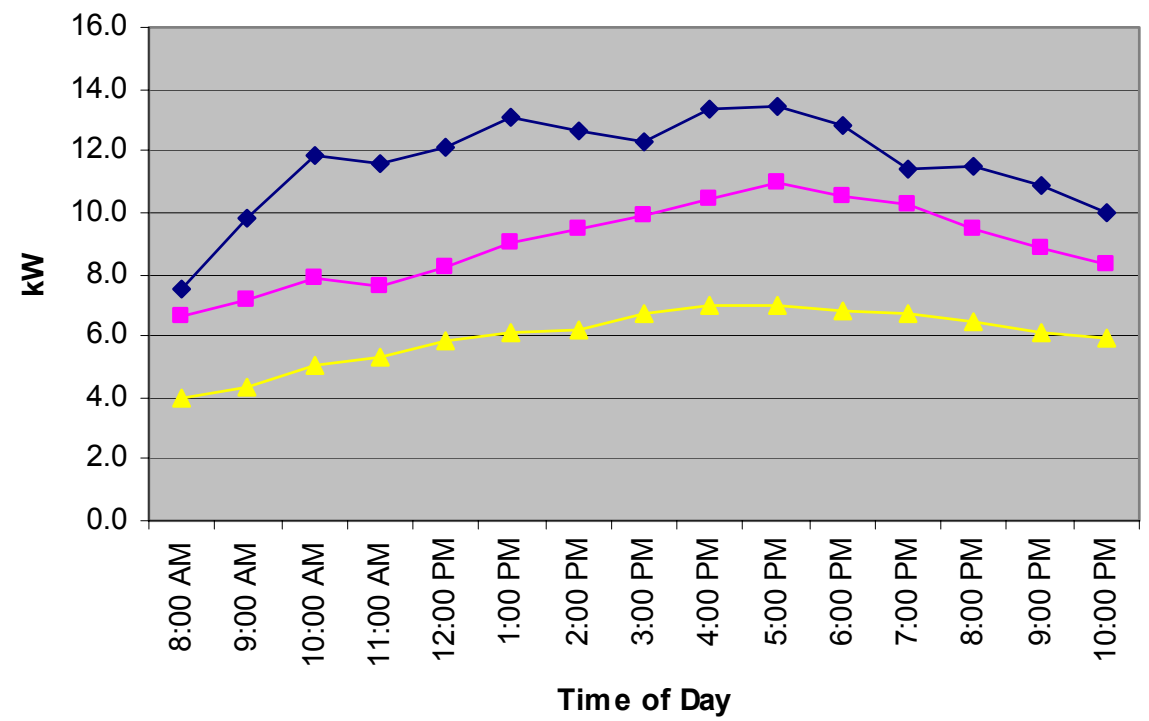

$$
\begin{aligned}
& \longrightarrow \text { July, } 01 \\
& \longrightarrow \text { Aug., } 01 \\
& - \text { Sept., } 01
\end{aligned}
$$

Time of Day 


\section{B.8 Composite Summer Data for Uncontrolled Rooms}

\begin{tabular}{|c|c|c|c|c|c|c|}
\hline \multicolumn{2}{|c|}{ UNCONTROLLED ROOMS } & \multirow[b]{2}{*}{ JULY 2001} & \multirow[b]{2}{*}{ AUG. 2001} & \multirow[b]{2}{*}{ AUG. 2001} & \multirow[b]{2}{*}{ SEPT., 2001} & \\
\hline & JULY 2001 & & & & & \\
\hline & & & & & Adj. For 12 Rooms & \\
\hline & Sum kW & Avg. Temp. & Sum & Avg. Temp & Sum kW & Avg. Temp. \\
\hline Time & & $\mathrm{F}$ & $\mathrm{kW}$ & $\mathrm{F}$ & & $\mathrm{F}$ \\
\hline $8: 00 \mathrm{AM}$ & 8.1 & 74.2 & 7.8 & 73.9 & 5.0 & 71.8 \\
\hline 9:00 AM & $\overline{9.6}$ & 74.1 & 8.4 & 73.9 & 5.1 & 72.0 \\
\hline 10:00 AM & 11.2 & 73.7 & 9.4 & 73.9 & 5.5 & 72.4 \\
\hline 11:00 AM & 12.2 & 73.5 & 10.6 & 73.9 & 6.8 & 72.8 \\
\hline 12:00 PM & 12.6 & 73.2 & 11.4 & 73.5 & 7.1 & 73.1 \\
\hline 1:00 PM & 12.7 & 73.0 & 11.4 & 73.4 & 7.9 & 73.3 \\
\hline 2:00 PM & 13.8 & 73.0 & 11.5 & 73.5 & 8.2 & 73.5 \\
\hline 3:00 PM & 14.1 & 72.9 & 11.7 & 73.5 & 8.8 & 73.6 \\
\hline 4:00 PM & 14.3 & 72.8 & 12.1 & 73.6 & 8.9 & 73.9 \\
\hline 5:00 PM & 14.0 & 72.8 & 12.6 & 73.5 & 9.2 & 73.9 \\
\hline $6: 00 \mathrm{PM}$ & 13.5 & 73.1 & 12.0 & 73.5 & 8.9 & 73.9 \\
\hline 7:00 PM & 12.9 & 73.4 & 11.5 & 73.7 & 8.4 & 73.9 \\
\hline 8:00 PM & 11.9 & 73.6 & 11.0 & 73.8 & 7.4 & 73.8 \\
\hline 9:00 PM & 11.4 & 73.8 & 10.3 & 73.8 & 6.7 & 73.8 \\
\hline 10:00 PM & 10.4 & 74.0 & 9.7 & 73.9 & 6.9 & 73.7 \\
\hline & 182.876 & & 161.571 & & 110.77 & \\
\hline & & & & & & \\
\hline
\end{tabular}

\section{Composite Energy Consumption Rate of 12 PTACs (Uncontrolled Rooms) in Pigeon Forge, TN (Jul., Aug., Sept., 2001 Data)}

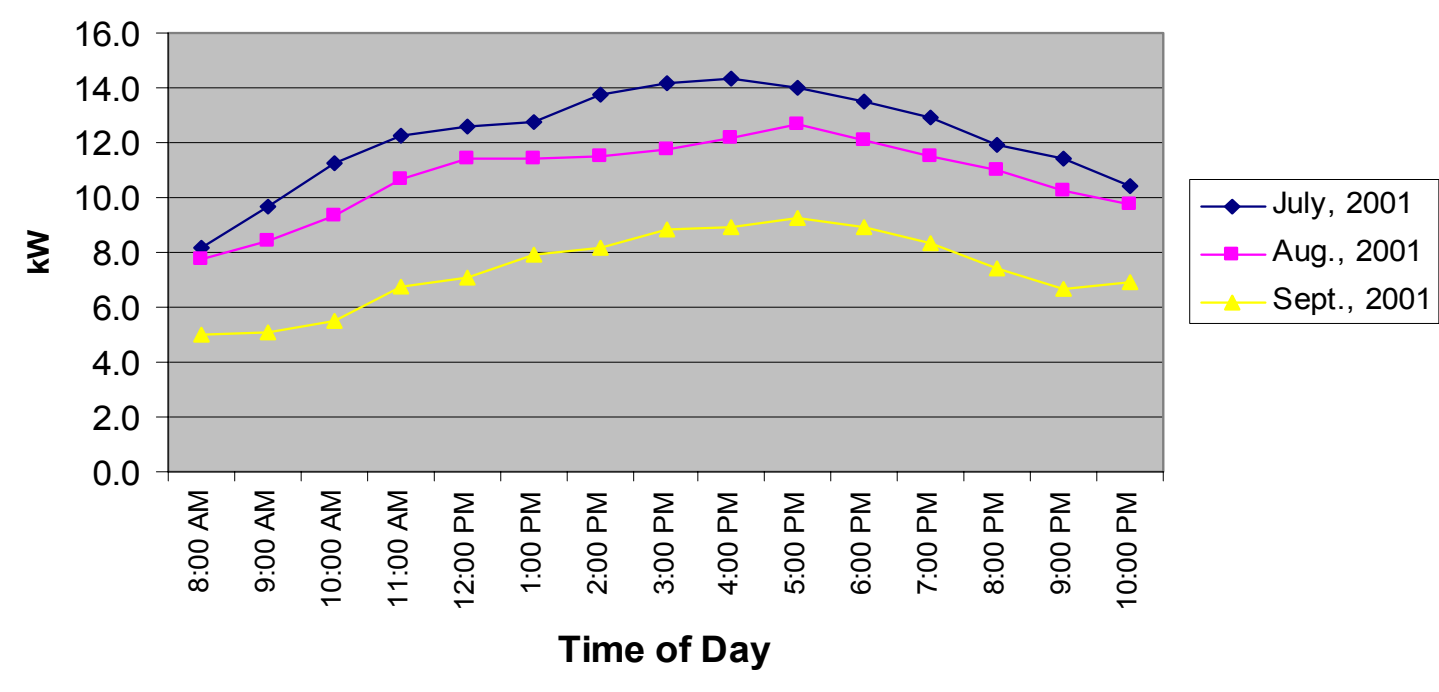




\section{B.9 Occupancy Rate During Summer for Controlled and Uncontrolled Rooms}

The occupancy rates for the controlled and uncontrolled groups were maintained intentionally as close as possible by the motel management for the purposes of energy consumption $(\mathrm{kWh})$ calculations. Note that the occupancy rate is highest in July when families are on vacation, especially during the $4^{\text {th }}$ of July weekend, and that is also the period when electricity demand peaks. From the composite summer data, it is evident that the greatest contribution to spinning reserve can be made in July.

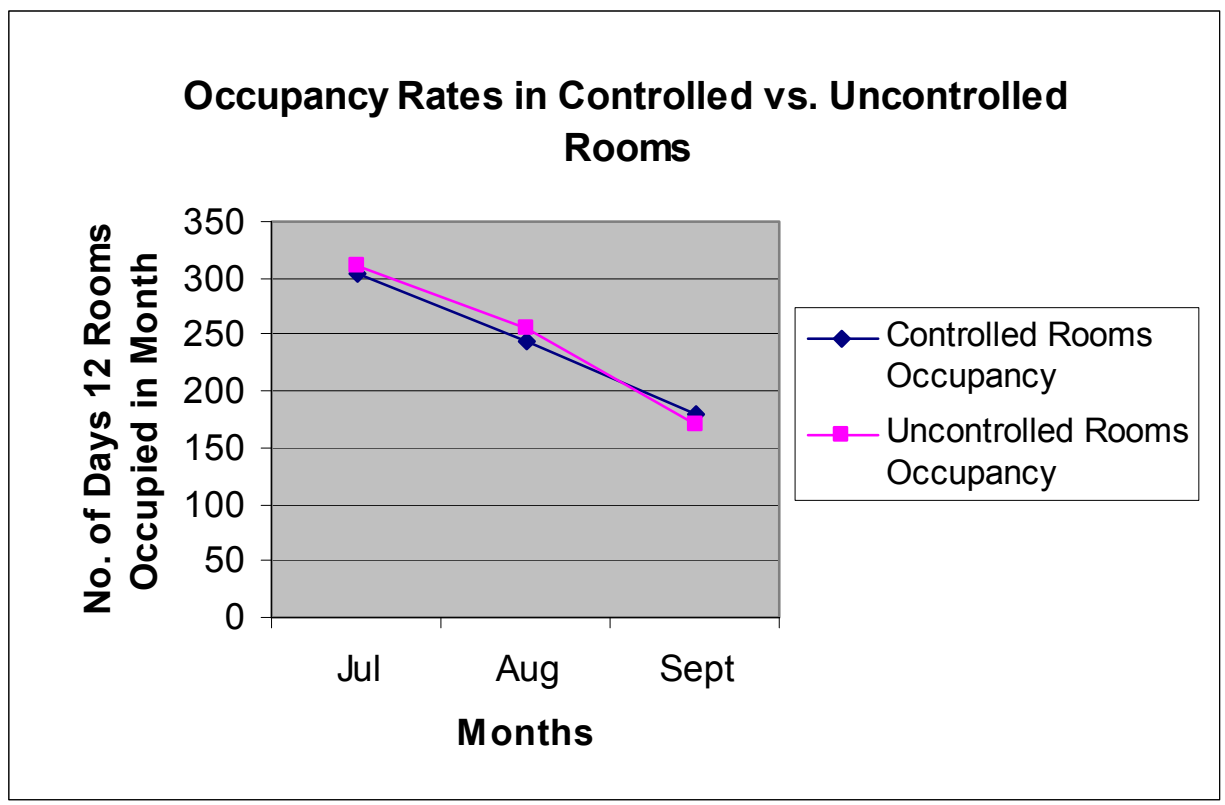




\section{Winter Data}

The winter data represents the heating load. Occupancy during the winter months is very low compared to the summer months. Our data indicates that the motel occupancy in winter is about $44 \%$ of that in the summer.

\section{B.10 Controlled Rooms - January}

\begin{tabular}{|c|c|c|c|c|c|c|c|c|c|c|c|c|}
\hline \multicolumn{5}{|c|}{ CONTROLLED ROOMS (January, 2001) } & & & & & & & & Adj. For 12 Rooms \\
\hline & Room 501 & Room 508 & Room 509 & Room 513 & Room 516 & Room 519 & Room 520 & $\begin{array}{ll}\text { Room } 524 \\
\end{array}$ & \begin{tabular}{|l|} 
Room 528 \\
\end{tabular} & \begin{tabular}{|l} 
Room 727 \\
\end{tabular} & Sum & Sum \\
\hline Time & kW & kW & kW & kW & kW & kW & kW & kW & kW & kW & $\mathrm{kW}$ & $\mathrm{kW}$ \\
\hline $8: 00 \mathrm{AM}$ & 0.607 & 0.621 & 0.458 & 0.416 & 0.658 & 0.681 & 0.816 & 0.77 & 0.561 & 1.106 & 6.69 & 8.03 \\
\hline $9: 00 \mathrm{AM}$ & 0.651 & 0.585 & 0.654 & 0.661 & 0.769 & 1.136 & 0.931 & 0.866 & 0.772 & 1.386 & 8.41 & 10.09 \\
\hline $10: 00 \mathrm{AM}$ & 0.836 & 0.823 & 0.797 & 0.793 & 0.735 & 1.34 & 0.922 & 1.209 & 0.758 & 1.161 & 9.37 & 11.25 \\
\hline 11:00 AM & 0.941 & 0.895 & 0.643 & 0.982 & 0.752 & 1.205 & 0.79 & 1.305 & 0.792 & 1.159 & 9.46 & 11.36 \\
\hline 12:00 PM & 0.984 & 0.824 & 0.552 & 0.803 & 0.698 & 1.493 & 0.884 & 1.164 & 0.853 & 1.456 & 9.71 & 11.65 \\
\hline 1:00 PM & 1.035 & 0.892 & 0.839 & 0.891 & 0.784 & 1.572 & 0.97 & 1.193 & 0.859 & 1.449 & 10.48 & 12.58 \\
\hline 2:00 PM & 1.165 & 0.81 & 0.845 & 0.964 & 0.86 & 1.435 & 1.02 & 1.123 & 0.944 & 1.463 & 10.63 & 12.75 \\
\hline 3:00 PM & 1.18 & 0.942 & 0.989 & 0.929 & 0.833 & 1.343 & 1.06 & 1.121 & 1.091 & 1.427 & 10.92 & 13.10 \\
\hline 4:00 PM & 1.095 & 1.056 & 0.88 & 0.91 & 1.055 & 1.246 & 1.178 & 1.311 & 1.066 & 1.611 & 11.41 & 13.69 \\
\hline 5:00 PM & 0.896 & 1.116 & 0.924 & 0.948 & 0.984 & 1.224 & 1.216 & 1.255 & 0.956 & 1.745 & 11.26 & 13.52 \\
\hline 6:00 PM & 0.968 & 0.902 & 1.004 & 0.934 & 0.86 & 1.222 & 1.287 & 1.087 & 1.021 & 1.711 & 11.00 & 13.20 \\
\hline 7:00 PM & 1.009 & 0.892 & 0.989 & 0.897 & 0.855 & 1.06 & 1.094 & 1.043 & 0.978 & 1.318 & 10.14 & 12.16 \\
\hline 8:00 PM & 0.898 & 0.886 & 0.93 & 0.801 & 0.833 & 1.221 & 1.169 & 0.972 & 0.921 & 1.358 & 9.99 & 11.99 \\
\hline 9:00 PM & 0.905 & 0.868 & 0.86 & 0.712 & 0.847 & 1.337 & 1.294 & 0.966 & 0.836 & 1.27 & 9.90 & 11.87 \\
\hline $10: 00 \mathrm{PM}$ & 0.687 & 0.739 & 0.912 & 0.629 & 0.941 & 1.055 & 1.244 & 0.916 & 0.817 & 1.51 & 9.45 & 11.34 \\
\hline & & & & & & & & & & & & 178.58 \\
\hline & & & & & & & & & & & & \\
\hline & Temp. & Temp. & Temp. & Temp. & Temp. & Temp. & Temp. & Temp. & Temp. & Temp. & Avg. Temp. & \\
\hline & $\mathrm{F}$ & $\mathrm{F}$ & $\mathrm{F}$ & $\mathrm{F}$ & $\mathrm{F}$ & $\mathrm{F}$ & $\mathrm{F}$ & $\mathrm{F}$ & $\mathrm{F}$ & $\mathrm{F}$ & $\mathrm{F}$ & \\
\hline & 73 & 76 & 74.4 & 75.7 & 72.3 & 77 & 74.2 & 76 & 76.1 & 71.8 & 74.7 & \\
\hline & 73.7 & 76.5 & 74.8 & 75.1 & 71.6 & 76.5 & 74.1 & 75.9 & 75.9 & 71.7 & 74.6 & \\
\hline & 73.9 & 76.3 & 74.5 & 74.3 & 72 & 75.9 & 74.1 & 75.1 & 76.1 & 73.2 & 74.5 & \\
\hline & 74.2 & 75.7 & 74.9 & 73.4 & 72.1 & 75.8 & 74.2 & 74.7 & 76 & 75.6 & 74.7 & \\
\hline & 74.3 & 75.4 & 75.5 & 73.8 & 72.4 & 75.6 & 74.4 & 74.5 & 76.1 & 75.5 & 74.8 & \\
\hline & 74.3 & 75 & 75 & 72.9 & 71.7 & 75.4 & 73.8 & 74.3 & 76.4 & 75.3 & 74.4 & \\
\hline & 74.2 & 74.9 & 74.7 & 72.3 & 71.5 & 75.3 & 74 & 74.3 & 76.2 & 75.4 & 74.3 & \\
\hline & 74.1 & 74.7 & 74.3 & 72.6 & 71.8 & 75.7 & 74.2 & 74.4 & 75.8 & 75.7 & 74.3 & \\
\hline & 73.8 & 74.3 & 74 & 73.2 & 71.7 & 75.1 & 73.9 & 74.3 & 75.7 & 75.9 & 74.2 & \\
\hline & 74.3 & 74.3 & 74.5 & 73.3 & 72.4 & 76.3 & 74 & 74.3 & 76 & 76.4 & 74.6 & \\
\hline & 74.3 & 74.7 & 74.4 & 72.7 & 73.2 & 76.5 & 73.9 & 74.8 & 76 & 77.1 & 74.8 & \\
\hline & 74.3 & 75.2 & 74.1 & 74.2 & 73.6 & 76.8 & 74 & 75 & 76 & 77.5 & 75.1 & \\
\hline & 74.4 & 75.4 & 73.9 & 74.4 & 73 & 76.5 & 74 & 75.4 & 76 & 77.8 & 75.1 & \\
\hline & 74.8 & 75.6 & 73.8 & 75.1 & 73.4 & 76.2 & 73.4 & 75.2 & 75.8 & 77.5 & 75.1 & \\
\hline & 75.9 & 75.9 & 73.6 & 75.2 & 73.4 & 76.1 & 73 & 75.1 & 75.7 & 77.1 & 75.1 & \\
\hline & & & & & & & & & & & 74.67 & \\
\hline
\end{tabular}

Composite Energy Consumption Rate for 12 Controlled Rooms, Pigeon Forge, TN for January, 2001 (average room temp. = 74.7 F)

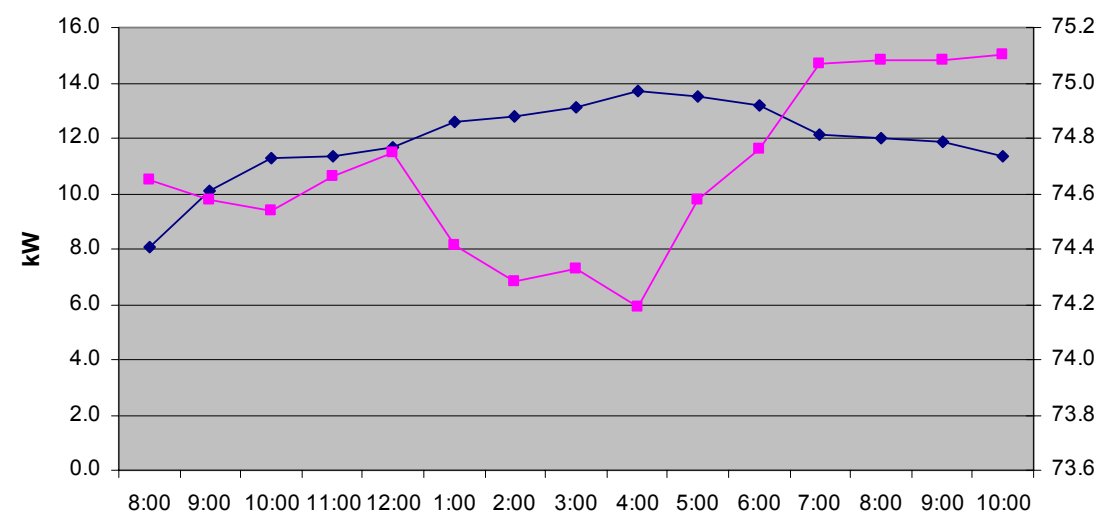

AM AM AM AM PM PM PM PM PM PM PM PM PM PM PM

Time of Day 


\section{B.11 Controlled Rooms - February}

\begin{tabular}{|c|c|c|c|c|c|c|c|c|c|c|c|c|c|c|}
\hline \multicolumn{3}{|c|}{ CONTROLLED ROOMS } & & & & & & & & & & & \multicolumn{2}{|c|}{ Adj. For 12 Rooms } \\
\hline & & & & & & & & & & & & & & \\
\hline & Room 501 & Room 502 & Room 508 & Room 509 & Room 513 & Room 516 & Room 519 & Room 520 & Room 523 & Room 524 & Room 528 & Sum & Sum & \\
\hline Time & kW & kW & $\mathrm{kW}$ & kW & $\mathrm{kW}$ & $\mathrm{kW}$ & $\mathrm{kW}$ & $\mathrm{kW}$ & $\mathrm{kW}$ & kW & $\mathrm{kW}$ & $\mathrm{kW}$ & $\mathrm{kW}$ & \\
\hline $8: 00 \mathrm{AM}$ & 0.618 & 0.503 & 0.099 & 0.442 & 0.487 & 0.132 & 0.093 & 0.117 & 0.209 & 0.49 & 0.409 & 3.60 & 3.93 & \\
\hline 9:00 AM & 0.462 & 0.424 & 0.169 & 0.225 & 0.396 & 0.155 & 0.069 & 0.141 & 0.15 & 0.568 & 0.373 & 3.13 & 3.42 & \\
\hline $10: 00 \mathrm{AM}$ & 0.422 & 0.264 & 0.102 & 0.358 & 0.407 & 0.201 & 0.091 & 0.228 & 0.085 & 0.41 & 0.162 & 2.73 & 2.98 & \\
\hline 11:00 AM & 0.239 & 0.112 & 0.073 & 0.376 & 0.495 & 0.132 & 0.058 & 0.186 & 0.077 & 0.431 & 0.136 & 2.32 & 2.53 & \\
\hline 12:00 PM & 0.224 & 0.072 & 0.041 & 0.208 & 0.354 & 0.264 & 0.05 & 0.182 & 0.094 & 0.498 & 0.114 & 2.10 & 2.29 & \\
\hline 1:00 PM & 0.236 & 0.055 & 0.053 & 0.187 & 0.3 & 0.255 & 0.044 & 0.188 & 0.057 & 0.595 & 0.08 & 2.05 & 2.24 & \\
\hline 2:00 PM & 0.21 & 0.046 & 0.037 & 0.159 & 0.21 & 0.14 & 0.105 & 0.182 & 0.055 & 0.505 & 0.186 & 1.84 & 2.00 & \\
\hline 3:00 PM & 0.334 & 0.146 & 0.029 & 0.112 & 0.306 & 0.11 & 0.055 & 0.2 & 0.057 & 0.446 & 0.167 & 1.96 & 2.14 & \\
\hline 4:00 PM & 0.343 & 0.155 & 0.027 & 0.126 & 0.299 & 0.111 & 0.061 & 0.165 & 0.065 & 0.428 & 0.109 & 1.89 & 2.06 & \\
\hline $5: 00 \mathrm{PM}$ & 0.233 & 0.187 & 0.051 & 0.171 & 0.359 & 0.116 & 0.07 & 0.166 & 0.105 & 0.404 & 0.104 & 1.97 & 2.14 & \\
\hline 6:00 PM & 0.248 & 0.218 & 0.072 & 0.153 & 0.417 & 0.197 & 0.118 & 0.134 & 0.323 & 0.54 & 0.128 & 2.55 & 2.78 & \\
\hline $7: 00 \mathrm{PM}$ & 0.354 & 0.149 & 0.128 & 0.15 & 0.526 & 0.116 & 0.111 & 0.129 & 0.163 & 0.494 & 0.234 & 2.55 & 2.79 & \\
\hline 8:00 PM & 0.331 & 0.211 & 0.167 & 0.158 & 0.455 & 0.112 & 0.073 & 0.12 & 0.241 & 0.414 & 0.424 & 2.71 & 2.95 & \\
\hline 9:00 PM & 0.325 & 0.248 & 0.124 & 0.154 & 0.479 & 0.125 & 0.065 & 0.1 & 0.158 & 0.575 & 0.231 & 2.58 & 2.82 & \\
\hline \multirow[t]{4}{*}{ 10:00 PM } & 0.334 & 0.216 & 0.12 & 0.137 & 0.509 & 0.188 & 0.234 & 0.104 & 0.167 & 0.481 & 0.38 & 2.87 & 3.13 & \\
\hline & 4.913 & 3.006 & 1.292 & 3.116 & 5.999 & 2.354 & 1.297 & 2.342 & 2.006 & 7.279 & 3.237 & 36.84 & 40.19 & \\
\hline & & & & & & & & & & & & & & \\
\hline & Temp & Temp. & Temp. & Temp. & Temp. & Temp. & Temp. & Temp. & Temp. & Temp. & Temp. & Avg. Temp. & & \\
\hline Time & $\mathrm{F}$ & $\mathrm{F}$ & $\mathrm{F}$ & $\mathrm{F}$ & $\mathrm{F}$ & $\mathrm{F}$ & $\mathrm{F}$ & $\mathrm{F}$ & $\mathrm{F}$ & $\mathrm{F}$ & $\mathrm{F}$ & $\mathrm{F}$ & & \\
\hline $8: 00 \mathrm{AM}$ & 67.95 & 66.38 & 67 & 70 & 69 & 68 & 67 & 70 & 68 & 71 & 67 & 68.3 & & \\
\hline 9:00 AM & 67.49 & 65.75 & 66 & 69 & 68 & 68 & 67 & 69 & 67 & 71 & 66.5 & 67.7 & & \\
\hline $10: 00 \mathrm{AM}$ & 68.02 & 66 & 66 & 70 & 68 & 69 & 68 & 70 & 68 & 71 & 67 & 68.3 & & \\
\hline 11:00 AM & 68.16 & 66 & 66 & 71 & 68 & 69 & 69 & 69 & 69 & 70 & 67 & 68.4 & & \\
\hline 12:00 PM & 68.73 & 66 & 67 & 73 & 69 & 70 & 70 & 69 & 70 & 70 & 67 & 69.1 & & \\
\hline 1:00 PM & 69.49 & 67 & 67 & 74 & 70 & 70 & 72 & 70 & 72 & 70 & 67 & 69.9 & & \\
\hline 2:00 PM & 70.48 & 67 & 67 & 74 & 70 & 70 & 73 & 70 & 73 & 71 & 68 & 70.3 & & \\
\hline 3:00 PM & 71.3 & 68 & 68 & 75 & 72 & 70 & 74 & 71 & 74 & 71 & 68 & 71.1 & & \\
\hline 4:00 PM & 72.04 & 69 & 69 & 75 & 72 & 70 & 75 & 71 & 75 & 72 & 69 & 71.7 & & \\
\hline $5: 00$ PM & 72.54 & 69 & 69 & 75 & 73 & 71 & 75 & 72 & 75 & 72 & 70 & 72.1 & & \\
\hline 6:00 PM & 72.65 & 69 & 69 & 74 & 73 & 71 & 74 & 72 & 74 & 72 & 70 & 71.9 & & \\
\hline $7: 00$ PM & 72.34 & 69 & 69 & 74 & 73 & 71.5 & 73 & 72 & 73 & 73 & 70 & 71.8 & & \\
\hline 8:00 PM & 71.74 & 69 & 69 & 73 & 73 & 71 & 72 & 72 & 72 & 73 & 70 & 71.4 & & \\
\hline 9:00 PM & 71.08 & 68 & 69 & 72 & 72 & 71 & 71 & 72 & 72 & 73 & 70 & 71.0 & & \\
\hline \multirow[t]{2}{*}{ 10:00 PM } & 70.46 & 68 & 69 & 72 & 71 & 71 & 71 & 71 & 71 & 73 & 69 & 70.6 & & \\
\hline & & & & & & & & & & & & 70.2 & & \\
\hline
\end{tabular}

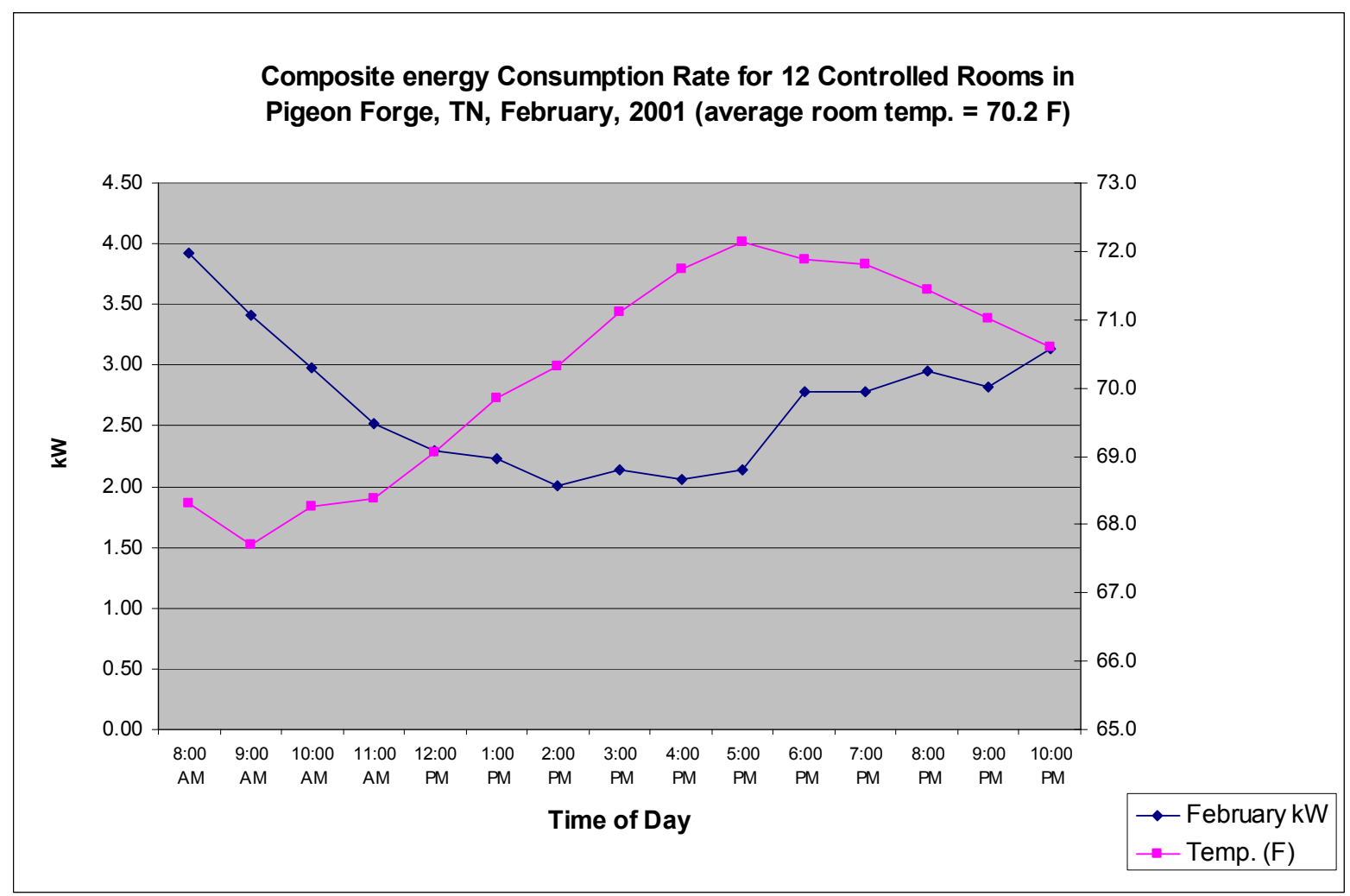




\section{B.12 Controlled Room - March}

\begin{tabular}{|c|c|c|c|c|c|c|c|c|c|c|c|c|c|c|}
\hline \multicolumn{4}{|c|}{ CONTROLLED ROOMS- March, 2001} & \multirow[b]{2}{*}{ Room 509} & \multirow[b]{2}{*}{ Room 513} & \multirow{2}{*}{\begin{tabular}{|l|} 
\\
Room 516 \\
\end{tabular}} & \multirow{2}{*}{ Room 519 } & \multirow[b]{2}{*}{ Room 520} & \multirow[b]{2}{*}{ Room 523} & \multirow[b]{2}{*}{ Room 524} & \multirow[b]{2}{*}{ Room 528} & \multicolumn{3}{|c|}{ Adj. For 12 Rooms } \\
\hline & Room 501 & Room 502 & Room 508 & & & & & & & & & Sum & Sum & \\
\hline Time & $\mathrm{kW}$ & $\mathrm{kW}$ & $\mathrm{kW}$ & $\mathrm{kW}$ & $\mathrm{kW}$ & $\mathrm{kW}$ & $\mathrm{kW}$ & $\mathrm{kW}$ & $\mathrm{kW}$ & $\mathrm{kW}$ & \begin{tabular}{|l|}
$\mathrm{kW}$ \\
\end{tabular} & $\mathrm{kW}$ & $\mathrm{kW}$ & \\
\hline $8: 00 \mathrm{AM}$ & 0.323 & 0.166 & 0.296 & 0.261 & 0.268 & 0.15 & 0.336 & 0.047 & 0.543 & 0.205 & 0.186 & 2.78 & 3.03 & \\
\hline 9:00 AM & 0.35 & 0.297 & 0.32 & 0.09 & 0.171 & 0.135 & 0.266 & 0.029 & 0.299 & 0.168 & 0.302 & 2.43 & 2.65 & \\
\hline 10:00 AM & 0.254 & 0.392 & 0.17 & 0.098 & 0.157 & 0.144 & 0.386 & 0.056 & 0.337 & 0.226 & 0.364 & 2.58 & 2.82 & \\
\hline 11:00 AM & 0.232 & 0.22 & 0.152 & 0.094 & 0.259 & 0.1 & 0.212 & 0.045 & 0.158 & 0.271 & 0.406 & 2.15 & 2.34 & \\
\hline 12:00 PM & 0.229 & 0.195 & 0.116 & 0.143 & 0.168 & 0.104 & 0.179 & 0.045 & 0.078 & 0.11 & 0.257 & 1.62 & 1.77 & \\
\hline 1:00 PM & 0.207 & 0.151 & 0.085 & 0.111 & 0.125 & 0.105 & 0.14 & 0.068 & 0.059 & 0.128 & 0.231 & 1.41 & 1.54 & \\
\hline $2: 00 \mathrm{PM}$ & 0.162 & 0.18 & 0.191 & 0.12 & 0.127 & 0.086 & 0.165 & 0.073 & 0.056 & 0.125 & 0.208 & 1.49 & 1.63 & \\
\hline 3:00 PM & 0.111 & 0.176 & 0.199 & 0.083 & 0.127 & 0.081 & 0.216 & 0.063 & 0.067 & 0.118 & 0.205 & 1.45 & 1.58 & \\
\hline 4:00 PM & 0.132 & 0.142 & 0.189 & 0.092 & 0.153 & 0.106 & 0.191 & 0.049 & 0.126 & 0.205 & 0.322 & 1.71 & 1.86 & \\
\hline $5: 00 \mathrm{PM}$ & 0.113 & 0.156 & 0.26 & 0.08 & 0.176 & 0.102 & 0.183 & 0.064 & 0.113 & 0.174 & 0.188 & 1.61 & 1.76 & \\
\hline 6:00 PM & 0.288 & 0.184 & 0.215 & 0.088 & 0.193 & 0.084 & 0.201 & 0.067 & 0.219 & 0.134 & 0.154 & 1.83 & 1.99 & \\
\hline 7:00 PM & 0.21 & 0.256 & 0.276 & 0.107 & 0.135 & 0.089 & 0.29 & 0.055 & 0.308 & 0.146 & 0.259 & 2.13 & 2.32 & \\
\hline 8:00 PM & 0.246 & 0.18 & 0.375 & 0.085 & 0.134 & 0.111 & 0.353 & 0.055 & 0.196 & 0.151 & 0.215 & 2.10 & 2.29 & \\
\hline 9:00 PM & 0.139 & 0.274 & 0.467 & 0.109 & 0.192 & 0.106 & 0.22 & 0.069 & 0.393 & 0.148 & 0.161 & 2.28 & 2.49 & \\
\hline \multirow[t]{6}{*}{ 10:00 PM } & 0.185 & 0.313 & 0.406 & 0.091 & 0.342 & 0.146 & 0.375 & 0.081 & 0.33 & 0.167 & 0.12 & 2.56 & 2.79 & \\
\hline & 3.181 & 3.282 & 3.717 & 1.652 & 2.727 & 1.649 & 3.713 & 0.866 & 3.282 & 2.476 & 3.578 & 30.12 & 32.86 & \\
\hline & & & & & & & & & & & & & & \\
\hline & & & & & & & & & & & & & & \\
\hline & & & & & & & & & & & & & & \\
\hline & Temp. & Temp. & Temp. & Temp. & Temp. & Temp. & Temp. & Temp. & Temp. & Temp. & Temp. & \multicolumn{2}{|l|}{ Avg. Temp. } & \\
\hline Time & $\mathrm{F}$ & $\mathrm{F}$ & $\mathrm{F}$ & $\mathrm{F}$ & $\mathrm{F}$ & $\mathrm{F}$ & $\mathrm{F}$ & $\mathrm{F}$ & $\mathrm{F}$ & $\mathrm{F}$ & $\mathrm{F}$ & $\mathrm{F}$ & & \\
\hline $8: 00 \mathrm{AM}$ & 63.8 & 65.9 & 67.1 & 68.4 & 65.2 & 67.9 & 67.9 & 69 & 67.3 & 69 & 66.3 & 67.1 & & \\
\hline 9:00 AM & 64.4 & 66.5 & 67.4 & 68.9 & 66 & 68 & 69.3 & 69 & 67.5 & 69 & 66.7 & 67.5 & & \\
\hline 10:00 AM & 65.9 & 66.8 & 67.5 & 69.9 & 65.7 & 68 & 72.3 & 69.2 & 68.5 & 69.1 & 67 & 68.2 & & \\
\hline 11:00 AM & 66.8 & 66.5 & 67.2 & 71.6 & 66.2 & 68 & 72.2 & 69.5 & 69.3 & 69.6 & 67.5 & 68.6 & & \\
\hline 12:00 PM & 67.2 & 67.5 & 67.2 & 72.9 & 66.9 & 68.7 & 73.2 & 70 & 69.8 & 69.7 & 67.8 & 69.2 & & \\
\hline 1:00 PM & 68.3 & 68 & 67.6 & 73.7 & 67.9 & 69.4 & 73.9 & 70.5 & 70.8 & 69.7 & 68.1 & 69.8 & & \\
\hline 2:00 PM & 68.5 & 67.9 & 68.2 & 74.1 & 68.8 & 69.8 & 74.6 & 70.9 & 71.7 & 69.9 & 68.6 & 70.3 & & \\
\hline $3: 00 \mathrm{PM}$ & 68.7 & 68.5 & 69.3 & 74.2 & 69.7 & 70.3 & 75.3 & 71.2 & 72.2 & 70.2 & 68.8 & 70.8 & & \\
\hline 4:00 PM & 69.1 & 68.8 & 69.5 & 74.1 & 70 & 70.6 & 75.9 & 71.5 & 72.6 & 70.3 & 69.3 & 71.1 & & \\
\hline 5:00 PM & 69.2 & 68.9 & 69.7 & 74 & 70.2 & 70.9 & 76.2 & 71.5 & 72.7 & 70.5 & 69.6 & 71.2 & & \\
\hline 6:00 PM & 69.9 & 69 & 69.7 & 73.7 & 70.6 & 70.9 & 76.4 & 71.5 & 72.1 & 70.8 & 69.5 & 71.3 & & \\
\hline 7:00 PM & 69.5 & 69 & 69.6 & 73.4 & 70.5 & 70.9 & 76.5 & 71.7 & 72.2 & 70.9 & 69.9 & 71.3 & & \\
\hline 8:00 PM & 68.7 & 68.8 & 69.7 & 72.8 & 70.1 & 71.1 & 76.6 & 71.7 & 71.6 & 70.9 & 69.7 & 71.1 & & \\
\hline 9:00 PM & 68.3 & 68.5 & 69.6 & 72.1 & 69.6 & 70.9 & 76.2 & 71.6 & 71.1 & 70.8 & 69.5 & 70.7 & & \\
\hline 10:00 PM & 67.8 & 68.1 & 69.7 & 71.4 & 69.1 & 70.7 & 73.9 & 71.2 & 70.6 & 70.6 & 69.1 & 70.2 & & \\
\hline & & & & & & & & & & & & 69.9 & & \\
\hline
\end{tabular}

\section{Energy Consumption Rate for 12 Controlled Rooms in Pigeon Forge, TN, for March, 2001 (average room temp. = 69.9 F)}

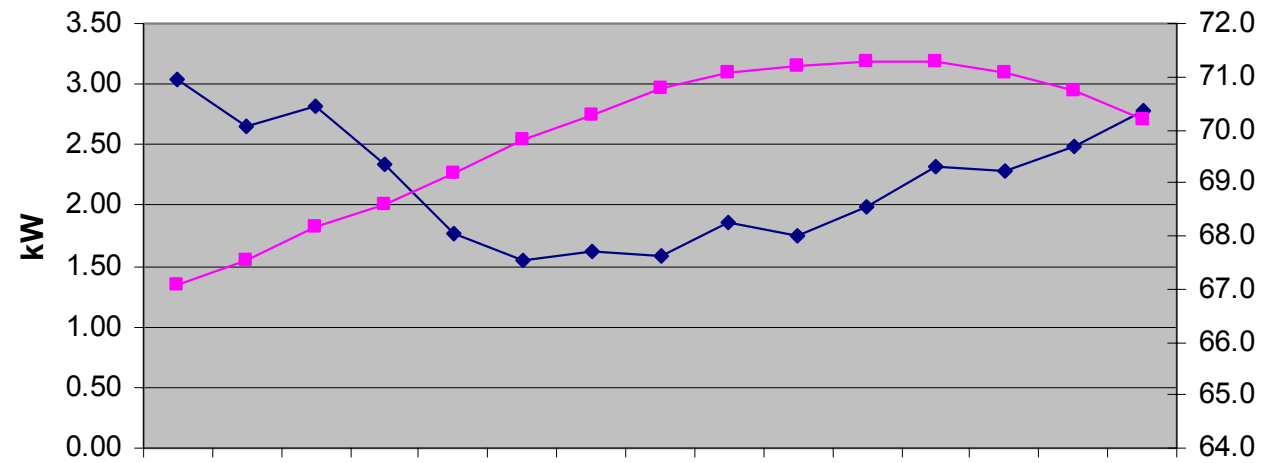

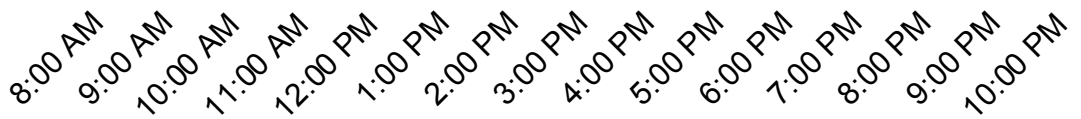

Time of Day

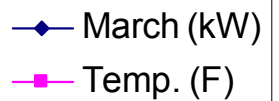




\section{B.13 Uncontrolled Rooms - January}

\begin{tabular}{|c|c|c|c|c|c|c|c|c|c|c|c|c|c|}
\hline \multicolumn{5}{|c|}{ UNCONTROLLED ROOMS (January 2001) } & \multirow[b]{2}{*}{ Room 609} & \multirow[b]{2}{*}{ Room 619} & \multirow[b]{2}{*}{ Room 620} & \multirow[b]{2}{*}{ Room 623} & \multirow[b]{2}{*}{ Room 624} & \multirow[b]{2}{*}{ Room 627} & \multirow[b]{2}{*}{ Room 628} & \multicolumn{2}{|c|}{ Adj. For 12 Rooms } \\
\hline & Room 413 & Room 416 & Room 602 & Room 608 & & & & & & & & Sum & Sum \\
\hline Time & kW & kW & kW & $\mathrm{kW}$ & $\mathrm{kW}$ & kW & kW & kW & kW & $\mathrm{kW}$ & kW & $\mathrm{kW}$ & $\mathrm{kW}$ \\
\hline 8:00 AM & 0.621 & 1.086 & 1.083 & 0.615 & 0.444 & 0.504 & 0.854 & 0.529 & 1.528 & 0.601 & 0.749 & 8.61 & 9.40 \\
\hline 9:00 AM & 0.775 & 1.215 & 0.945 & 0.737 & 0.581 & 0.543 & 0.854 & 0.841 & 0.955 & 0.919 & 0.994 & 9.36 & 10.21 \\
\hline $10: 00 \mathrm{AM}$ & 0.898 & 1.249 & 0.801 & 0.884 & 0.565 & 0.726 & 1.049 & 0.939 & 1.037 & 1.099 & 1.285 & 10.53 & 11.49 \\
\hline $11: 00 \mathrm{AM}$ & 0.876 & 1.241 & 0.812 & 0.908 & 0.75 & 0.963 & 0.965 & 0.956 & 1.244 & 1.079 & 1.164 & 10.96 & 11.95 \\
\hline 12:00 PM & 0.857 & 1.25 & 0.75 & 0.767 & 0.763 & 0.97 & 1.249 & 0.971 & 1.255 & 0.987 & 1.154 & 10.97 & 11.97 \\
\hline 1:00 PM & 0.839 & 1.444 & 0.794 & 0.748 & 0.821 & 1.06 & 1.267 & 1.102 & 1.336 & 1.118 & 1.111 & 11.64 & 12.70 \\
\hline 2:00 PM & 0.911 & 1.443 & 0.982 & 0.814 & 0.951 & 1.026 & 1.335 & 1.161 & 1.225 & 1.242 & 1.133 & 12.22 & 13.33 \\
\hline 3:00 PM & 1.145 & 1.423 & 0.966 & 0.933 & 0.931 & 1.06 & 1.383 & 1.117 & 1.109 & 1.275 & 1.083 & 12.43 & 13.55 \\
\hline 4:00 PM & 1.417 & 1.313 & 0.912 & 1.057 & 0.851 & 1.104 & 1.485 & 1.082 & 1.012 & 1.301 & 1.139 & 12.67 & 13.83 \\
\hline 5:00 PM & 1.423 & 1.413 & 0.866 & 1.087 & 0.789 & 1.032 & 1.476 & 0.896 & 1.059 & 1.108 & 1.184 & 12.33 & 13.45 \\
\hline 6:00 PM & 1.265 & 1.487 & 0.799 & 1.101 & 0.886 & 1.002 & 1.302 & 0.96 & 1.163 & 1.18 & 1.137 & 12.28 & 13.40 \\
\hline 7:00 PM & 1.121 & 1.196 & 0.793 & 1.087 & 0.773 & 0.991 & 1.279 & 0.905 & 1.033 & 1.101 & 1.147 & 11.43 & 12.46 \\
\hline $8: 00 \mathrm{PM}$ & 0.871 & 1.084 & 0.678 & 1.172 & 0.694 & 0.942 & 1.358 & 0.817 & 1.057 & 1.076 & 0.939 & 10.69 & 11.66 \\
\hline 9:00 PM & 0.959 & 0.997 & 0.605 & 1.119 & 0.597 & 0.858 & 1.236 & 0.814 & 1.205 & 1.081 & 0.951 & 10.42 & 11.37 \\
\hline 10:00 PM & 0.97 & 0.884 & 0.562 & 0.926 & 0.54 & 0.779 & 1.232 & 0.492 & 1.198 & 0.837 & 0.787 & 9.21 & 10.04 \\
\hline & & & & & & & & & & & & & 180.82 \\
\hline & & & & & & & & & & & & & \\
\hline & Temp. & Temp. & Temp. & Temp. & Temp. & Temp. & Temp. & Temp. & Temp. & Temp. & Temp & & Avg. Temp. \\
\hline & $\mathrm{F}$ & $\mathrm{F}$ & $\mathrm{F}$ & $\mathrm{F}$ & $\mathrm{F}$ & $\mathrm{F}$ & $\mathrm{F}$ & $\mathrm{F}$ & $\mathrm{F}$ & $\mathrm{F}$ & $\mathrm{F}$ & & $\mathrm{F}$ \\
\hline & 74.8 & 74.5 & 74.2 & 72.2 & 75.9 & 75.6 & 73.3 & 74.9 & 74.6 & 75 & 73.4 & & 74.4 \\
\hline & 75.3 & 73.7 & 74.4 & 71.8 & 76.1 & 75.7 & 73 & 74.8 & 74.4 & 75.1 & 72.4 & & 74.2 \\
\hline & 75.3 & 73.5 & 74.1 & 71.6 & 76.4 & 75.8 & 72 & 73.6 & 73.8 & 74.9 & 72 & & 73.9 \\
\hline & 74.9 & 73.6 & 73.5 & 71.6 & 76.1 & 75.3 & 71.6 & 73.4 & 72.9 & 75.1 & 71.3 & & 73.6 \\
\hline & 74.3 & 73.3 & 73.1 & 72 & 76 & 74.9 & 71 & 73.3 & 72.4 & 74.8 & 71.1 & & 73.3 \\
\hline & 74.8 & 73.5 & 73.1 & 71.8 & 75.9 & 74.6 & 71.2 & 72.7 & 71.6 & 74.6 & 71.4 & & 73.2 \\
\hline & 75.2 & 73.3 & 72.3 & 72.2 & 75.8 & 75 & 70.5 & 72.5 & 72.2 & 74.3 & 71.7 & & 73.2 \\
\hline & 75.2 & 73.2 & 72 & 71.9 & 75.5 & 75 & 70.5 & 72.3 & 72.3 & 74.3 & 71.9 & & 73.1 \\
\hline & 75.1 & 72.4 & 72.4 & 71.4 & 75.7 & 75 & 69.7 & 72.3 & 73.7 & 74 & 72.2 & & 73.1 \\
\hline & 74.3 & 72.2 & 73 & 71.1 & 75.9 & 75.1 & 69.8 & 72.8 & 73.8 & 74.5 & 72.1 & & 73.1 \\
\hline & 74.1 & 72.6 & 74.2 & 71.2 & 76 & 75.1 & 70.4 & 73.2 & 73.4 & 74.5 & 72.1 & & 73.3 \\
\hline & 74.1 & 73.5 & 74.7 & 71.7 & 76.3 & 75.2 & 70.6 & 73.2 & 73.8 & 74.7 & 71.9 & & 73.6 \\
\hline & 74.5 & 74.1 & 75 & 71 & 76.5 & 75.2 & 70.9 & 73.3 & 73.9 & 75.2 & 72.4 & & 73.8 \\
\hline & 74.9 & 74.5 & 75.5 & 70.6 & 76.8 & 75.1 & 70.8 & 73.5 & 73.5 & 75.2 & 72.8 & & 73.9 \\
\hline & 74.8 & 74.6 & 75.6 & 70.9 & 76.9 & 75.3 & 71 & 74.3 & 73.1 & 75.1 & 73.1 & & 74.1 \\
\hline & & & & & & & & & & & & & 73.59 \\
\hline
\end{tabular}

\section{Composite Energy Consumption Rates for 12 Uncontrolled Rooms in Pigeon Forge, TN, January, 2001 (average room temp. = 73.59 F)}

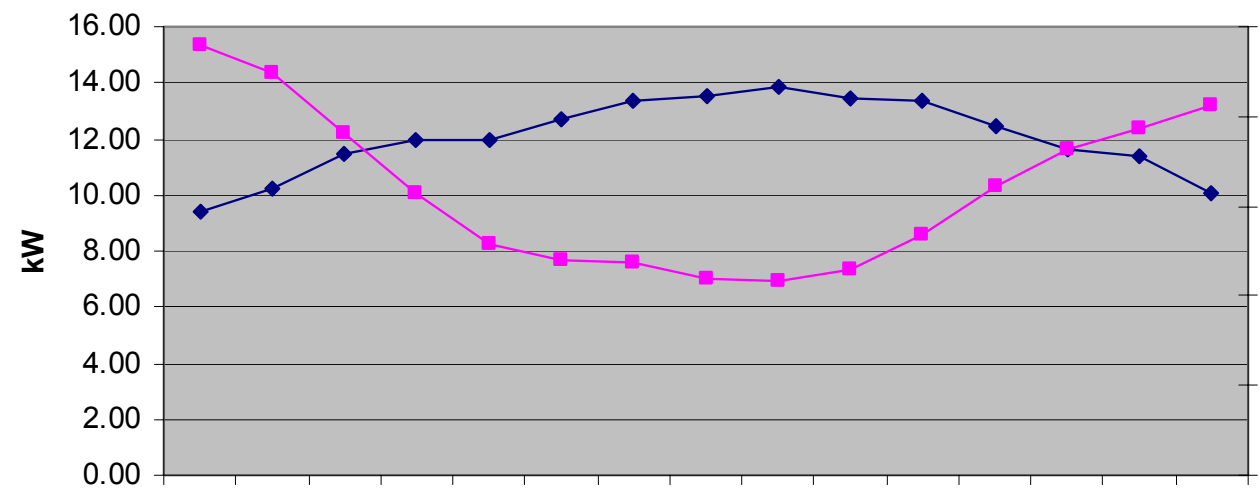

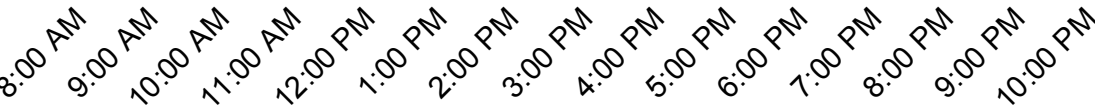

Time of Day

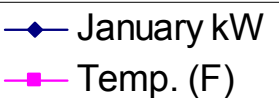




\section{B.14 Uncontrolled Rooms - February}

\begin{tabular}{|c|c|c|c|c|c|c|c|c|c|c|c|c|c|}
\hline \multicolumn{14}{|c|}{ UNCONTROLLED ROOMS-February } \\
\hline & Room 401 & Room 413 & Room 416 & Room 602 & Room 608 & Room 609 & Room 619 & Room 620 & Room 623 & Room 624 & Room 627 & Room 628 & Sum \\
\hline Time & $\mathrm{kW}$ & $\mathrm{kW}$ & $\mathrm{kW}$ & $\mathrm{kW}$ & $\mathrm{kW}$ & $\mathrm{kW}$ & $\mathrm{kW}$ & $\mathrm{kW}$ & $\mathrm{kW}$ & $\mathrm{kW}$ & $\mathrm{kW}$ & $\mathrm{kW}$ & $\mathrm{kW}$ \\
\hline 8:00 AM & 1.428 & 0.298 & 0.162 & 0.284 & 0.436 & 0.198 & 0.094 & 0.102 & 0.119 & 0.35 & 0.773 & 0.329 & 4.57 \\
\hline 9:00 AM & 1.234 & 0.341 & 0.166 & 0.258 & 0.289 & 0.166 & 0.105 & 0.215 & 0.248 & 0.258 & 0.538 & 0.261 & 4.08 \\
\hline 10:00 AM & 1.601 & 0.22 & 0.161 & 0.297 & 0.316 & 0.073 & 0.098 & 0.156 & 0.037 & 0.209 & 0.239 & 0.24 & 3.65 \\
\hline 11:00 AM & 1.408 & 0.158 & 0.128 & 0.137 & 0.208 & 0.115 & 0.104 & 0.079 & 0.023 & 0.148 & 0.205 & 0.22 & 2.93 \\
\hline 12:00 PM & 1.461 & 0.127 & 0.136 & 0.059 & 0.249 & 0.051 & 0.058 & 0.071 & 0.034 & 0.157 & 0.222 & 0.246 & 2.87 \\
\hline 1:00 PM & 1.336 & 0.119 & 0.135 & 0.088 & 0.187 & 0.045 & 0.047 & 0.206 & 0.059 & 0.137 & 0.279 & 0.198 & 2.84 \\
\hline 2:00 PM & 1.072 & 0.108 & 0.144 & 0.035 & 0.185 & 0.042 & 0.147 & 0.034 & 0.061 & 0.112 & 0.149 & 0.18 & 2.27 \\
\hline 3:00 PM & 1.037 & 0.14 & 0.15 & 0.031 & 0.197 & 0.058 & 0.097 & 0.038 & 0.056 & 0.157 & 0.202 & 0.181 & 2.34 \\
\hline 4:00 PM & 0.741 & 0.153 & 0.227 & 0.035 & 0.233 & 0.132 & 0.079 & 0.025 & 0.055 & 0.224 & 0.261 & 0.271 & 2.44 \\
\hline 5:00 PM & 0.821 & 0.115 & 0.218 & 0.1 & 0.23 & 0.231 & 0.133 & 0.036 & 0.061 & 0.232 & 0.476 & 0.272 & 2.93 \\
\hline 6:00 PM & 0.886 & 0.101 & 0.193 & 0.103 & 0.23 & 0.206 & 0.069 & 0.174 & 0.055 & 0.324 & 0.425 & 0.271 & 3.04 \\
\hline 7:00 PM & 1.116 & 0.085 & 0.19 & 0.232 & 0.208 & 0.164 & 0.047 & 0.157 & 0.173 & 0.273 & 0.416 & 0.276 & 3.34 \\
\hline 8:00 PM & 1.079 & 0.099 & 0.258 & 0.274 & 0.234 & 0.264 & 0.093 & 0.045 & 0.127 & 0.235 & 0.318 & 0.249 & 3.28 \\
\hline 9:00 PM & 1.085 & 0.091 & 0.24 & 0.279 & 0.159 & 0.143 & 0.165 & 0.069 & 0.148 & 0.246 & 0.264 & 0.368 & 3.26 \\
\hline \multirow[t]{4}{*}{ 10:00 PM } & 1.149 & 0.161 & 0.214 & 0.477 & 0.175 & 0.191 & 0.15 & 0.073 & 0.167 & 0.237 & 0.323 & 0.38 & 3.70 \\
\hline & 17.454 & 2.316 & 2.722 & 2.689 & 3.536 & 2.079 & 1.486 & 1.48 & 1.423 & 3.299 & 5.09 & 3.942 & 47.52 \\
\hline & & & & & & & & & & & & & \\
\hline & Temp & Temp. & Temp. & Temp. & Temp. & Temp. & Temp. & Temp. & Temp. & Temp. & Temp. & Temp. & Avg. Temp \\
\hline Time & $\mathrm{F}$ & $\mathrm{F}$ & $\mathrm{F}$ & $\mathrm{F}$ & $\mathrm{F}$ & $\mathrm{F}$ & $\mathrm{F}$ & $\mathrm{F}$ & $\mathrm{F}$ & $\mathrm{F}$ & $\mathrm{F}$ & $\mathrm{F}$ & $\mathrm{F}$ \\
\hline 8:00 AM & 69.4 & 67.6 & 67.1 & 63 & 66.7 & 66.2 & 67.2 & 65.8 & 65.4 & 67.5 & 68.5 & 65.5 & 66.7 \\
\hline 9:00 AM & 69.7 & 67.5 & 67.2 & 63.2 & 65.84 & 66.5 & 67.4 & 66.1 & 66.3 & 67.6 & 67 & 64.3 & 66.6 \\
\hline 10:00 AM & 70.2 & 68.4 & 67.4 & 63.9 & 66.04 & 68.7 & 68.1 & 66.1 & 67.7 & 67.7 & 67.5 & 64.6 & 67.2 \\
\hline $11: 00 \mathrm{AM}$ & 70.8 & 68.7 & 67.4 & 64.3 & 66.17 & 70.7 & 69.1 & 66.3 & 69.1 & 67.9 & 67 & 64.8 & 67.7 \\
\hline 12:00 PM & 71.5 & 69.1 & 67.6 & 64.4 & 66.5 & 72.1 & 70.1 & 66.9 & 70.5 & 67.8 & 67.5 & 65.3 & 68.3 \\
\hline 1:00 PM & 72.3 & 69.4 & 68 & 64.4 & 66.93 & 73.2 & 70.8 & 67.8 & 71.7 & 68 & 68.4 & 65.9 & 68.9 \\
\hline 2:00 PM & 72.6 & 70.4 & 68.4 & 65 & 67.7 & 74 & 72.1 & 68.1 & 72.8 & 68.5 & 68.9 & 66.6 & 69.6 \\
\hline 3:00 PM & 72.8 & 71.3 & 68.8 & 65.6 & 68.37 & 73.9 & 73.1 & 68.7 & 73.8 & 69 & 69.6 & 67 & 70.2 \\
\hline 4:00 PM & 72.8 & 71.8 & 69.4 & 66.3 & 68.97 & 73.6 & 74.4 & 69.2 & 74.1 & 69.6 & 69.8 & 67.6 & 70.6 \\
\hline 5:00 PM & 73.1 & 72.3 & 69.8 & 66.6 & 69.19 & 73.3 & 74.5 & 69.2 & 73.9 & 70 & 70.2 & 67.9 & 70.8 \\
\hline 6:00 PM & 73.4 & 72.4 & 69.7 & 66.6 & 69.06 & 72.8 & 74.3 & 69.5 & 73.2 & 70.1 & 70.4 & 67.8 & 70.8 \\
\hline 7:00 PM & 73.3 & 71.9 & 69.6 & 66.7 & 68.86 & 72.1 & 73.8 & 69.6 & 72.1 & 70.1 & 70.4 & 67.6 & 70.5 \\
\hline 8:00 PM & 72.9 & 71.4 & 69.6 & 66.6 & 68.64 & 71.7 & 73.3 & 69.3 & 71.2 & 69.8 & 69.8 & 67.4 & 70.1 \\
\hline 9:00 PM & 72.4 & 70.7 & 69.2 & 66.6 & 68.46 & 71 & 72.5 & 69.1 & 70.1 & 69.6 & 69.1 & 67.2 & 69.7 \\
\hline 10:00 PM & 71.9 & 70.4 & 69 & 66.8 & 68.33 & 70.4 & 72.1 & 68.9 & 69.6 & 69.3 & 68.5 & 67 & 69.4 \\
\hline & & & & & & & & & & & & & 69.1 \\
\hline
\end{tabular}

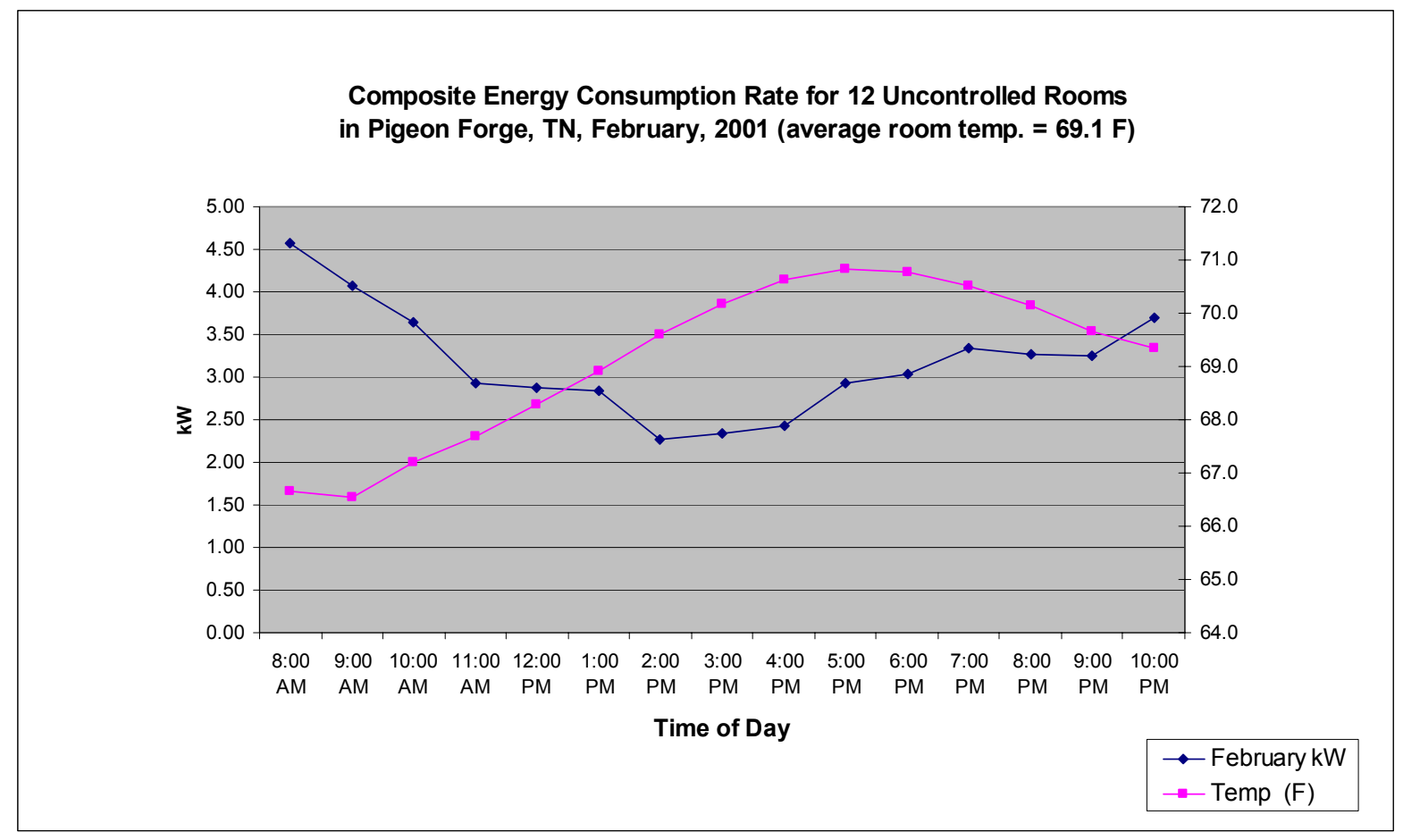




\section{B.15 Uncontrolled Rooms - March}

\begin{tabular}{|c|c|c|c|c|c|c|c|c|c|c|c|c|c|}
\hline \multicolumn{14}{|c|}{ UNCONTROLLED ROOMS-March, 2001} \\
\hline & & & & & & & & & & & & & \\
\hline & Room 401 & Room 413 & Room 416 & Room 602 & Room 608 & Room 609 & Room 619 & Room 620 & Room 623 & Room 624 & Room 627 & Room 628 & Sum \\
\hline Time & kW & kW & $\mathrm{kW}$ & $\mathrm{kW}$ & kW & $\mathrm{kW}$ & $\mathrm{kW}$ & $\mathrm{kW}$ & \begin{tabular}{|l|}
$\mathrm{kW}$ \\
\end{tabular} & $\mathrm{kW}$ & $\mathrm{kW}$ & $\mathrm{kW}$ & $\mathrm{kW}$ \\
\hline $8: 00 \mathrm{AM}$ & 0.61 & 0.279 & 0.116 & 0.782 & 0.162 & 0.081 & 0.119 & 0.147 & 0.173 & 0.316 & 0.336 & 0.239 & 3.36 \\
\hline 9:00 AM & 0.67 & 0.275 & 0.077 & 0.493 & 0.125 & 0.177 & 0.082 & 0.242 & 0.119 & 0.192 & 0.231 & 0.198 & 2.88 \\
\hline $10: 00 \mathrm{AM}$ & 0.57 & 0.068 & 0.068 & 0.431 & 0.119 & 0.099 & 0.175 & 0.204 & 0.119 & 0.314 & 0.185 & 0.189 & 2.54 \\
\hline 11:00 AM & 0.44 & 0.022 & 0.106 & 0.336 & 0.114 & 0.119 & 0.08 & 0.136 & 0.156 & 0.333 & 0.169 & 0.121 & 2.13 \\
\hline 12:00 PM & 0.38 & 0.019 & 0.067 & 0.218 & 0.093 & 0.083 & 0.1 & 0.126 & 0.13 & 0.164 & 0.255 & 0.229 & 1.86 \\
\hline 1:00 PM & 0.34 & 0.019 & 0.058 & 0.198 & 0.104 & 0.063 & 0.08 & 0.118 & 0.098 & 0.202 & 0.148 & 0.205 & 1.63 \\
\hline $2: 00 \mathrm{PM}$ & 0.24 & 0.019 & 0.066 & 0.208 & 0.09 & 0.057 & 0.072 & 0.125 & 0.09 & 0.186 & 0.291 & 0.185 & 1.63 \\
\hline 3:00 PM & 0.7 & 0.031 & 0.079 & 0.296 & 0.079 & 0.061 & 0.114 & 0.107 & 0.086 & 0.167 & 0.232 & 0.173 & 2.13 \\
\hline 4:00 PM & 0.57 & 0.047 & 0.057 & 0.331 & 0.128 & 0.068 & 0.114 & 0.119 & 0.212 & 0.28 & 0.275 & 0.12 & 2.32 \\
\hline 5:00 PM & 0.58 & 0.078 & 0.069 & 0.27 & 0.279 & 0.209 & 0.073 & 0.134 & 0.2 & 0.411 & 0.281 & 0.167 & 2.75 \\
\hline 6:00 PM & 0.49 & 0.138 & 0.062 & 0.315 & 0.173 & 0.085 & 0.115 & 0.173 & 0.108 & 0.465 & 0.216 & 0.106 & 2.45 \\
\hline $7: 00 \mathrm{PM}$ & 0.56 & 0.107 & 0.05 & 0.268 & 0.201 & 0.083 & 0.073 & 0.225 & 0.119 & 0.373 & 0.213 & 0.149 & 2.42 \\
\hline 8:00 PM & 0.46 & 0.081 & 0.068 & 0.249 & 0.188 & 0.11 & 0.164 & 0.207 & 0.122 & 0.335 & 0.337 & 0.314 & 2.64 \\
\hline 9:00 PM & 0.44 & 0.226 & 0.105 & 0.271 & 0.194 & 0.083 & 0.225 & 0.253 & 0.173 & 0.252 & 0.399 & 0.314 & 2.94 \\
\hline \multirow[t]{3}{*}{ 10:00 PM } & 0.48 & 0.412 & 0.144 & 0.348 & 0.213 & 0.207 & 0.179 & 0.263 & 0.324 & 0.201 & 0.41 & 0.208 & 3.39 \\
\hline & 7.53 & 1.82 & 1.19 & 5.01 & 2.26 & 1.59 & 1.77 & 2.58 & 2.23 & 4.19 & 3.98 & 2.92 & 37.06 \\
\hline & Temp. & Temp. & Temp. & Temp. & Temp. & Temp. & Temp. & Temp. & Temp. & Temp. & Temp. & Temp & Avg. Temp \\
\hline Time & $\mathrm{F}$ & $\mathrm{F}$ & $\mathrm{F}$ & $\mathrm{F}$ & $\mathrm{F}$ & $\mathrm{F}$ & $\mathrm{F}$ & $\mathrm{F}$ & $\mathrm{F}$ & $\mathrm{F}$ & $\mathrm{F}$ & $\mathrm{F}$ & $\mathrm{F}$ \\
\hline $8: 00 \mathrm{AM}$ & 66 & 65.5 & 66.2 & 66.3 & 64.8 & 66.2 & 68.5 & 66.1 & 66.2 & 66.1 & 65.6 & 64.4 & 66.0 \\
\hline 9:00 AM & 66.4 & 65.8 & 66.3 & 66.1 & 64.9 & 66.2 & 69.1 & 66.4 & 66.9 & 66.5 & 66 & 64.7 & 66.3 \\
\hline $10: 00 \mathrm{AM}$ & 67.3 & 66.1 & 66.6 & 66.3 & 64.9 & 68.4 & 70.1 & 66.1 & 68.2 & 66.3 & 67.1 & 64.8 & 66.9 \\
\hline $11: 00 \mathrm{AM}$ & 67.4 & 66.3 & 66.6 & 66.2 & 65.1 & 70.2 & 70.9 & 65.8 & 69.2 & 66.5 & 67.3 & 65.3 & 67.2 \\
\hline 12:00 PM & 67.7 & 67 & 66.7 & 66.6 & 65.6 & 71.4 & 71.5 & 66.2 & 69.6 & 66.9 & 67.7 & 65.8 & 67.7 \\
\hline 1:00 PM & 68.3 & 67.7 & 67.3 & 66.8 & 66.1 & 72.1 & 71.7 & 66.9 & 70.7 & 67 & 67.9 & 66.3 & 68.2 \\
\hline $2: 00 \mathrm{PM}$ & 69.1 & 68.6 & 67.9 & 67.4 & 66.7 & 72.6 & 72.2 & 67.4 & 71.5 & 67.1 & 68.4 & 66.8 & 68.8 \\
\hline 3:00 PM & 69.8 & 69.3 & 68.2 & 67.9 & 67.1 & 72.7 & 73 & 68 & 71.9 & 67.9 & 68.7 & 67 & 69.3 \\
\hline 4:00 PM & 70.3 & 69.8 & 68.5 & 68.3 & 67.5 & 72.6 & 73.5 & 68.4 & 72.3 & 68.4 & 69.2 & 67.1 & 69.7 \\
\hline $5: 00 \mathrm{PM}$ & 70.9 & 70.4 & 68.8 & 68.5 & 70.7 & 72.4 & 73.6 & 68.6 & 72.2 & 68.7 & 69.3 & 67.2 & 70.1 \\
\hline 6:00 PM & 71 & 70.8 & 68.9 & 68.3 & 67.8 & 72.2 & 73.3 & 68.9 & 71.7 & 69.1 & 69.1 & 67.2 & 69.9 \\
\hline $7: 00 \mathrm{PM}$ & 70.6 & 70.8 & 68.9 & 68.1 & 68 & 71.7 & 72.9 & 69.2 & 71.1 & 69.4 & 68.6 & 67.1 & 69.7 \\
\hline 8:00 PM & 70.1 & 69.9 & 68.9 & 68.2 & 68.1 & 71.1 & 72.5 & 69.4 & 70.4 & 69.4 & 68.3 & 67 & 69.4 \\
\hline 9:00 PM & 69.4 & 69.1 & 68.8 & 68.2 & 68.2 & 70.1 & 71.9 & 69.4 & 69.9 & 69.3 & 67.7 & 67 & 69.1 \\
\hline $10: 00 \mathrm{PM}$ & 68.6 & 68.9 & 68.6 & 68 & 68 & 69.7 & 71.8 & 69.4 & 69.6 & 68.9 & 67.6 & 66.6 & 68.8 \\
\hline & & & & & & & & & & & & & 68.5 \\
\hline
\end{tabular}

\section{Energy Consumption Rate for 12 Uncontrolled Rooms in Pigeon Forge, TN for March, 2001 (average room temp = 68.5 F)}

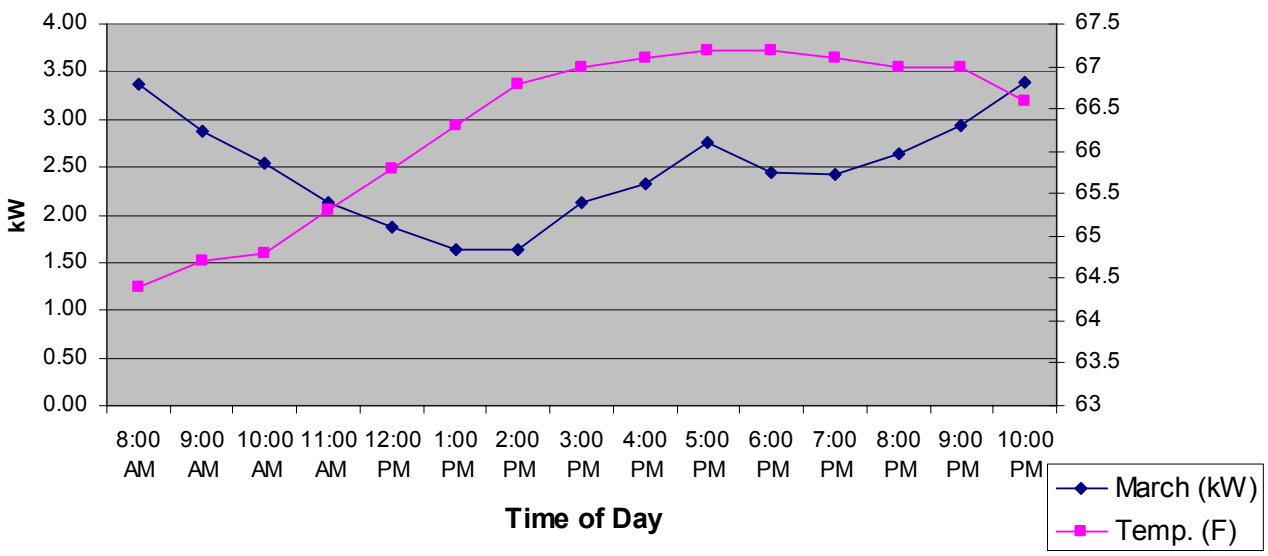





\section{INTERNAL DISTRIBUTION}

1. M. R. Ally, 3147, MS-6070

2. M. A. Brown, $4500 \mathrm{~N}$, MS-6186

3. J. E. Christian, 3147, MS-6070

4. P. D. Fairchild, 3147, MS-6070

5. M. A. Karnitz, 4500 N, 6186

6-10. B. J. Kirby, 3147, MS-6070

11. J. J. Tomlinson, 3147, MS-6070

12. ORNL Central Research Library, 4500N, MS-6191

13-14. Laboratory Records, 4500N, MS-6285

\section{EXTERNAL DISTRIBUTION}

15. Fernando L. Alvarado, Professor, Department of Electrical and Computer Engineering, University of Wisconsin-Madison, 2544 Engineering Hall, 1415 Engineering Drive, Madison, WI 53706, E-mail: Alvarado@engr.wisc.edu

16. James R. Brodrick, EE-2J/Forrestal Building, U. S. Department of Energy, 1000 Independence Avenue, SW, Washington, DC 20585, E-mail: James.Brodrick@ee.doe.gov

17. Vikram S. Budhraja, President, Electric Power Group, LLC, 201 South Lake Avenue, Suite 400, Pasadena, CA 91101, E-mail: budhraja@electricpowergroup.com

18. Jim Dyer, Electric Power Group, LLC, 201 South Lake Avenue, Suite 400, Pasadena, CA 91101, E-mail: dyer@electricpowergroup.com

19-23. Joseph Eto, CERTS Program Manager, Lawrence Berkeley National Laboratory, Bldg. 90 Room 4126K, MS: 90-4000, University of California, Berkeley, CA 94720

24. Charles Goldman, Environmental Energy Technology, Lawrence Berkeley National Laboratory, 1 Cyclotron Road, MS: 90R4000, Berkeley, CA 94720, E-mail: CAGoldman@lbl.gov

25. George Gross, Professor, Department of Electrical and Computer Engineering, University of Illinois at Urbana-Champaign, 339 William L. Everitt Laboratory, MC 702, 1406 West Green Street, Urbana, IL 61801, E-mail: gross@,staff.uiuc.edu

26. Carl H. Imhoff, Product Line Manager for Energy Operations and Maintenance, Pacific Northwest National Laboratory, 902 Battelle Boulevard, P. O. Box 999, Richland, WA 99352, E-mail: Carl.Imhoff@pnl.gov

27. Mark D. Levine, Director, Environmental Energy Technologies Division, Lawrence Berkeley National Laboratory, 1 Cyclotron Road, MS-90R3027D, Berkeley, CA 94720, E-mail: mdlevine@lbl.gov

28. Chris Marnay, Energy Analysis, Lawrence Berkeley National Laboratory,1 Cyclotron Road, MS 90R4000, Berkeley, CA 94720, E-mail: C_Marnay@lbl.gov

29. Carlos A. Martinez, Electric Power Group, LLC, 201 South Lake Avenue, Suite 400, Pasadena, CA 91101, E-mail: martinca@edisonX.com 
30. Timothy D. Mount, Professor, Applied Economics and Management, 214 Warren Hall, Cornell University, Ithaca, NY 14853-7801, E-mail: tdm2@cornell.edu

31. Shmuel S. Oren, Department of Industrial Engineering and Operations Research, 4119 Etcheverry Hall, University of California at Berkeley, Berkeley, CA 94720-1777, Email: shmuel@euler.berkeley.edu

32. Richard Orrison, EE-2J/Forrestal Building, U. S. Department of Energy, 1000 Independence Avenue, SW, Washington, DC 20585, E-mail: Richard.Orrison@EE.DOE.GOV

33. Philip N. Overholt, EE-16/Forrestal Building, U. S. Department of Energy, 1000 Independence Avenue, SW, Washington, DC 20585

34. Alonso Rodriguez, Electric Power Group, LLC, 201 South Lake Avenue, Suite 400, Pasadena, CA 91101

35. William D. Schulze, Professor, Applied Economics and Management, 301 Warren Hall, Cornell University, Ithaca, NY 14853-7801, E-mail: wds3@,cornell.edu

36. Richard E. Schuler, Professor, Civil and Environmental Engineering and Economics, 466 Uris Hall, Cornell University, Ithaca, NY 14853-7801, E-mail: res1@,cornell.edu

37. Sarosh N. Talukdar, Carnegie Mellon, ECE Department, Pittsburgh, PA 15213, E-mail: talukdar@ece.cmu.edu

38. Marjorie Tatro, Director, Energy and Transportation Security Department, Sandia National Laboratory, 1515 Eubank SE, MS 0704, Albuquerque, NM 87185-0704, Email:mitatro@sandia.gov

39. Robert J. Thomas, Director, Power Systems Engineering Research Center, Cornell University, 428 Phillips Hall, Ithaca, NY 14853, E-mail: rjt1@cornell.edu 